\title{
Power Transfer Potential to the Southeast in Response to a Renewable Portfolio Standard: Final Report
}

November 2009

Prepared by

ORNL

EPRI

Cascade Consulting Partners

LCG Consulting 


\section{DOCUMENT AVAILABILITY}

Reports produced after January 1, 1996, are generally available free via the U.S. Department of Energy (DOE) Information Bridge:

Web site: http://www.osti.gov/bridge

Reports produced before January 1, 1996, may be purchased by members of the public from the following source:

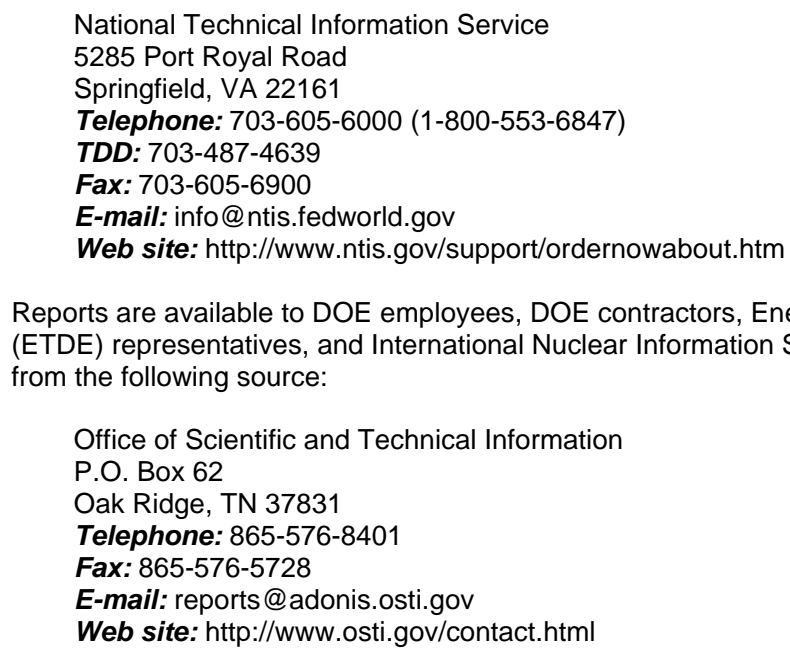
from the following source:

Office of Scientific and Technical Information

P.O. Box 62

Oak Ridge, TN 37831

Telephone: 865-576-8401

Fax: 865-576-5728

E-mail: reports@adonis.osti.gov

Web site: http://www.osti.gov/contact.html

Reports are available to DOE employees, DOE contractors, Energy Technology Data Exchange (ETDE) representatives, and International Nuclear Information System (INIS) representatives

This report was prepared as an account of work sponsored by an agency of the United States Government. Neither the United States government nor any agency thereof, nor any of their employees, makes any warranty, express or implied, or assumes any legal liability or responsibility for the accuracy, completeness, or usefulness of any information, apparatus, product, or process disclosed, or represents that its use would not infringe privately owned rights. Reference herein to any specific commercial product, process, or service by trade name, trademark, manufacturer, or otherwise, does not necessarily constitute or imply its endorsement, recommendation, or favoring by the United States Government or any agency thereof. The views and opinions of authors expressed herein do not necessarily state or reflect those of the United States Government or any agency thereof. 


\title{
Power Transfer Potential to the Southeast in Response to a Renewable Portfolio Standard: Final Report
}

\author{
Stanton W. Hadley - ORNL \\ Thomas Key - EPRI \\ Rajat Deb - LCG Consulting \\ Cascade Consulting Partners
}

November 2009

OAK RIDGE NATIONAL LABORATORY

Oak Ridge, Tennessee 37831 managed by

UT-BATTELLE, LLC

for the

U.S. DEPARTMENT OF ENERGY

under contract No. DE-AC05-00OR22725 


\section{CONTENTS}

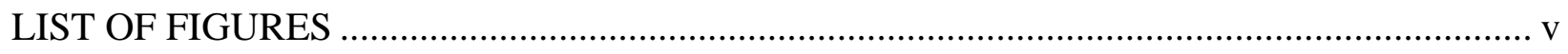

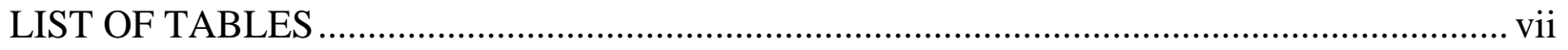

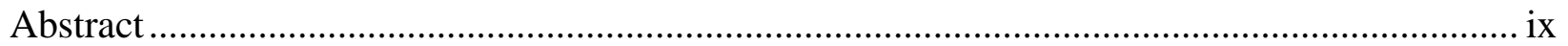

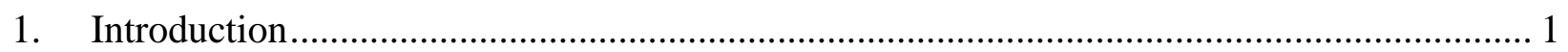

$1.1 \quad$ Renewables in the Southeast needed under RPS ................................................. 1

1.2 SE Renewables and Neighboring Wind Resources ................................................ 2

2. Economic Analysis of Wind Energy Transfers .............................................................. 4

2.1 Application of EPRI Electric Sector Model.......................................................... 4

$2.2 \quad$ Base Case Assumptions and Results................................................................ 7

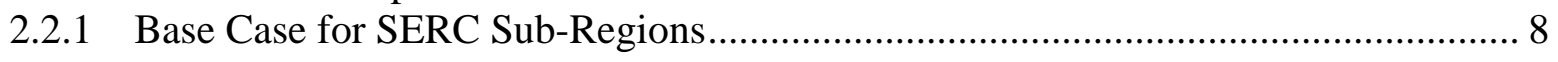

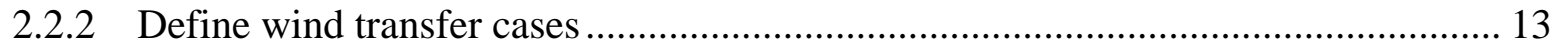

2.3 Marginal Analysis of Inter-Regional Wind Transfers ............................................ 16

2.3.1 Discussion of Transmission Assumptions ..................................................... 21

2.3.2 Conclusions from the Marginal Analysis. ......................................................... 22

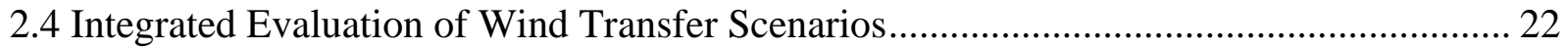

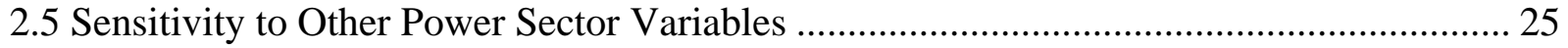

2.6 Conclusions from Wind Transfer Analysis.................................................................. 29

3. Stakeholder Workshop and Feedback........................................................................ 31

3.1 Plan, Participation and Agenda (see appendix B)................................................. 31

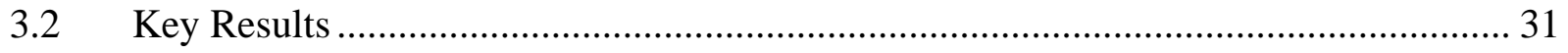

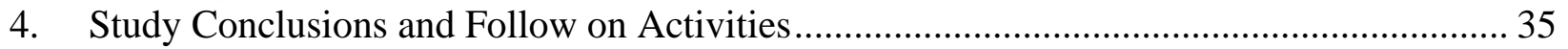

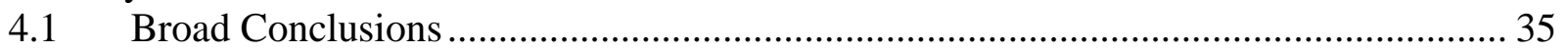

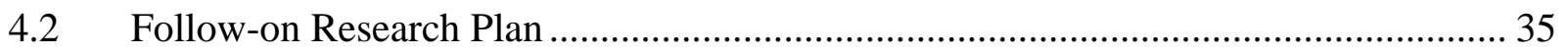

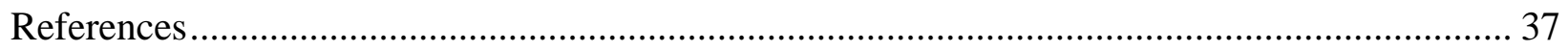

Appendix A Available renewable resources in the Southeast ........................................... 39

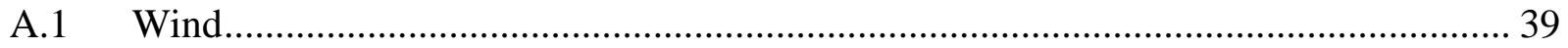

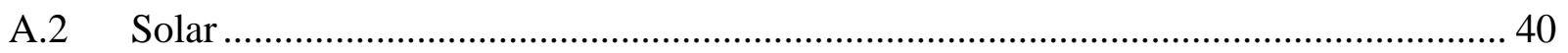

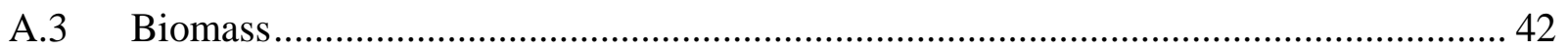

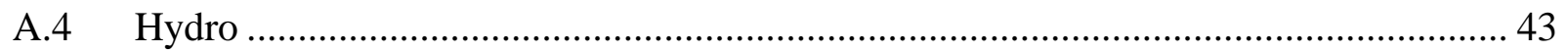

A.5 Amount deployed under different scenarios ....................................................... 44

Appendix B Workshop Invitation, Agenda and Participants ............................................ 48

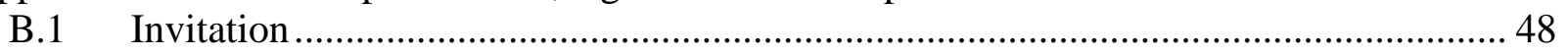

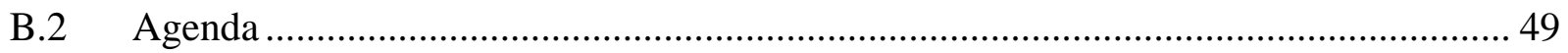

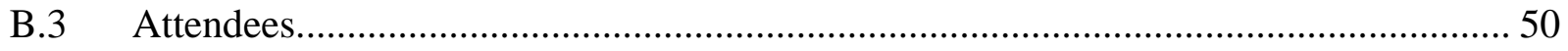

B.4 Workshop Presentations - Southwest Power Pool ............................................... 51

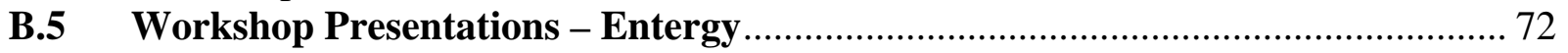

B.6 Workshop Presentations - Southern............................................................... 75

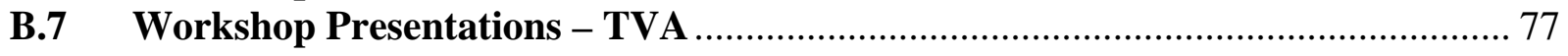

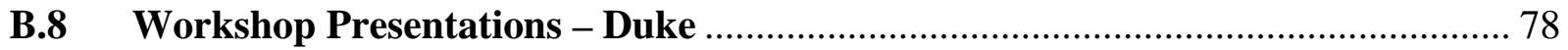

Appendix C Alternative means to meet RPS goal in SE ................................................. 79

C.1 RPS expectation with regional balancing of supply/demand .................................. 79

C.1.1 National RPS Levels with Different Policies................................................. 80

C.1.2 Eastern Interconnect and SE RPS Potential with different Polices .................... 81

C.2 Other Studies.......................................................................................... 85 



\section{LIST OF FIGURES}

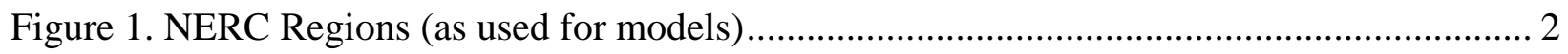

Figure 2. Relations Between NEMS and NESSIE (Source: EPRI) .............................................. 5

Figure 3. Southeastern Regions Analyzed: Four SERC/STV sub-regions and FRCC (SERC/FL) 8

Figure 4. Average Annual Energy and Peak Load Growth Rate from 2010 to 2030..................... 9

Figure 5. Total Installed Generating Capacity in 2010 and 2030 (in Megawatts)........................ 11

Figure 6. Annual Electric Generation in 2010 and 2030 (in Terawatt-hours) .............................. 12

Figure 7. Renewable Generation as Percent of Total Generation in the US and in the Southeast

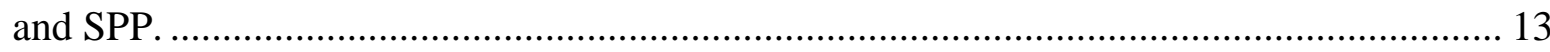

Figure 8. Regional Differences in Wind Resource Available (at Power Class 3 or Better), Wind Energy Production in 2030 and Regional Electrical Demand in 2030 ................................. 14

Figure 9. Indentifying Potential for Wind Energy Transfers from SPP to SERC/STV sub-regions

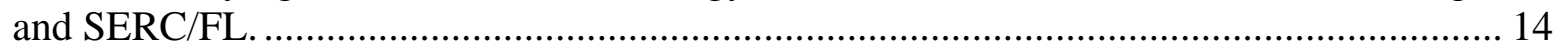

Figure 10. SPP Wind Production Profiles for SERC Peak Summer Day ...................................... 16

Figure 11. Marginal Value of Wind Energy Transfers, Net of Transmission Costs ..................... 19

Figure 12. Marginal Value of Wind Energy Transfers: Sensitivity to Transmission Losses. ...... 20

Figure 13. Marginal Value of Wind Energy Transfers: Sensitivity to Wind Capital Cost........... 20

Figure 14. Regional Annual Generation in 2030 with and without the Favorable Transmission

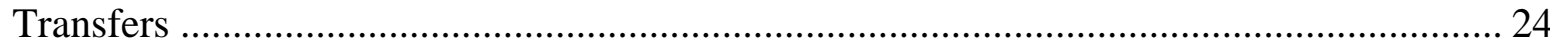

Figure 15. 2020 Renewable Generation as Percent of Total Generation in the Southeast and SPP before and after Wind Energy Transfers........................................................................ 24

Figure 16. Sensitivity Analysis: Price of Natural Gas and CO2 Emission Allowances................ 25

Figure 17. 2020 Renewable Generation as Percent of Total Generation in the Southeast before and after Wind Energy Transfers, under the Assumptions of Low Prices of Natural Gas and CO2 Emission Allowances. .................................................................................... 26

Figure 18. Cumulative Nuclear Capacity Limit on New Capacity Additions over Time.............. 27

Figure 19. 2020 Renewable Generation as Percent of Total Generation in the Southeast US and SPP before and after Wind Energy Transfers, under the Assumptions of Delayed Nuclear

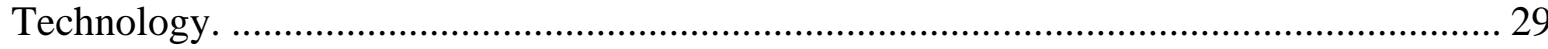

Figure 20. Locations of Southeast Offshore Wind in EWITS study .......................................... 40

Figure 21. Price difference between solar PV levelized costs and residential electricity in 2015 with a 13\% increase in residential prices and no incentives (Paidipati et al. 2008) ............. 41

Figure 22. Total potential biomass resources in the southeast by type (Milbrandt 2005) ............ 42

Figure 23. Location of Hydroelectric facilities in the Southeast (EPA 2008) ................................ 43

Figure 24. Wind Resources Relative to Population Centers........................................................... 79 
Figure 25. Renewable Share of Total Generation for Three Scenarios .................................... 80

Figure 26. US Annual Electricity Generation under Different Scenarios (TWh)...................... 81

Figure 27. Thirteen NERC Regions used in NEMS and NESSIE Model. ............................... 81

Figure 28. Regional Variation in Renewable Generation, RPS Policy Case (2020) ................... 82

Figure 29. Regional Electricity Generation, RPS Policy Case 2020 ........................................ 83

Figure 30. SPP Generation with No Policy, Federal RPS, and Federal Climate Policy.............. 83

Figure 31 SERC Generation with No Policy, Federal RPS, and Federal Climate Policy ............ 84

Figure 32. Comparison of Regional Cost of Electricity, $\mathrm{CO}_{2}$ Policy Case................................. 84

Figure 33 ECAR Generation with No Policy, Federal RPS, and Federal Climate Policy............ 85

Figure 34. 20\% Wind Energy Scenario Conceptual Transmission Overlay (Source JCSP 2008)86

Figure 35. Scenario 2 Interface Contour: Annual Energy Difference Copper Sheet Minus

Constrained Case (Source NREL 2009)...................................................................... 87 


\section{LIST OF TABLES}

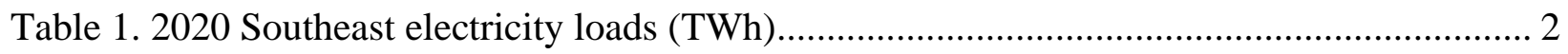

Table 2. Southeast RPS Requirement and Potential Supplies (2020)............................................ 3

Table 3. Total Available Renewable Resources in Southern United States (Megawatts) ............. 10

Table 4. Existing Generating Capacity by Type in SERC Sub-regions, including Florida, and

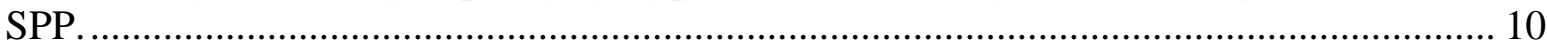

Table 5. Study Assumptions for Selected Variables..................................................................... 17

Table 6. Illustration of Marginal Approach to Calculate Wind Value ........................................... 18

Table 7. Value of Wind Energy Transfers, Based on NESSIE Model Runs .................................. 23

Table 8. Value of Wind Energy Transfers under the Assumptions of Low Prices of Natural Gas and CO2 Emission Allowances ....................................................................................... 26

Table 9. Value of Wind Energy Transfers under the Assumptions of Delayed Nuclear

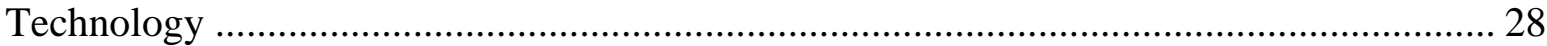

Table 10. Potential Onshore Wind Capacity in SERC region by state (EPRI)............................. 39

Table 11. Southeast states' cumulative rooftop PV capacity (MW) in 2015 under BAU and best case scenarios (Paidipati et al. 2008) ................................................................................ 41

Table 12. Estimated National Waterpower Capacity Gains (MW) by 2025 (Source EPRI 2007)44

Table 13. Southeast 2020 electricity capacity, generation and load from AEO2009 post-stimulus (EIA 2009) 45

Table 14. Southeast electricity capacity, generation and load from EIA evaluation of RPS policy in American Clean Energy and Security Act (Source EIA2009b) .......................................... 46

Table 15. Southeastern renewable generation in 2030 under Markey Bill (TWh) (Source Sullivan 2009) 46

Table 16. Renewable resources in 2030 from different scenarios and models............................... 47

Table 17. Three Possible Policy Scenarios, Source EPRI Report 1015805, March 2009 “Role of Future Generation Options for the U.S. Electric Sector" 80 



\begin{abstract}
Electricity consumption in the Southeastern US, including Florida, is approximately 32\% of the total US. The availability of renewable resources for electricity production is relatively small compared to the high consumption. Therefore meeting a national renewable portfolio standard (RPS) is particularly challenging in this region. Neighboring regions, particularly to the west, have significant wind resources and given sufficient transmission these resources could serve energy markets in the SE. This report looks at renewable resource supply relative to demands and the potential for power transfer into the SE. We found that significant wind energy transfers, at the level of 30-60 GW, are expected to be economic in case of federal RPC or CO2 policy. Development of wind resources will depend not only on the available transmission capacity and required balancing resources, but also on electricity supply and demand factors.
\end{abstract}





\section{Introduction}

\subsection{Renewables in the Southeast needed under RPS}

Current discussions about increasing the amount of renewable energy in the U.S. center on the creation of a Renewable Portfolio Standard (RPS). Each utility would be required to provide an increasing fraction of their total production from qualified renewable resources. A key concern is that the Southeastern U.S. does not have as many cost-effective renewable energy resources as other regions of the country. Therefore utilities may need to import significant quantities of renewable energy, most likely wind power from the Midwestern states. Other options may be available too, such higher-cost local renewable generation, purchase of renewable energy credits without the physical transmission of power, or payment of an alternative compliance payment to the U.S. Treasury.

Under the recently proposed RPS from Sen. Bingaman, "each utility that sells electricity to electric consumers shall obtain a percentage of the base quantity of electricity the electric utility sells to electric consumers in any calendar year from new renewable energy, existing renewable energy, or energy efficiency.” The percentage ramps up from 4\% in 2011 to 20\% by 2021 and thereafter. The utility will utilize renewable energy credits, energy efficiency credits (not more than $25 \%$ of total) and/or payments of $3 \$ / \mathrm{kWh}$ (adjusted for inflation). Tradeable credits will be issued to new renewable production, but existing renewable energy will receive non-tradable credits. Existing hydroelectric power and municipal solid waste facilities are not included in either the numerator or denominator when calculating the percentage of generation from renewable power.

Other bills have been proposed and any final law will likely be different from all of the current proposals. For example, the Waxman-Markey bill sets the standard at $17.5 \%$ in 2020 , with a long-term goal of $25 \%$ from 2025 to 2039. As a consequence of these variations, this report will evaluate the potential impact on the Southeast of a 15\% RPS by 2020; any higher amount will simply amplify the impacts. We will also show some results from a $20 \%$ RPS in order to show the differential involved with higher RPS targets. A recent study from NREL compares the requirements and effects of three recently proposed bills: the Bingaman, Markey, and WaxmanMarkey (Sullivan, et al. 2009).

The regions used for this analysis (Figure 1) are those defined in the Energy Information Administration (EIA) NEMS model (DOE 2008). These regions that have been used in NEMS through the 2009 Annual Energy Outlook are based on the North American Electric Reliability Council (NERC) reliability regions from 2004. There have been several changes in regional boundaries, most notably the addition of Gateway (eastern Missouri and southern Illinois) and most of Kentucky to SERC. For consistency with the EIA data and reporting, the models used in this study, both the EPRI NESSIE model and LCG's UPLAN model, also use these regions in their analysis of the electric power sector. 


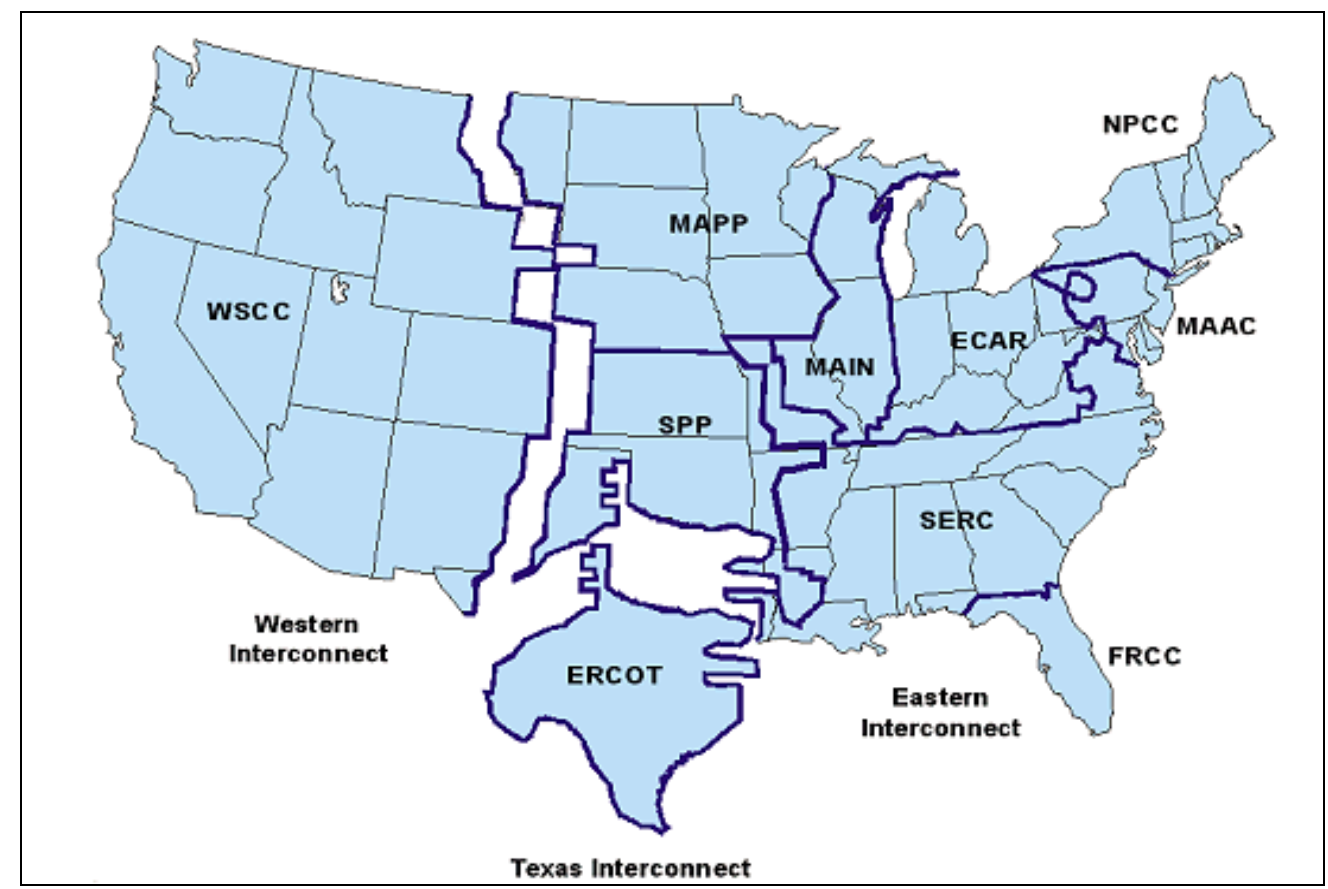

Figure 1. NERC Regions (as used for models)

Using the demands from the latest EIA Annual Energy Outlook 2009 Reference Case (postStimulus Bill), the expected sales of electric power (Net Energy for Load) in the Southeast (SERC and FRCC) are shown in Table 1. With a 15\% RPS, 186 TWh would need to be produced or delivered to the Southeast while a 20\% RPS would require $248 \mathrm{TWh}$ in 2020 . Because of the variety of definitions of "renewable" the actual amount needed may be different. For example, the Bingaman bill does not include existing hydropower and municipal solid waste. When excluding these sources, the total amount of renewables needed in the 15\% RPS drops from 186 TWh to 180 TWh. However, since these two technologies provide 39 TWh in 2020 (in the AEO2009 Reference scenario) the amount of other renewables required is higher than if they are included. See this project’s Task 1 interim report (Hadley and Key 2009) for more details.

Table 1. 2020 Southeast electricity loads (TWh)

\begin{tabular}{cccc}
\hline & SERC & FRCC & Total SE \\
\hline Net Energy for Load & 970 & 270 & 1240 \\
15\% of NEL & 145 & 40 & 186 \\
20\% of NEL & 194 & 54 & 248 \\
\hline
\end{tabular}

\subsection{SE Renewables and Neighboring Wind Resources}

So how much of a gap is there between what is needed to satisfy an RPS of $15 \%$ and the possible sources within the southeast? Table 2 lists the amounts of supplies potentially available within the region, based on various references. None of the sources by themselves can meet the requirements. Solar in the long term is expected to come closest, but these values are based on a very rough extrapolation of technical potential for the region based on a Florida study by Navigant (Navigant 2008). The estimate does not take into account the time it would take to construct such sources, nor does it consider the cost to provide that level of demand. Biomass has the next largest potential, but again, the amount is based on the maximum utilization of all 
resources without regard to construction time or economic cost. It also does not consider that some of the biomass available will be used for liquid fuels.

Table 2. Southeast RPS Requirement and Potential Supplies (2020)

\begin{tabular}{|c|c|}
\hline Generation Needed in 2020 & 186 - 248 TWh (15\% to $20 \%$ RPS) \\
\hline \multirow[t]{3}{*}{ Wind Resources } & 19 TWh generated within SERC (EPRI) \\
\hline & 6.7 TWh Onshore + 14 TWh Offshore (EWITS) \\
\hline & $7-11 \mathrm{TWh}(\mathrm{EIA})$ \\
\hline \multirow[t]{2}{*}{ Solar } & 2 TWh generation by 2015 Rooftop potential (NREL) \\
\hline & $\begin{array}{l}0-160 \text { TWh ground-mount potential depending on policies } \\
\text { (SACE and Navigant) }\end{array}$ \\
\hline \multirow[t]{3}{*}{ Biomass } & $\begin{array}{l}145 \text { TWh technical potential biomass generation (Calculated } \\
\text { from NREL supply estimates) }\end{array}$ \\
\hline & 19 - 55 TWh generated in 2020 depending on policies (EIA) \\
\hline & 46 TWh generated by 2020 in SERC with $\mathrm{CO}_{2}$ policy (EPRI) \\
\hline New Hydro (incremental) & $\begin{array}{l}40 \text { - } 50 \text { TWh generation nationally (SERC amount } \\
\text { unknown) (EPRI) }\end{array}$ \\
\hline Gap in Supplies & $\begin{array}{l}\text { From } 174 \text { TWh are needed to less than zero depending } \\
\text { on solar and biomass deployment }\end{array}$ \\
\hline
\end{tabular}

When considering how much wind from other regions will be needed to meet the renewable portfolio standard in the southeast, it becomes clear that without massive investment in biomass and solar technologies, imported wind is the best choice. To bring in this wind large amounts of transmission will be needed. It then becomes a question of how much the solar and biomass can realistically be deployed in the next 11 years. While biomass generation has an established base in the region, a scale-up from the current projection of 12 TWh will require the construction of new plants, conversion of existing fossil plants, and an established biomass fuel production infrastructure. Solar production has not been developed in the southeast yet. An expansion to cover $\sim 1 \%$ of the land area of the southeast would be required but is not likely in the near term.

Further analysis of the other renewables resources (comparative cost, supplies, policies required) is beyond the scope of this study. Further details on the estimated available renewables by resource type are covered in appendix $\mathrm{A}$. 


\section{Economic Analysis of Wind Energy Transfers}

The main objective of this analysis is to evaluate alternative scenarios that change conditions for development and transport of future wind energy to meet generation requirements in the Southeastern U.S. Given the size of the regional electricity market and the relative shortage of renewable resources in SERC, the focus of this analysis will be to assess the potential for imports of wind generation from regions with a relative abundance of wind resource, such as SPP and MAPP.

This evaluation considers the following key factors:

- Regional markets for new generation, in SERC and adjacent regions

- Cost and performance of wind generation, and anticipated future technology development

- Geographical patterns of available wind resource, including the amount by resource class

- Feasibility of wind transfers, given distances between regions, required transmission investments, and line losses, and

- Regulations, including both potential CO2 regulations and RPS policies.

The starting point for this analysis are results from EPRI previous work on "Modeling the U.S. Electricity Generation Mix, Technical Update, March 2009”, which is summarized in Appendix C. Also, see this project's Task 2 interim report (Hadley, Key and Deb 2009) for more details.

\subsection{Application of EPRI Electric Sector Model}

A major challenge to forecasting deployment of renewable and other electric generation options is to develop an energy system model that is not only valid but also flexible and easy to use. These attributes make it possible for effective application of the model for sensitivity and scenario analyses with relative ease and without changing the model's internal details. As characterized below, EPRI's National Electric System Simulation Integrated Evaluator (NESSIE) was developed to capture complexities without sacrificing flexibility.

NESSIE was originally developed as a capacity expansion and operations model for the U.S. electric sector. It is designed to study the sustainability of the electric system, understand the role of new, low- and non-emitting generation technologies, and analyze the profitability of existing and new generating assets under varying scenarios for the future. ${ }^{1}$ NESSIE incorporates submodels to simulate bulk power markets in individual U.S. regions and to calculate prices and quantities at both regional and aggregate levels. The prices and quantities, along with the values for other parameters employed as inputs to NESSIE, provide the basis for calculating cash flows and profits for generating technologies in regional electricity markets.

NESSIE requires many input values. In general, the inputs fall into two categories. The first category covers the characteristics of generating technologies, such as fixed and variable costs, efficiency, availability, capacity factor, etc. These cost-performance characteristics and projections are generally based on historic data and expert judgments.

\footnotetext{
${ }^{1}$ EPRI, 2003. Evaluating the Potential Effects of Environmental Regulation and Other Variables on Future NonEmitting Generation Profitability. Palo Alto, CA: 1007732.
} 
The second category of inputs includes values determined in markets that are separate from or broader than regional electricity markets. These markets include, for example, natural gas markets (in which electricity generation is only one of many competing uses for gas) and other fuel markets, broader energy markets (in which electricity is one form of energy that competes with others to deliver services), and emission allowance markets (which, while closely related to electricity markets, are separate and extend over larger geographic regions).

Providing these market value inputs requires the use of the National Energy Modeling System (NEMS) so that all energy sectors are considered. NESSIE employs NEMS for a variety of reasons:

- NEMS is comprehensive making it suitable for modeling a wide range of scenarios reflecting different regulatory and other conditions.

- NEMS is viewed as credible within the modeling community, given its association with EIA and its long history of use for analyzing the U.S. energy system.

- NEMS is publicly available from and extensively documented by EIA, characteristics that have led to it being fairly widely used and well understood, relative to other large and complex energy system models.

Figure 2 illustrates the ways in which the two models are used together, and it identifies key inputs and outputs from each of the models.

\section{EIA National Energy Modeling System}

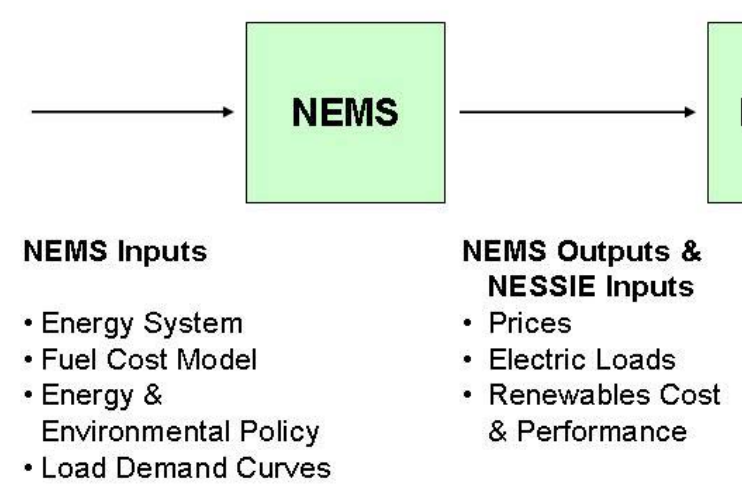

EPRI National Electric System Simulation Integrated Evaluator

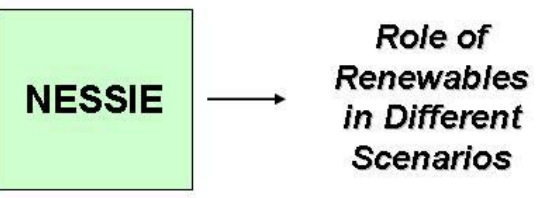

NESSIE Outputs

- Electric Prices

(Consumer Value)

- Producer Profits

(Utility Value)

- Capacity \& Energy

Balance

- Capacity Expansion

- Emissions

Figure 2. Relations Between NEMS and NESSIE (Source: EPRI)

It is an important point that NEMS is a general equilibrium model where supply and demand are specified as functions. Thus, both supply and demand change as the model solves for equilibrium. The equilibrium is reached by finding the demand that is consistent with the prices generated by the supply function. If a scenario leads to higher costs for electricity, then the 
demand for electricity will drop. NESSIE follows the same equilibrium approach for the electric sector, starting with results from NEMS as an input.

In January 2007, a comparison of NEMS, NESSIE, and NREL's WinDS (now called ReEDS) models was completed to determine how renewable generation is treated in each model. The results show that all three of these energy models have advantages and disadvantages. ${ }^{2}$ A key conclusion for the NESSIE model was to expand the number of renewable options and the details on treatment of regional resource availability and uncertainty regarding technology evolution.

There are a number of generation options for meeting electrical demand. Therefore deployment of renewable generation depends on the relative cost of all other generation options as well as factors such as demand growth and implementation of conservation or energy efficiency measures. The NESSIE model covers the following generation options:

- Thermal Generation: conventional and advanced coal, including near-term integrated gasification combined cycle (IGCC) and longer-term technology with carbon capture and storage (CCS); natural gas combined cycle; gas turbine; oil/gas boiler; nuclear; biomass; landfill gas; municipal solid waste; geothermal; fuel cells; biomass co-firing in existing coal units built before and after 1975; retrofits of the existing coal units built after 1975 with the CCS equipment; and retrofits of the existing coal units built after 1975 with a new boiler to use biomass fuel exclusively.

- Non-thermal Generation: wind; solar, including central-station solar thermal electric and photovoltaic (PV); and hydro, including conventional (impounded), run of river and pumped storage.

Regional demand is based on the NEMS model estimates, but can be adjusted by region for different growth scenarios or energy efficiency measures.

The following modeling capabilities contained in NESSIE make it a particularly useful framework to evaluate the potential costs and benefits of interregional wind transfers to the Southeastern US:

- Explicit consideration of regional constraints on available wind resource. NESSIE incorporates regional estimates of wind resource by power class, which directly impacts the quantity and economic attractiveness of new wind generation in each region.

- Capture of regional differences in alternative generation resources. The market for new wind generation depends on the availability of alternative generation that will compete with wind to meet future generation requirements.

- Incorporation of the impacts of climate legislation. NESSIE explicitly models the impact of potential climate legislation such as a tax on carbon emissions or a cap-and-trade mechanism, state and federal Resource Portfolio Standards (RPS), and various tax incentives for renewable generation or other non-emitting technologies.

${ }^{2}$ EPRI, 2007. Role of Renewable Energy in a Sustainable Electricity Generation Portfolio. Palo Alto, CA: 1012730. 
- Model of the impact of variability in wind generation. Using wind production patterns from representative wind sites, NESSIE incorporates the variability in output from potential wind sites in each region. This representation of variability is used explicitly in quantifying the value of wind generation for meeting future regional capacity and generation requirements.

As the result of its unique modeling capabilities, NESSIE was chosen by the project team to evaluate the potential of the wind energy transfers into the Southeastern US. The following key steps summarize this evaluation:

Step 1. Development of a base case that allowed more detailed modeling of the Southeastern US that was necessary for this study. Section 2.2 describes the development of this base case and the base case results for different regions of the Southeastern US.

Step 2. Definition of the potential wind energy transfer scenarios into the Southeastern US. This definition was based on

- Identifying the potential exporting regions of wind energy into the Southeastern US as indicated by the base case results from NESSIE. Section 2.2 describes this process.

- $\quad$ Understanding the value of transferring wind energy of different quality, as defined by the achieved annual average capacity factor, to different parts of the Southeastern US. This evaluation was performed through a marginal analysis of the economic value of a small $(1 \mathrm{~kW})$ wind energy transfer to different parts of the Southeastern US. Section 2.3 details this analysis.

Step 3. Integrated evaluation of the wind energy transfer scenarios, defined based on the results of Step 2 of the analysis. Section 2.4 describes this evaluation.

Step 4. Sensitivity analysis of the economic value of the wind energy transfers into the Southeastern US. Section 2.5 depicts the analysis performed.

Section 2.6 presents the main conclusions of the study of the potential wind energy transfers into the Southeastern US.

\subsection{Base Case Assumptions and Results}

The analysis on this project examines potential transfers of wind generation into the Southeastern US. The study assumes that the Southeastern US consists of the SERC/STV and SERC/FL (or FRCC) NERC regions as modeled in NEMS. These two regions are large electrically, representing approximately 30\% of electric generation for the country. In addition, these regions cover a large geographic territory.

To enable more accurate modeling of different parts of the Southeastern US, SERC/STV region was divided into four sub-regions, based on the pre-2006 NERC sub-regional definitions. Figure 3 shows the four SERC/STV sub-regions and SERC/FL (FRCC) imposed on a map. The analysis was performed at the level of SERC sub-regions to capture differences in the following generating system characteristics that can impact the potential value of wind transfers:

- Electric demand growth. SERC sub-regions and FRCC vary significantly in forecasts of future demand growth and in seasonal and daily patterns of demand, resulting in different requirements for new installations of renewable generating capacity. 
- Existing generation mix. The value of imported wind generation depends on the price of electricity produced by a region's own resources, which varies with the mix of installed generation capacity in each sub-region.

- Availability of renewable resources. While the Southeastern US is generally limited in the amount and quality of wind and other renewable resources, there remain significant subregional differences which impact the value of imports, as well a sub-region's capability to meet state or federal Renewable Portfolio Standards (RPS).

- Transmission requirements. Given the wide geography covered by SERC, the costs of transmission for importing wind from resource-rich regions will vary considerably with the transmission distances to each respective sub-region.

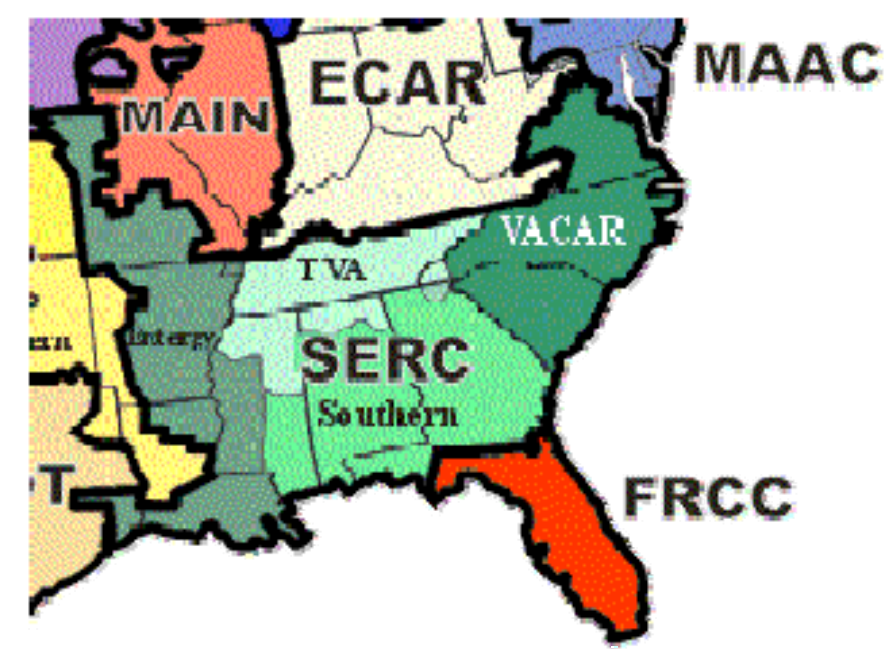

Figure 3. Southeastern Regions Analyzed: Four SERC/STV sub-regions and FRCC (SERC/FL)

\subsubsection{Base Case for SERC Sub-Regions}

To provide this level of regional detail, an initial step in the analysis was to develop a new base case with each of the four SERC/STV sub-regions represented as a stand alone market within NESSIE. Evaluation of the impact of inter-regional wind transfers was then performed using this revised base case as the starting point. The base case data set for each of the four sub-regions within SERC/STV (Entergy, Southern, TVA, and VACAR) plus the FRCC region required several changes to the NESSIE model assumptions ${ }^{3}$. First, the team allocated the loads for the larger region to the SERC/STV sub-regions. This allocation was based on the following data inputs:

1) NEMS estimate of the SERC/STV energy and peak demand over time,

\footnotetext{
${ }^{3}$ The sub-regional definition for SERC/STV is based on the pre-2006 NERC sub-regions to stay consistent with the 2008 NEMS model used for the analysis that relies on the pre-2006 NERC regional definition. Starting in 2006, NERC sub-regional definition for SERC/STV is 1) Delta (previously Entergy, plus approximately 95\% of Missouri),

2) Central (previously TVA, plus approximately 90\% of Kentucky), 3) Gateway (not part of SERC/STV pre-2006),

4) Southeastern (previously Southern), and 5) VACAR.
} 
2) North American Electric Reliability Corporation's (NERC) historical energy by subregion ${ }^{4}$,

3) NERC forecast of energy growth by sub-region ${ }^{5}$,

4) Hourly load data for dominant regional utilities (Entergy, Southern Company, S. MS Electric Power, Oglethorpe, TVA, Duke, Progress Energy (CP\&L), and SC Electric \& Gas) ${ }^{6}$.

The resulting load data for the SERC/STV sub-regions were consistent with the electric load data for SERC/STV as a whole, based on the NEMS data, and reflected the sub-regional variations in energy growth. Figure 4 displays the annual average energy and peak load growth rates from 2010 to 2030 in SERC/STV sub-regions, FRCC (FL), and for the US.

The second step in refining the NESSIE input data was to allocate the renewable resources from SERC/STV to the sub-regions using state-level resource estimates. Table 3 shows the resulting total available renewable resources. Finally, the project team allocated the existing generation capacity to the sub-regions, producing the results displayed in Table 4.

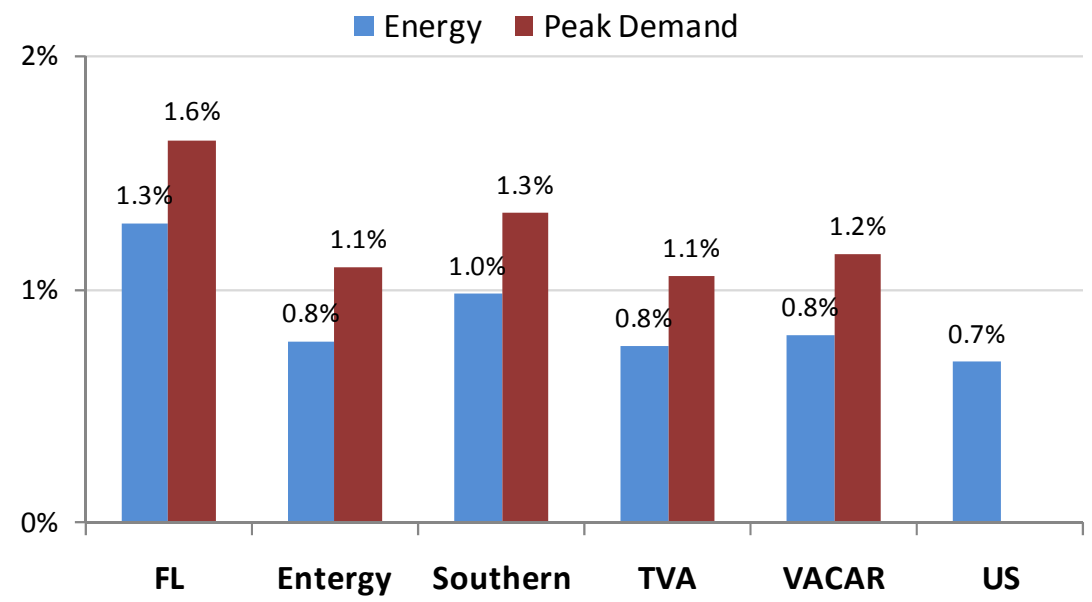

Figure 4. Average Annual Energy and Peak Load Growth Rate from 2010 to 2030.

\footnotetext{
${ }^{4}$ NERC. 2008. Electricity Supply and Demand (ES\&D): Frequently Requested Reports. Historic Capacity and Demand.

${ }^{5}$ Ibid.

${ }^{6}$ Federal Energy Regulatory Commission, FERC Form-714 data.
} 
Table 3. Total Available Renewable Resources in Southern United States (Megawatts) ${ }^{7}$

\begin{tabular}{|c|c|c|c|c|c|}
\hline Resource & Florida & Entergy & Southern & TVA & VACAR \\
\hline Biomass & 1,598 & 7,204 & 6,272 & 2,739 & 4,455 \\
\hline Wind & - & 6,290 & - & 1,097 & 3,973 \\
\hline New Hydro & 8 & 227 & 433 & 570 & 923 \\
\hline Geothermal & - & 1,635 & 198 & 165 & 1 \\
\hline Landfill Gas & 116 & 90 & 117 & 92 & 253 \\
\hline Solar PV & Unlimited & Unlimited & Unlimited & Unlimited & Unlimited \\
\hline
\end{tabular}

Table 4. Existing Generating Capacity by Type in SERC Sub-regions, including Florida, and SPP ${ }^{8}$.

\begin{tabular}{lrrrrrr}
\hline \multirow{2}{*}{ Technology } & \multicolumn{7}{c}{ SERC } & \multirow{2}{*}{ SPP } \\
\cline { 2 - 5 } & \multicolumn{1}{c}{ Florida } & \multicolumn{1}{c}{ Entergy } & \multicolumn{1}{c}{ Southern } & \multicolumn{1}{c}{ TVA } & \multicolumn{1}{c}{ VACAR } & \\
\hline Coal & 9,030 & 6,071 & 23,807 & 15,227 & 23,229 & 22,451 \\
Combined Cycle & 15,635 & 11,496 & 17,576 & 2,294 & 6,451 & 12,446 \\
Gas Turbine & 9,897 & 3,111 & 12,376 & 6,039 & 13,000 & 8,219 \\
Oil/Gas Boiler & 11,307 & 16,243 & 1,185 & - & 2,078 & 12,827 \\
Nuclear & 3,902 & 3,860 & 6,752 & 6,493 & 14,362 & 1,166 \\
Biomass & 357 & 476 & 1,181 & 182 & 847 & 388 \\
Landfill Gas & 24 & 5 & -10 & 10 & 58 & 3 \\
Municipal Solid Waste & 413 & - & 11 & - & 171 & 16 \\
Wind & - & - & - & 190 & - & 1,598 \\
Peak Hydro & 85 & 163 & 2,873 & 4,018 & 3,017 & 2,005 \\
Run-of-River Hydro & - & 2,106 & 90 & - & 599 & 436 \\
Pumped Storage & - & - & 1,364 & 1,684 & 5,614 & 260 \\
\hline & & $\mathbf{4 3 , 5 3 2}$ & $\mathbf{6 7 , 2 2 0}$ & $\mathbf{3 6 , 1 3 7}$ & $\mathbf{6 9 , 4 2 6}$ & $\mathbf{6 1 , 8 1 5}$
\end{tabular}

The base case assumes that there is a national policy to reduce the emissions of CO2. This policy is the same as the policy used in the base case documented in the 2009 technical update (EPRI, 2009). This CO2 policy has a cap-and-trade or CO2 tax and results in a 2015 price of $\$ 27$ per metric ton of CO2 in 2006 dollars. This price escalates at 5\% real per year. This price stream combined with the other assumptions in NESSIE allow the nation to achieve the electric sector's reductions in $\mathrm{CO} 2$ emissions to comply with the targets in the Waxman-Markey bill passed in 2009 by the US House of Representatives. The base case scenario assumes no inter-regional transfers of wind generation in meeting future SERC generation requirements.

\footnotetext{
${ }^{7}$ Sources: Calculations by Cascade Consulting Partners, based on

- Wind: Tom Key's (EPRI) personal communication with US DOE, NREL. 2008.

- Biomass and landfill gas: Milbrant, A. 2005. A Geographic Perspective on the Current Biomass Resource Availability in the United States. U.S. DOE, NREL.

- Geothermal: Petty, S., G. Porro. 2007. Updated U. S. Geothermal Supply Characterization. U.S. DOE, NREL.

- New Hydro (re-powering): EPRI's estimate that equals $10 \%$ of existing hydroelectric capacity.

${ }^{8}$ The existing generating capacity is based primarily on the U.S. Department of Energy's 2005 and 2006 EIA906/920 Monthly Time Series and EIA-860 files. The data reflect the existing capacity as of January 1, 2007 and the estimated wind capacity additions by 2010 as of January 2008.
} 
The base case NESSIE results include capacity expansion and generation results for all of the regions, including results for each of the four SERC sub-regions plus FRCC. Figure 5 shows the installed capacity for 2010 and 2030. In the Southeastern US, the model forecasts installations with a diverse capacity mix. Over time, however, a large amount of gas-fueled capacity is installed in the region, consisting of both combined-cycle and simple-cycle gas turbines. Nuclear capacity installed increases noticeably, while total coal capacity installed declines from 2010 to 2030, mostly due to the economic retirement of older existing plants. At the same time, the model does not forecast significant installations of renewable capacity in the SERC sub-regions. In contrast, substantial wind resource is used in the SPP region by 2030. Figure 6 displays the annual generation in 2010 and 2030 for the five Southeastern sub-regions and SPP. As expected, the low variable cost technologies - primarily nuclear and coal - dispatch with higher capacity factors. More wind power is used in SPP, as compared to the SERC sub-regions. This occurs both due to higher installations of wind capacity and availability of better wind resource, as measured by average annual capacity factor, in SPP than in SERC/STV.

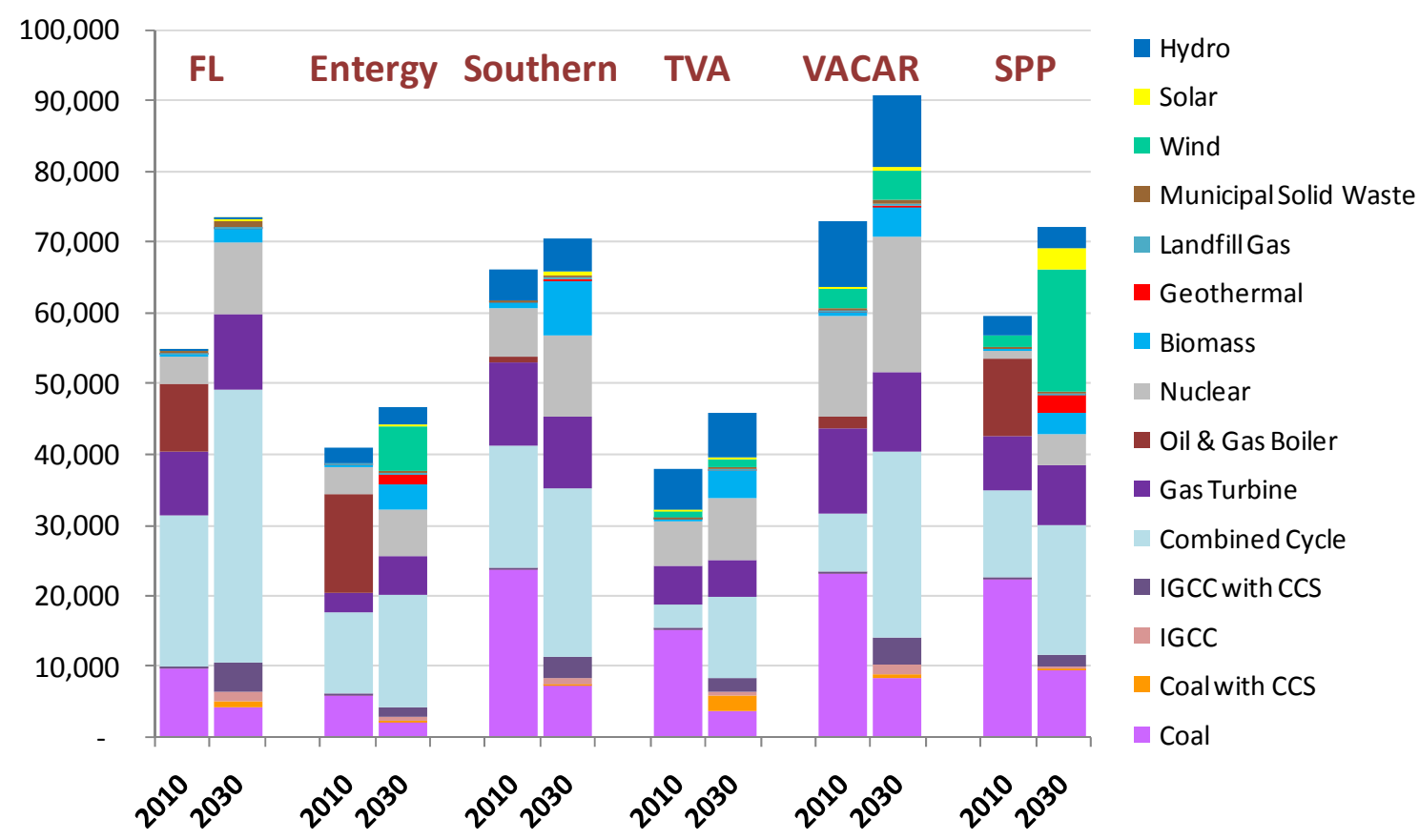

Figure 5. Total Installed Generating Capacity in 2010 and 2030 (in Megawatts) 


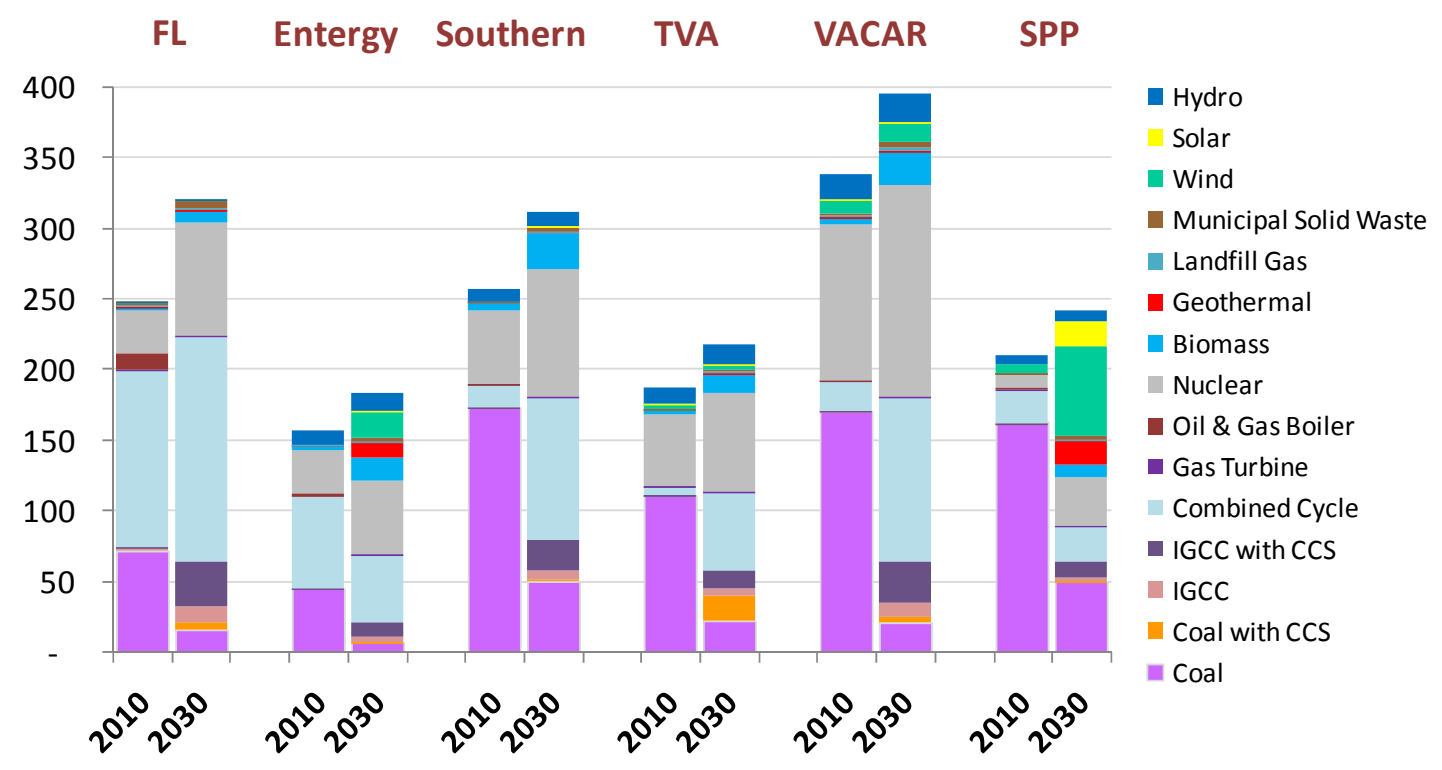

Figure 6. Annual Electric Generation in 2010 and 2030 (in Terawatt-hours)

Figure 7 shows the amount of renewable resources used as a percentage of total generation in the six regions in 2020 as well as for the entire US over time. The definition of renewable resources and the method for computing the renewable generation as percent of total are based on the Waxman-Markey bill. This bill also defines targets for renewable generation that must be met over time. The chart on the left of Figure 7 shows large increases in renewable generation over time for the US as a whole. In fact, the renewable generation as percent of total is high enough to meet the requirements in the Waxman-Markey bill, denoted by the dotted line. However, the renewable generation achieved in the Southeastern sub-regions is not sufficient to comply with the Waxman-Market targets in 2020, with an exception of Entergy. This result is due primarily to the relatively limited amounts of renewable resources located in the Southeastern US. SPP meets the renewable generation target in 2020, with the largest contribution from wind generation. 
In US over Time

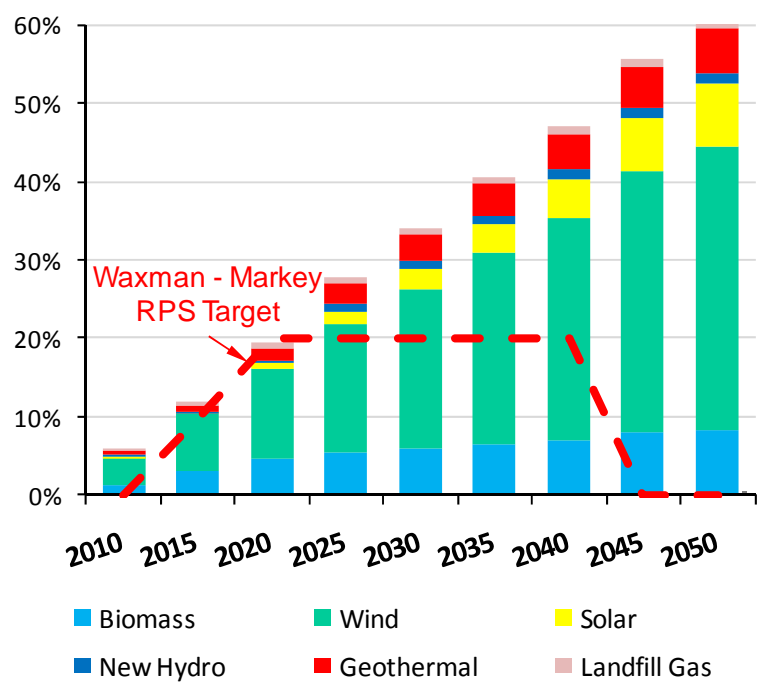

In the S.E. US and SPP, in 2020

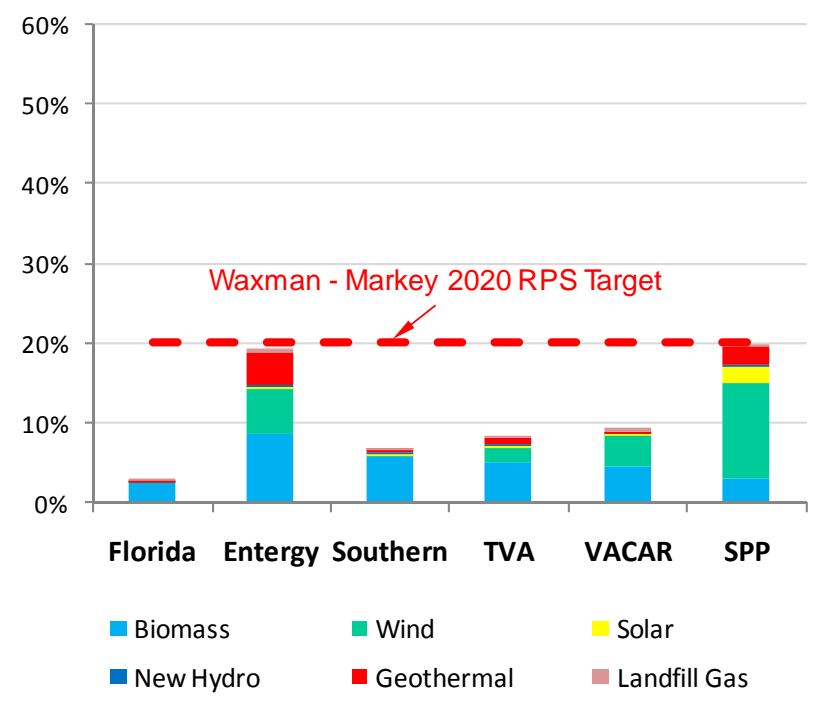

Figure 7. Renewable Generation as Percent of Total Generation in the US and in the Southeast and SPP.

\subsubsection{Define wind transfer cases}

The NESSIE model was run without any wind transfers from outside the Southeast. The team analyzed the detailed results, specifically the use of the wind resources of the Southeast and surrounding regions. Figure 8 shows NESSIE results from the year 2030, which indicate a significant imbalance between the wind resource available to the Southeastern sub-regions and four adjacent NERC regions - ECAR, ERCOT, MAIN and SPP. Due to the limited wind resource in the Southeast, the base case NESSIE results show that the Southeast will use all of its available wind resource from Power Class 3 and above. In contrast, the surrounding areas have a significant wind resource potential not used by 2030 at Power Class 3 or better.

The project team focused this study on transfers from SPP to the Southeastern US, rather than attempt to evaluate the full set of possible wind transfers from each of the adjacent regions. SPP provides a good source for imported wind generation, due to both its large surplus of wind resource and its geographical proximity to SERC, particularly the Entergy and TVA sub-regions. Narrowing the scope to SPP enabled the project team to perform a credible analysis of the value of potential transfers, while managing the complexity that would be required to investigate a broader set of potential regional imports.

At a detailed level, the NESSIE results show that the SPP region did not use all of its Class 5 wind resources by 2030. These detailed results appear in Figure 9. Based on the available wind resource at Power Class 4 and 5 in SPP, we defined a feasible set of inter-regional transfers of wind generation that, together with internal generation resources, can be used to meet future SERC generation requirements. From this set of feasible inter-regional wind transfers, we identified a set of economically attractive transfers, involving imports to each of the SERC subregions as well as FRCC. Transfers were defined in terms of potential megawatts transferred by resource power class from SPP to each potential importing region. 


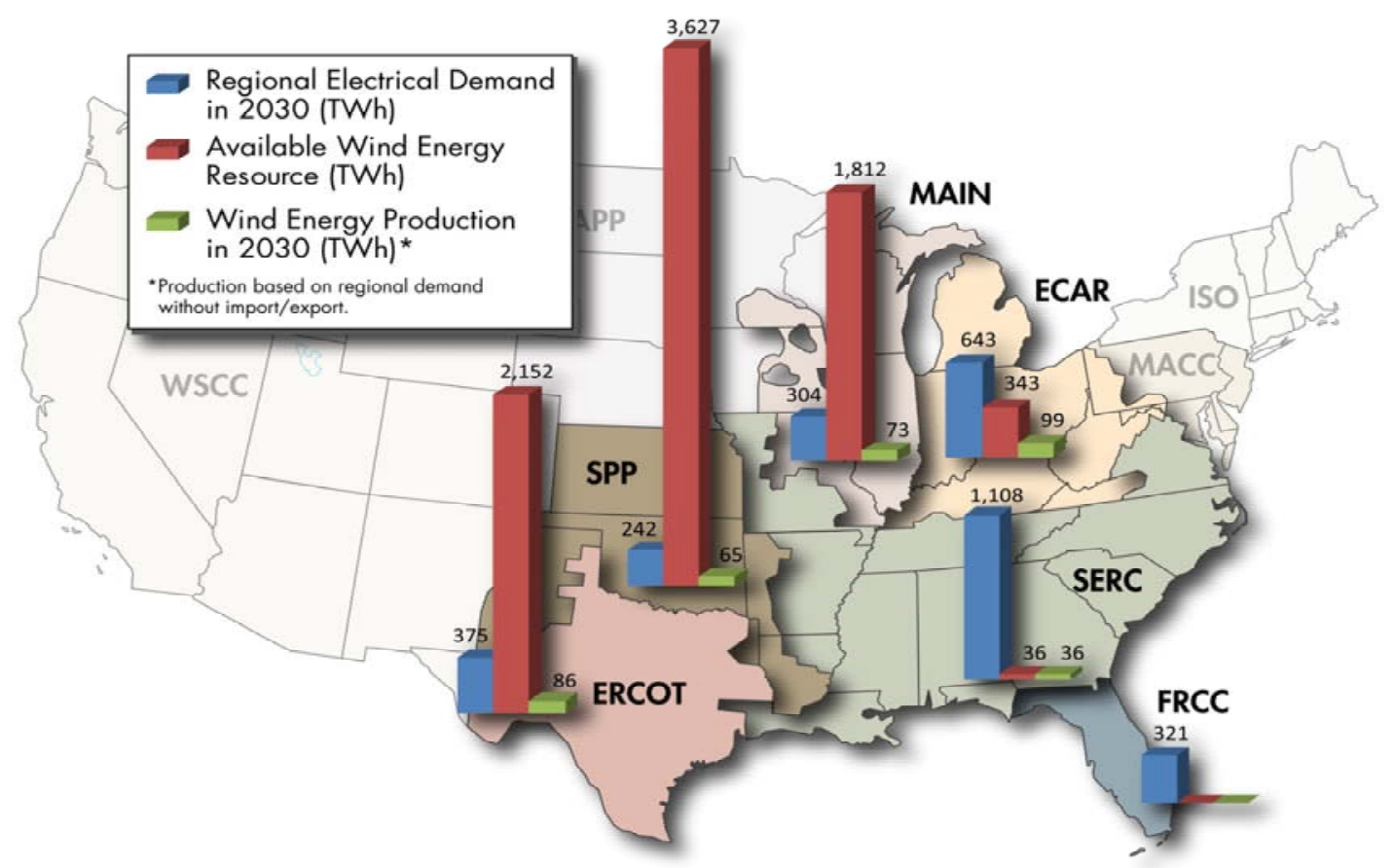

Figure 8. Regional Differences in Wind Resource Available (at Power Class 3 or Better), Wind Energy Production in 2030 and Regional Electrical Demand in 2030.

\begin{tabular}{|c|c|c|c|}
\hline \multicolumn{2}{|l|}{ SPP has plentiful wind resource } & \multicolumn{2}{|c|}{$\begin{array}{l}\text { All wind resource is used in SERC sub-regions } \\
M W \text { installed by } 2030\end{array}$} \\
\hline \multirow[t]{4}{*}{ MW installed by 2030} & 17,139 & $\begin{array}{l}\text { SERC / FL } \\
\text { SERC / Entergy }\end{array}$ & $6,290^{-}$ \\
\hline & & SERC / Southern & \\
\hline & & SERC / TVA & 1,097 \\
\hline & & SERC / VACAR & 3,973 \\
\hline Marginal Wind Class & 5 & Marginal Wind Class & 3 \\
\hline Marginal Capacity Factor (\%) & $43.0 \%$ & Marginal Wind Capacity Factor (\%) & $35.0 \%$ \\
\hline Remaining Wind in Class 5 (MW) & 17,132 & & \\
\hline Class 5 Wind Capacity Factor (\%) & $43.0 \%$ & & \\
\hline Remaining Wind in Class 4 (MW) & 344,925 & \multirow{2}{*}{\multicolumn{2}{|c|}{$\begin{array}{l}\text { Note: SERC/FL and SERC/Southern do not have any } \\
\text { wind resource. }\end{array}$}} \\
\hline Class 4 Wind Capacity Factor (\%) & $39.0 \%$ & & \\
\hline
\end{tabular}

Figure 9. Indentifying Potential for Wind Energy Transfers from SPP to SERC/STV subregions and SERC/FL.

The value of importing wind from SPP to the SERC sub-regions depends not only on the availability of surplus SPP wind with a higher power class than native SERC wind, but on the seasonal, daily and hourly variability of this resource. In particular, the interaction of this variability in SPP wind resource with the patterns of SERC sub-regional electric demand and system dispatch is critical in determining the value of wind transfers. 
We compute the variation in SPP wind generation by evaluating wind generation profiles from selected SPP sites in the database for the Eastern Wind Integration and Transmission Study $(\text { EWITS })^{9}$. This database contains estimated wind production for selected wind plant sites used in the EWITS study of wind transfers through the Eastern Interconnection. Data for each plant site represented in the database contains wind output data at ten minute intervals for one or more entire study years. The project team used this data to develop SPP wind generation profiles for analysis within NESSIE using the following steps:

1. Select data for 10 representative SPP sites. The project team selected five quality sites (Class 4 or Class 5) with approximately 1000 megawatts of potential from each of the two states comprising most of SPP: Oklahoma and Kansas. The team did not perform extensive statistical analysis in selecting the sites. Rather, the goal was to identify 10 fairly representative sites that have a high likelihood of early development.

2. Average the wind production data across the 10 selected sites. Averaging across the sites in both states avoids some of the abrupt variability that may exist for a single site, and thereby better represents the aggregate wind production for a region.

3. Assign wind production to day types, based on the peak electric demand days for SERC - the importing region. We assigned this wind production to four day types: Peak and Normal days, for the both Peak (May through September) and Off-peak (October through April) seasons.

4. Evaluate the variability of wind output within each of the four day types. The net result of this step, combined with Step 3, is to provide the correct correlation between the variability in wind production from the exporting region (SPP) and the variability in electric demand in the importing region (SERC). For wind generation, we specify this variability in terms of the mean, variance and skewness (3rd moment) of the daily wind output for all of the days assigned to each day type.

5. Create "High" and "Low" wind production profiles for each day type. The "High" profile is calculated by averaging the profiles for the highest $\mathrm{X}$ percent of the days within a day type (as defined by total daily wind output), while the "Low" profile is calculated by averaging the lowest 1 - X percent of the days for the same day type. The value of $\mathrm{X}$ is selected to best preserve the mean, variance and skewness calculated in step 4. Thus, we are able to create a two-point probability distribution on wind production that preserves the important variability characteristics of the true distribution.

The wind production profiles calculated in Step 5 are used as input data for NESSIE in evaluating wind transfers from SPP to SERC. Capturing wind generation in terms of these "High" and "Low" profiles (each with associated probabilities) for each day type provides relatively concise way to represent the impact of this variability on SERC system dispatch. Figure 10 shows the "High" and "Low" generation profiles used in the study to represent the imported SPP wind generation on a peak summer day in SERC. As the figure shows, there is a high likelihood (80\%) that imported SPP wind will provide generation equal to only about $20 \%$ of installed wind capacity during the critical peak hours of the SERC peak day. This low

\footnotetext{
${ }^{9}$ US DOE, NREL. 2009. Eastern Wind Integration and Transmission Study: FTP Site. Time series data for landbased sites. Retrieved from ftp://ftp2.nrel.gov/pub/ewits/TimeSeries/LandBased/.
} 
availability during peak periods reduces the amount of imported wind capacity that can counted on to meet SERC system reliability requirements within NESSIE

\section{SPP Wind Production - Peak Summer Day in SERC}

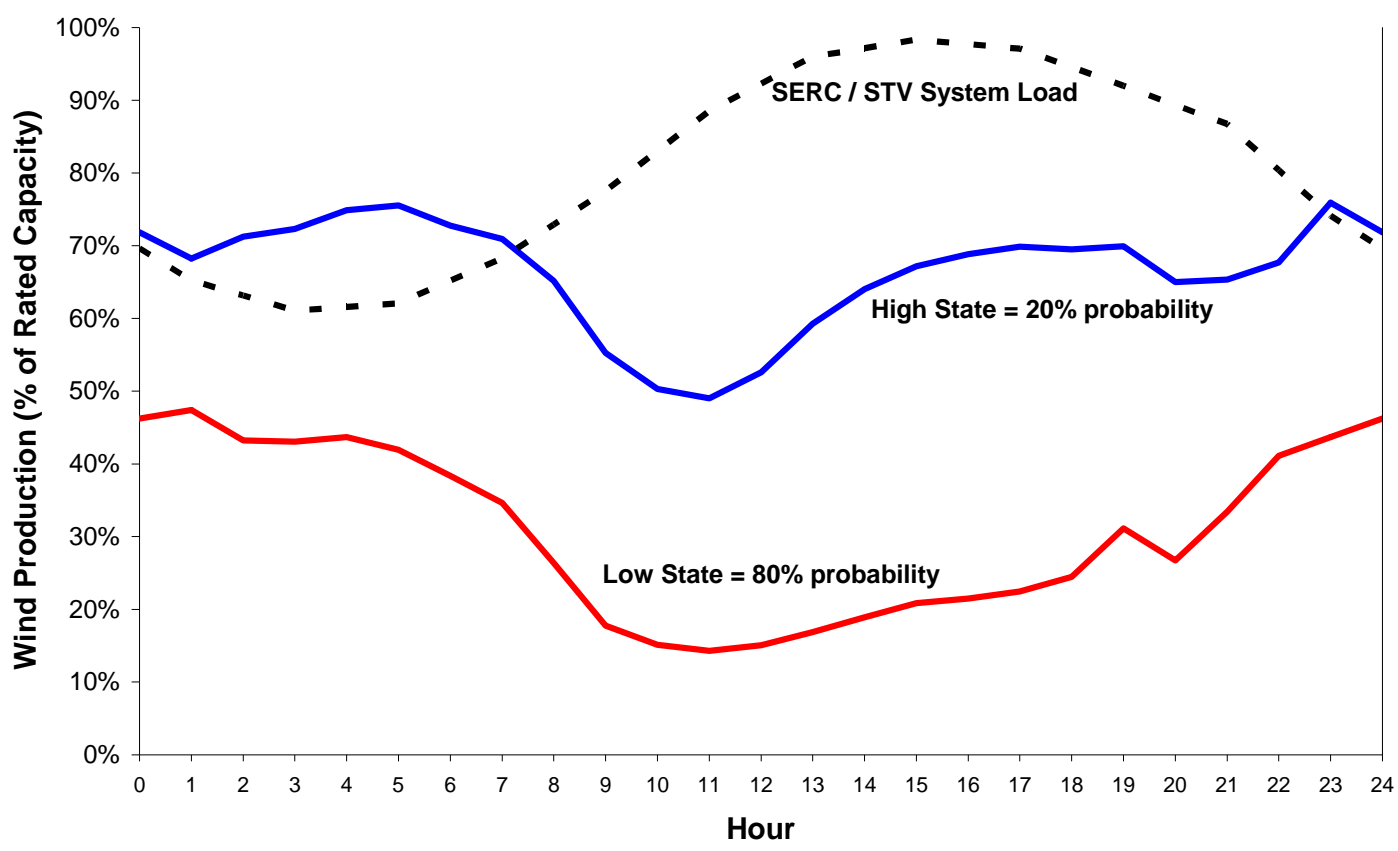

Figure 10. SPP Wind Production Profiles for SERC Peak Summer Day

\subsection{Marginal Analysis of Inter-Regional Wind Transfers}

The value of wind energy transfers from SPP to the SERC sub-regions plus FRCC will depend not only on the attractiveness of the available resources but also on the transmission costs, including losses, to deliver the power. The scenarios for the transmission costs are shown in Table 5. The top section of the table ("Reference Transmission Flow") describes an assumed delivery path for each of the five Southeastern sub-regions. The mileage is approximated with Google maps. The second section of the table ("Transmission Costs (\$2006 / kW)") displays the three estimates used for the analysis of the transmission capital cost needed to deliver the wind power from SPP to the Southeastern sub-regions. The third section of the table ("Transmission Losses”) outlines the two scenarios used for the analysis to represent transmission losses incurred in transfers of wind generation. Finally, the last section of the table ("SPP Transfer Capacity Factor") compares wind annual average capacity factor as generated in SPP to the effective capacity after delivery to the each of the Southeastern sub-regions. This difference is due to losses assumed in each of the two transmission loss scenarios. For example, a wind turbine built in areas with Power Class 5 wind in SPP will generate at an average annual capacity factor of $43 \%$. This energy is equivalent to energy generated by a wind turbine located in SERC/VACAR with an annual average capacity factor of $41.5 \%$ under the base-case transmission losses and $40.4 \%$ under the higher transmission loss scenario. 
Table 5. Study Assumptions for Selected Variables.

\begin{tabular}{|c|c|c|c|c|c|}
\hline & \multicolumn{5}{|c|}{ SERC Sub-Region } \\
\hline & Florida & Entergy & Southern & TVA & VACAR \\
\hline Reference Transmission Flow & $\begin{array}{l}\text { Tulsa to } \\
\text { Tampa }\end{array}$ & $\begin{array}{l}\text { Tulsa to } \\
\text { Little Rock }\end{array}$ & $\begin{array}{l}\text { Tulsa to } \\
\text { Atlanta }\end{array}$ & $\begin{array}{l}\text { Tulsa to } \\
\text { Memphis }\end{array}$ & $\begin{array}{c}\text { Wichita to } \\
\text { Washington } \\
\text { D.C. }\end{array}$ \\
\hline Miles & 1,233 & 272 & 781 & 400 & 1,102 \\
\hline \multicolumn{6}{|l|}{ Transmission Costs $(\$ 2006 /$ kW) } \\
\hline$\$ 800 / \mathrm{MW}-\mathrm{mile}^{*}$ & 986 & 218 & 625 & 320 & 882 \\
\hline$\$ 1200$ / MW - mile* & 1,480 & 326 & 937 & 480 & 1,322 \\
\hline$\$ 1600$ / MW - mile* & 1,973 & 435 & 1,250 & 640 & 1,763 \\
\hline \multicolumn{6}{|l|}{ Transmission Losses } \\
\hline Base Case & $3.5 \%$ & $3.5 \%$ & $3.5 \%$ & $3.5 \%$ & $3.5 \%$ \\
\hline Higher Losses & $6.0 \%$ & $3.5 \%$ & $6.0 \%$ & $3.5 \%$ & $6.0 \%$ \\
\hline \multicolumn{6}{|l|}{ SPP Transfer Capacity Factor } \\
\hline Base Case & $41.5 \%$ & $41.5 \%$ & $41.5 \%$ & $41.5 \%$ & $41.5 \%$ \\
\hline Higher Losses & $40.4 \%$ & $41.5 \%$ & $40.4 \%$ & $41.5 \%$ & $40.4 \%$ \\
\hline \multicolumn{6}{|l|}{ Class $4(39 \%)$} \\
\hline Base Case & $37.6 \%$ & $37.6 \%$ & $37.6 \%$ & $37.6 \%$ & $37.6 \%$ \\
\hline Higher Losses & $36.7 \%$ & $37.6 \%$ & $36.7 \%$ & $37.6 \%$ & $36.7 \%$ \\
\hline
\end{tabular}

The project applied NESSIE in two different ways to evaluate potential transfers of wind generation from SPP to SERC. In the first approach, we used the results of the base case (without wind transfers) to provide marginal generation prices for each of the SERC sub-regions. These marginal prices were then used to evaluate the marginal value of transferring one $\mathrm{kW}$ of wind generation capacity to each SERC sub-region. In the second approach, the amount of generation capacity that can be transferred is specified within NESSIE, and the model explicitly represents the sub-regional capacity expansion and system dispatch decisions resulting from this available resource. In this study, the results of the marginal analysis were used to inform the design of the transfer scenarios used in the integrated NESSIE analysis, by identifying and developing wind transfer scenarios that the marginal analysis shows to be economically attractive.

Table 6 summarizes the results of the marginal analysis, for each potential sub-regional wind transfer. NESSIE estimates the annual operating profit (measured in dollars per $\mathrm{kW}$-year) for each wind class by multiplying the respective wind production profile for one $\mathrm{kW}$ of installed wind capacity within each power class, by the sub-regional marginal prices, less fixed and variable operating costs. This calculation is performed across all dimensions of variation used by NESSIE to calculate marginal prices, including both time dimensions (season, day type, hour) and system operating conditions (demand cycles, generating plant outages). The present value operating profit is calculated by discounting the stream of annual operating profits computed for each of the nine periods of the model horizon, assuming an initial wind plant operating date of 2015. 
The last line of Table 6 shows the net present value of wind transfers into each Southeastern subregion for each wind resource class, after accounting for the net change in capital investment from constructing a wind facility in 2015. This capital investment impact includes two components: 1) the direct capital cost of building $1 \mathrm{~kW}$ of wind capacity in 2015 and 2) the deferred capital costs of alternative generating capacity that would have been built in the absence of the wind plant. For this second component, we make a simplifying assumption that a construction of a gas combined-cycle plant would be deferred, with the wind plant receiving a 20 percent capacity credit, due to the intermittent nature of its output (see Figure 10). In other words, we assume for this marginal analysis that the net capital investment of installing $1 \mathrm{~kW}$ of wind capacity in 2015 is equal to the capital investment of $1 \mathrm{~kW}$ of wind less a capital investment of $0.2 \mathrm{~kW}$ of a gas combined-cycle plant. A gas combined-cycle plant is used as the avoided generation investment in this analysis because, when we look at detailed capacity choice results within NESSIE, combined-cycle plants compete strongly with wind as generation alternatives in each period of the model horizon, and in each of the five Southeastern subregions.

As the last line of Table 6 shows, the net value of transferred wind, including generation capital costs but before the costs of transmission between SPP and SERC are considered, is positive for all five sub-regions for both Class 4 and Class 5 SPP wind resource. Specifically, the net value ranges from $\$ 1,167$ to $\$ 1,354$ per $\mathrm{kW}$ for Class 5 transfers and from $\$ 830$ to $\$ 999$ per $\mathrm{kW}$ for Class 4 transfers. The variability in net value among regions is due to differences in regional marginal prices, which tend to be somewhat lower in VACAR and highest in Florida and Southern.

\begin{tabular}{|c|c|c|c|c|c|c|c|c|c|c|}
\hline \multirow[t]{2}{*}{ Year } & \multicolumn{5}{|c|}{ Wind Operating Profit for Class 5 ( $\$ 2006 / \mathrm{kW}-\mathrm{yr}$ ) } & \multicolumn{5}{|c|}{ Wind Operating Profit for Class 4 (\$2006 / kW-yr) } \\
\hline & Florida & Entergy & Southern & TVA & VACAR & Florida & Entergy & Southern & TVA & VACAR \\
\hline 2010 & 285 & 262 & 214 & 268 & 251 & 257 & 237 & 193 & 242 & 227 \\
\hline 2015 & 270 & 269 & 258 & 255 & 236 & 244 & 243 & 233 & 231 & 213 \\
\hline 2020 & 256 & 260 & 262 & 247 & 231 & 231 & 235 & 237 & 223 & 209 \\
\hline 2025 & 249 & 241 & 260 & 250 & 243 & 225 & 217 & 235 & 225 & 219 \\
\hline 2030 & 277 & 257 & 276 & 276 & 267 & 250 & 232 & 249 & 249 & 241 \\
\hline 2035 & 307 & 288 & 300 & 305 & 300 & 277 & 260 & 271 & 276 & 271 \\
\hline 2040 & 342 & 320 & 328 & 347 & 343 & 309 & 289 & 297 & 314 & 310 \\
\hline 2045 & 378 & 363 & 372 & 400 & 396 & 341 & 328 & 336 & 362 & 358 \\
\hline 2050 & 412 & 396 & 432 & 469 & 465 & 372 & 358 & 391 & 424 & 420 \\
\hline
\end{tabular}

$\begin{array}{lcccccccccc}\text { NPV for } 2015 \text { Installation }(\$ 2006 / \mathrm{kW}) & & & & & & & & \\ \text { Operating Profit } & 3,663 & 3,571 & 3,662 & 3,630 & 3,476 & 3,308 & 3,225 & 3,308 & 3,278 & 3,138 \\ \text { Less: Incremental } & \mathbf{1 , 3 5 4} & \mathbf{1 , 2 6 2} & \mathbf{1 , 3 5 4} & \mathbf{1 , 3 2 1} & \mathbf{1 , 1 6 7} & \mathbf{9 9 9} & \mathbf{9 1 6} & \mathbf{9 9 9} & \mathbf{9 6 9} & \mathbf{8 3 0} \\ \text { Capital Cost } & & & & & & & & & & \end{array}$

Because of the large distances involved in moving wind generation from SPP to the Southeast, estimates of the cost of inter-regional transmission are critical in estimating the benefits of wind transfers. We apply the transmission capital cost estimates shown in Table 5 to the net generation values shown in Table 6 to compute the net present value (in dollars per kilowatt) of each wind transfer scenario, after the costs of transmission between SPP and SERC are considered. Figure 11 displays these results for each of the three transmission cost scenarios defined in Table 5. 
As the figure shows, a transfer of wind energy at Power Class 5 from SPP results in benefits to all of the Southeastern sub-regions for the lowest cost transmission case ( $\$ 800$ / megawatt-mile). Higher transmission costs erode the wind marginal value in all regions. The marginal wind value to the more distant sub-regions - Florida and VACAR - becomes negative at the medium cost level (\$1,200 / megawatt-mile). Due to the lower capacity factors of wind production for Class 4 wind resource, transfers of Class 4 wind are less economic than transfers of Class 5 for all subregions. Resulting net benefits of Class 4 wind are still positive for sub-regions with relatively low transmission costs - Entergy and TVA - while the benefits disappear completely for the regions with the longest transmission distance from SPP - Florida and VACAR. For Southern, Class 4 wind energy transfers result in positive benefits under low cost transmission assumptions, but become negative as transmission costs increase.

For SPP Class 5 Resource

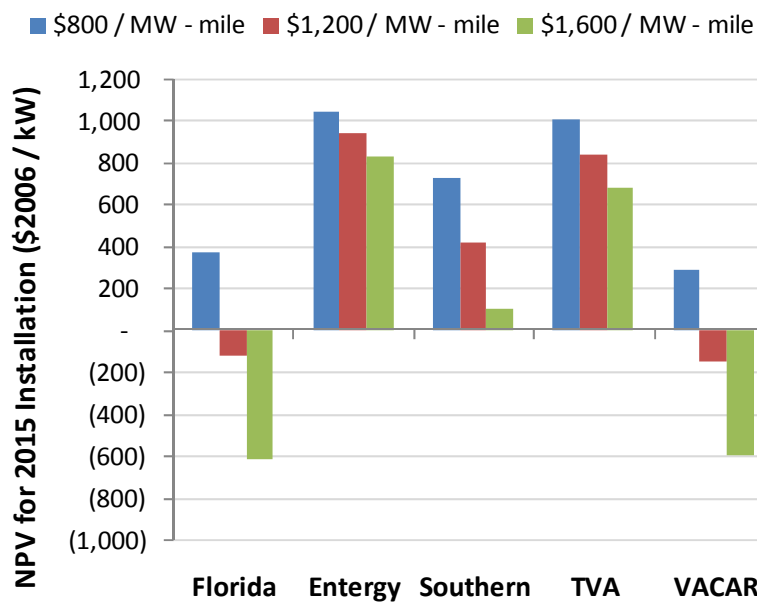

For SPP Class 4 Resource

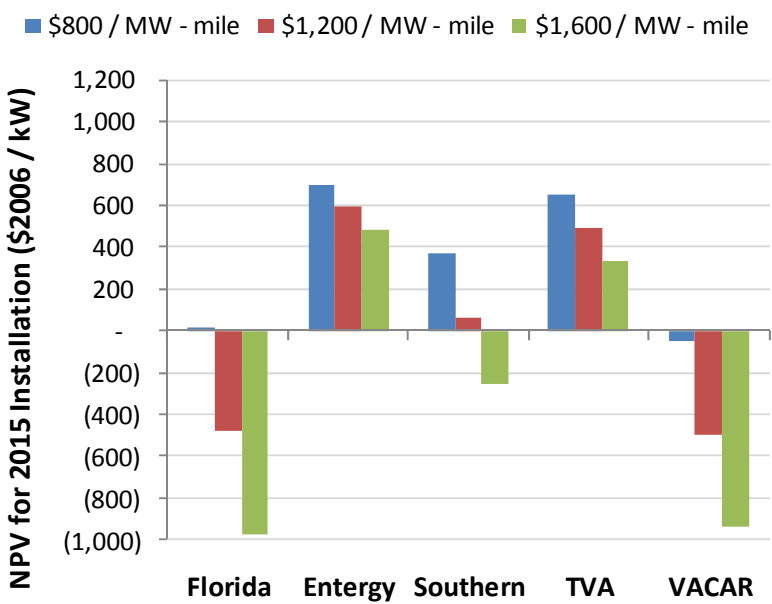

Figure 11. Marginal Value of Wind Energy Transfers, Net of Transmission Costs

Figure 12 shows the sensitivity of the net value of wind transfers to the assumptions for the transmission line losses. As the figure shows, the higher line losses (6 percent versus 3.5 percent) assumed for the regions with the longest transmission distances - Florida, Southern, and VACAR - result in reduced net value for the respective wind transfers. However, the impact of higher losses is relatively small, particularly when compared to the impact of transmission costs. 
For SPP Class 5 Resource

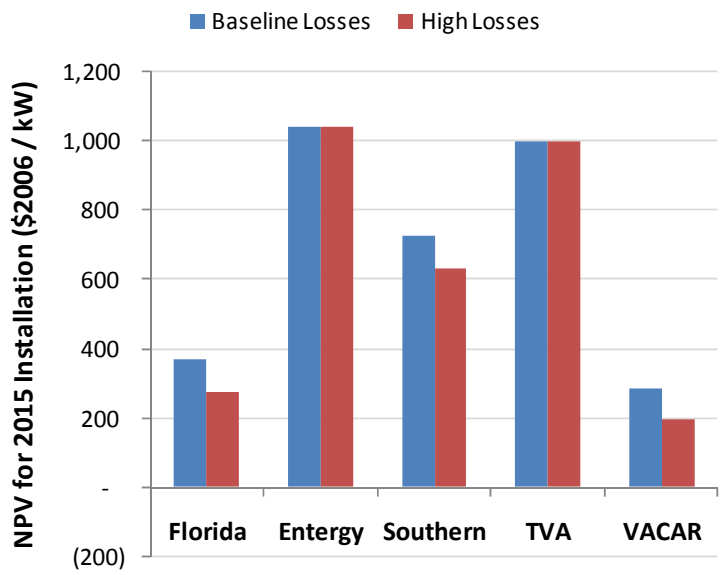

For SPP Class 4 Resource

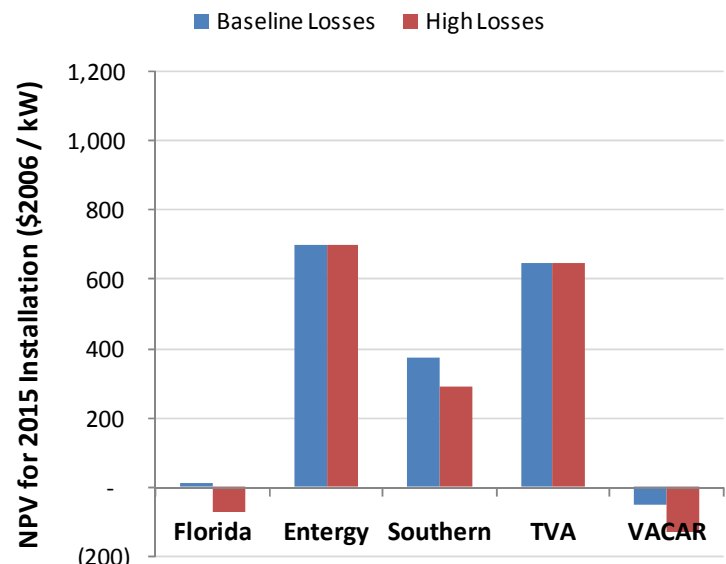

Figure 12. Marginal Value of Wind Energy Transfers: Sensitivity to Transmission Losses.

Figure 13 demonstrates the sensitivity of the net value of wind energy transfers to the assumptions of wind turbine overnight capital cost. The net value of each wind transfer scenario is computed for a wide range of wind overnight capital cost assumptions - from a low value of about $\$ 1,200$ per kilowatt to a high value of about $\$ 2,100$ per kilowatt. The sub-regions indicated by top two lines on each graph - Entergy and TVA - show significant positive benefits for wind transfers across the full range of wind turbine capital costs, and for both Power Class 4 and 5. However, these results also show that the marginal economic benefits are more tenuous for both power classes in the sub-regions with longer transmission paths, particularly Florida and VACAR.

At transmission capital cost of $\$ 800$ / MW - mile:

For SPP Class 5 Resource

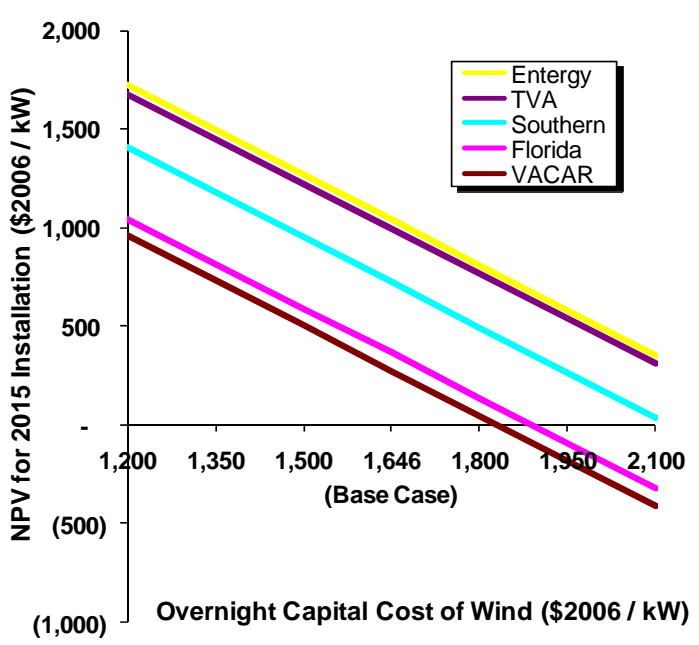

For SPP Class 4 Resource

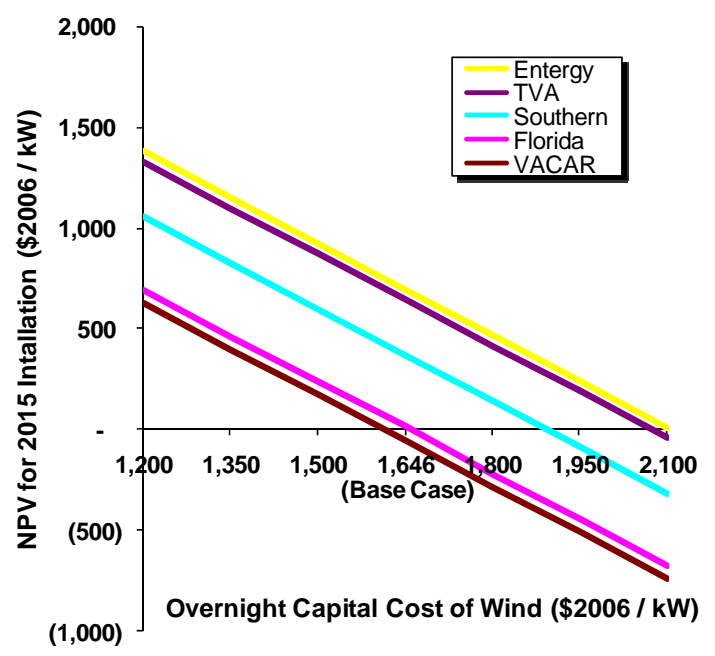

Figure 13. Marginal Value of Wind Energy Transfers: Sensitivity to Wind Capital Cost. 


\subsubsection{Discussion of Transmission Assumptions}

The work described in this section demonstrates the critical importance of the transmission system for determining the economic value of wind imports. Given uncertainty about the way the US transmission is likely to be developed in the future, and the resulting uncertainty in the cost of its development, this finding was not surprising. For this study, we have adopted a simple model of transmission costs as a function of transmission distance, and used the results of other studies to provide a range of reasonable future scenarios.

There are numerous sources for potential error in our approach. The transmission system does not allow for the physical point-to-point transmission service assumed in the cost estimates. Much more detailed analysis of the transmission system is required. These studies would include load flow modeling over large regions, possibly including the entire Eastern Interconnect. More importantly, these studies must be conducted in the context of the likely future development of the US electric system. The Eastern transmission system has been constructed for a very different world than the one many expect when the wind imports are likely to occur.

One important difference is the likely adoption of a national policy to reduce CO2 emissions to mitigate the risks of global climate change. Such a policy would change the value of different generation sources. In fact, the motivation for importing wind to the Southeast is often based on the need to reduce $\mathrm{CO} 2$ emissions from the electric sector. Most CO2 policies result in a price for the right to emit $\mathrm{CO} 2$, which changes the relative economics of electricity generation depending on the $\mathrm{CO} 2$ intensity of different generators. Coal plants today often dispatch at a significant discount to gas-fired electricity. This disparity has motivated long-standing interregional transfers from coal-rich regions to regions that rely on gas for bulk power. The price of CO2 will reduce and ultimately eliminate the cost advantage of coal plants today, eliminating the use of the transmission system for economic transfers of coal power. This change may open up transfer capacity to move wind to load centers that have less plentiful or uneconomic wind resources. Analysis of transmission investments needed to transfer the wind power must be made in light of these changes in generation economics.

Three decades ago transmission lines were constructed in the Southeast to move coal power from the Southern sub-region to the Florida peninsula, where oil- and gas-fueled generation has been used for electric production. NESSIE calculates a wholesale price of bulk power across the year. In 2010, when NESSIE assumes that there is a zero price on CO2 emission allowances, the estimated bulk power prices average $\$ 73$ per megawatt-hour for Florida and \$58 per megawatthour for SERC/STV, a price gap of \$15 per megawatt-hour. By 2015, when the price of CO2 emission allowances is $\$ 27$ per metric ton of $\mathrm{CO} 2$, the price gap will decrease to $\$ 4$ per megawatt-hour. From 2020 to 2050 the average electricity prices between the two regions never exceeds $\$ 2$ per megawatt-hour. While the amount of economic energy sales between the regions depends on the hourly rather than the average electricity price differences, these results indicate the potential to free up some of the existing transmission capacity for importing wind energy from SPP, without additional transmission investment. If this potential can be realized, electricity transmission from SPP to Florida would cost roughly the same as transmission to the Southern sub-region. 


\subsubsection{Conclusions from the Marginal Analysis.}

This subsection described a simplified analysis of the wind transfer problem by calculating the value of a small (one kilowatt) transfer of wind from SPP to the Southeast. This analysis shows that there may be significant economic benefits for wind transfers, but that the benefits may vary widely depending on regional economics, the quality of wind resource, the cost of new wind plants, and the cost of inter-regional transmission. Transfers of Power Class 5 wind provide value across a wide range of scenarios, while the value of Power Class 4 wind transfers is more uncertain, especially in the sub-regions with longer transmission distances. Finally, better understanding the future development of the US transmission system, and the resulting costs of new inter-regional transmission lines, is critical for determining the value of wind energy transfers.

As we said at the beginning of this section, these results of the marginal analysis guide the design of the integrated analysis described in Section 2.4. In particular, these results enabled the project team to focus the integrated analysis on transfer scenarios that show economic potential in the marginal analysis. These include transfers of Power Class 5 wind resource to all SERC subregions and Florida under low to medium transmission cost assumptions, but limit the scope of Power Class 4 transfers to regions with relatively short transmission distances - Entergy, TVA and, if transmission costs are low, Southern.

\subsection{Integrated Evaluation of Wind Transfer Scenarios}

NESSIE was used to perform an integrated evaluation of set of potential wind transfer scenarios between SPP and the Southeastern US. In this analysis, wind transfer scenarios are specified as the total amount of generation capacity that can be potentially transferred from SPP to each respective sub-region. NESSIE explicitly represents the sub-regional decisions about how much of this potential wind generation to transfer, as well as how much of all types of new generating capacity to build, and models the sub-regional system dispatch to determine electric generation costs in each year of the model horizon. The value of the transfers is then evaluated by comparing NESSIE electricity cost results with and without the transfers.

The model was run multiple times to understand what amount of energy transferred to each of the Southeastern sub-regions results in the highest economic benefits for that sub-region. This section presents the model results for the transfer scenarios that yield close to the maximum economic benefit to the region under selected assumptions. The project team evaluated wind transfers under both a "Favorable" and an "Unfavorable" set of transmission assumptions. The assumptions for these two cases are

1) Favorable transmission case: low transmission capital cost ( $\$ 800$ per megawatt-mile) and the base case transmission line losses (3.5\% in all regions).

2) Unfavorable transmission case: high transmission capital cost $(\$ 1,600$ per megawattmile) and higher transmission line losses (3.5\% in Entergy and TVA, and 6\% in Florida, Southern, and VACAR).

Table 7 shows the results, with the two transmission cases shown in the top and bottom sections of the table. For the favorable transmission scenario, there are significant economic transfers from SPP to each of the five Southeastern sub-regions. SPP generation totaling 27,000

megawatts is imported into the Southeast, including 16,000 megawatts of Power Class 5 and 11,000 megawatts of Power Class 4. Consistent with the results of the marginal analysis 
described in the previous section, the Class 4 transfers under favorable transmission assumptions are limited to Entergy, TVA and Southern while the Class 5 transfers are distributed across all five sub-regions.

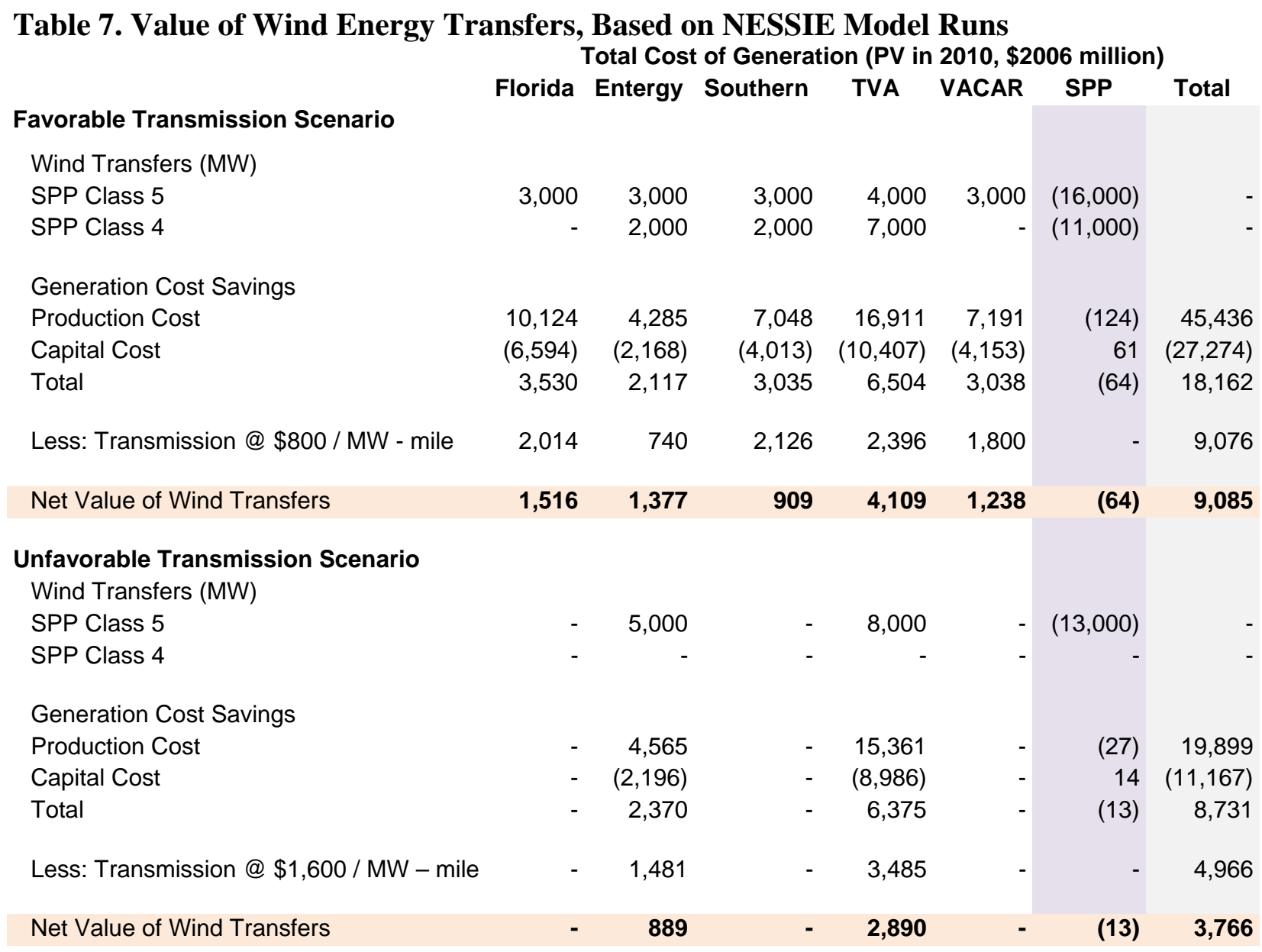

The table also presents the measures of economic attractiveness of the wind transfers. The results show the regional generation savings from the transfer, the change in the capital cost of the generation and the cost of the required transmission investment. The generation capital cost impact includes the additional cost of building new wind farms in SPP and the net cost (or benefit) of any changes to the importing regions' capacity plans. Each of the importing subregions benefits from the wind transfers, while the SPP incurs a very small net cost due to small changes in its capacity plan resulting from the transfers. As is shown in the right hand column, the combined economic benefit to the Southeastern US and SPP is over $\$ 9$ billion in present value.

In the unfavorable transmission scenario, the higher transmission costs cause the level of economic transfers from SPP to decline to 13,000 megawatts, with only Class 5 wind energy transfers to Entergy and TVA producing economic value. The net benefit of the transfers across the Southeastern US and SPP declines to about \$3.8 billion. 
Figure 14 shows the generation in 2030 with and without the favorable transmission transfers for the five sub-regions. The contribution of wind energy to meeting Southeastern generation requirements increases, replacing some generation by gas- and coal-fueled units. The additional wind generation also increases the renewable energy fraction for the Southeastern sub-regions, as shown in Figure 15. Assuming favorable transmission costs, renewable generation as percent of total generation increases in all Southeastern sub-regions. In Entergy and TVA the renewable generation reaches the targets in the proposed climate legislation sponsored by Waxman and Markey (2009). When transmission costs are high, the wind transfers are only economic to Entergy and TVA (the regions with the shortest transmission path from SPP), so the renewable generation in the other regions remains unchanged.

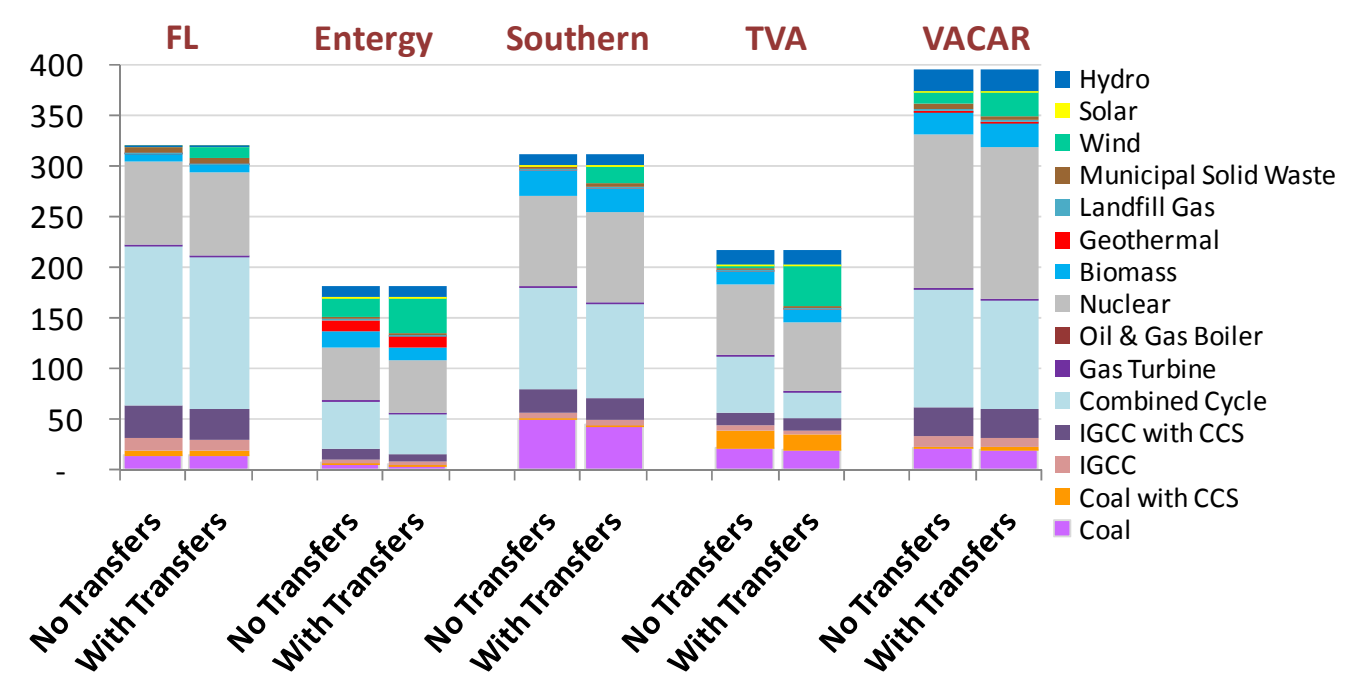

Figure 14. Regional Annual Generation in 2030 with and without the Favorable Transmission Transfers

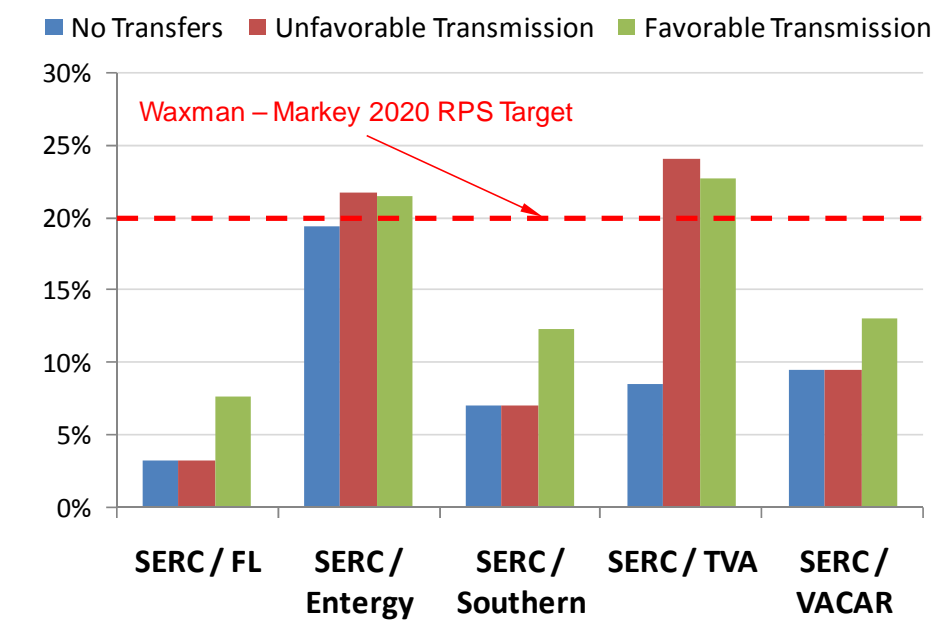

Figure 15. 2020 Renewable Generation as Percent of Total Generation in the Southeast and SPP before and after Wind Energy Transfers. 


\subsection{Sensitivity to Other Power Sector Variables}

The project team ran additional sensitivity cases to better understand the key uncertainties in assign the value of wind energy transfers from SPP to the Southeastern US. The first sensitivity such case assumed lower values for the cost of natural gas and $\mathrm{CO} 2$ emission allowances. Figure 16 shows the changes from the base case estimates for these two commodity prices. The assumptions for the low prices for natural gas and $\mathrm{CO} 2$ emission allowances are based on the "Low Gas / Low Carbon" NEMS model run that is described in the 2009 EPRI technical update (EPRI, 2009). The results are shown in Table 8. Low prices for CO2 emission allowances reduce the economic advantage of wind generation from having zero $\mathrm{CO} 2$ emissions. As a consequence, economic wind energy transfers from SPP decrease to 6,000 megawatts from the 27,000 megawatts under the Base Case under favorable transmission assumptions. Under these low CO2 and natural gas prices, wind energy transfers are only economic into the Entergy and TVA subregions. In addition, the lower cost of gas means that the power displaced by imported wind is lower in cost. These factors lead to a reduction in the economic benefits of wind energy transfers to the Southeastern US and SPP to under $\$ 700$ million in present value. All of these findings are for the favorable transmission cost case; no transfers are economic under the unfavorable transmission case assumptions under this scenario with low natural gas and $\mathrm{CO} 2$ emission allowance prices. Figure 17 shows that in this sensitivity case the wind energy transfers are not sufficient to allow the Southeast US to comply with the Waxman-Markey targets for renewable generation in 2020.

Price of Natural Gas

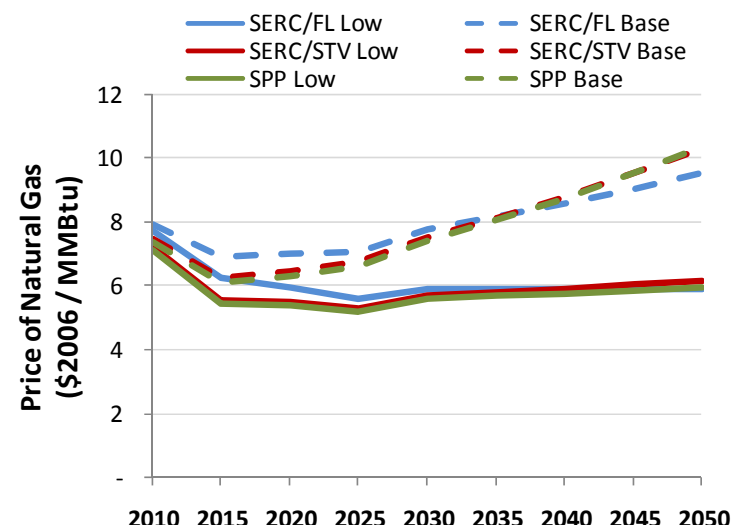

Price of $\mathrm{CO}_{2}$ Emission Allowances

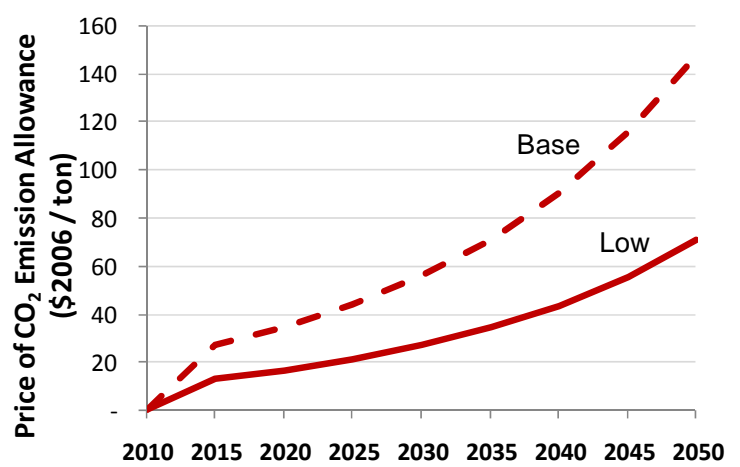

Figure 16. Sensitivity Analysis: Price of Natural Gas and CO2 Emission Allowances. 
Table 8. Value of Wind Energy Transfers under the Assumptions of Low Prices of Natural Gas and $\mathrm{CO} 2$ Emission Allowances

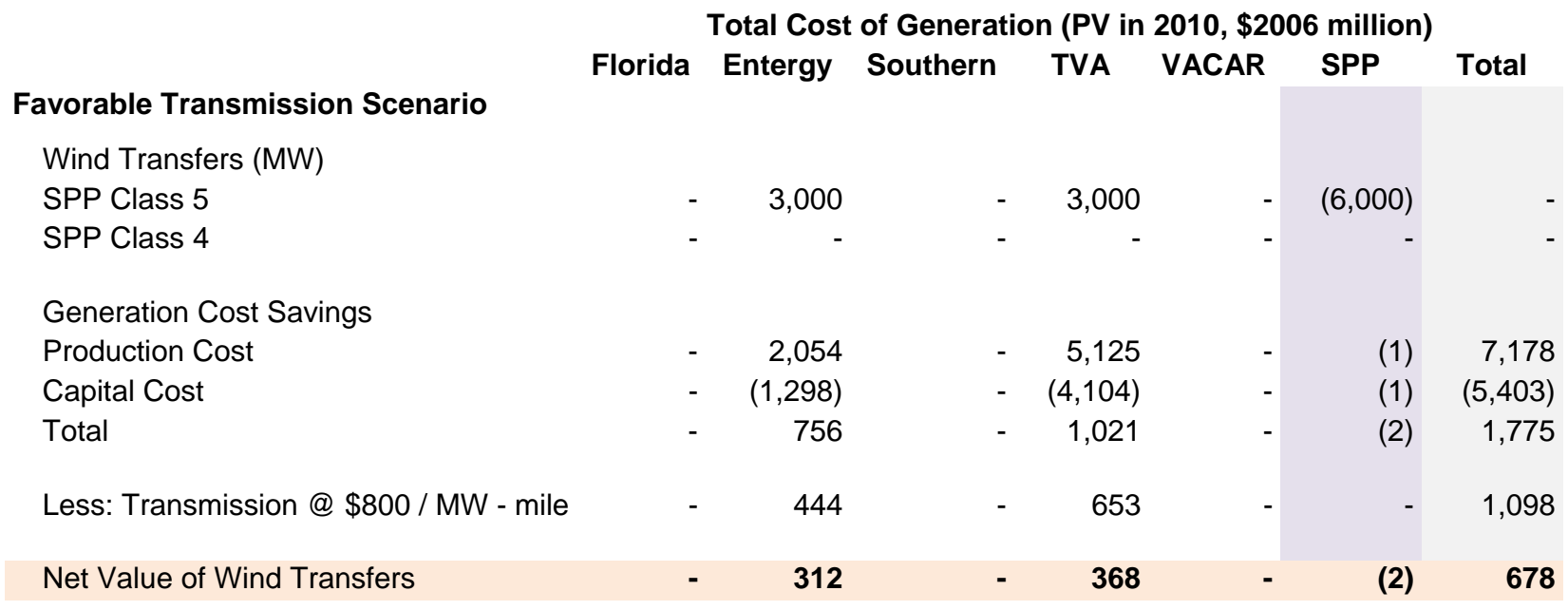

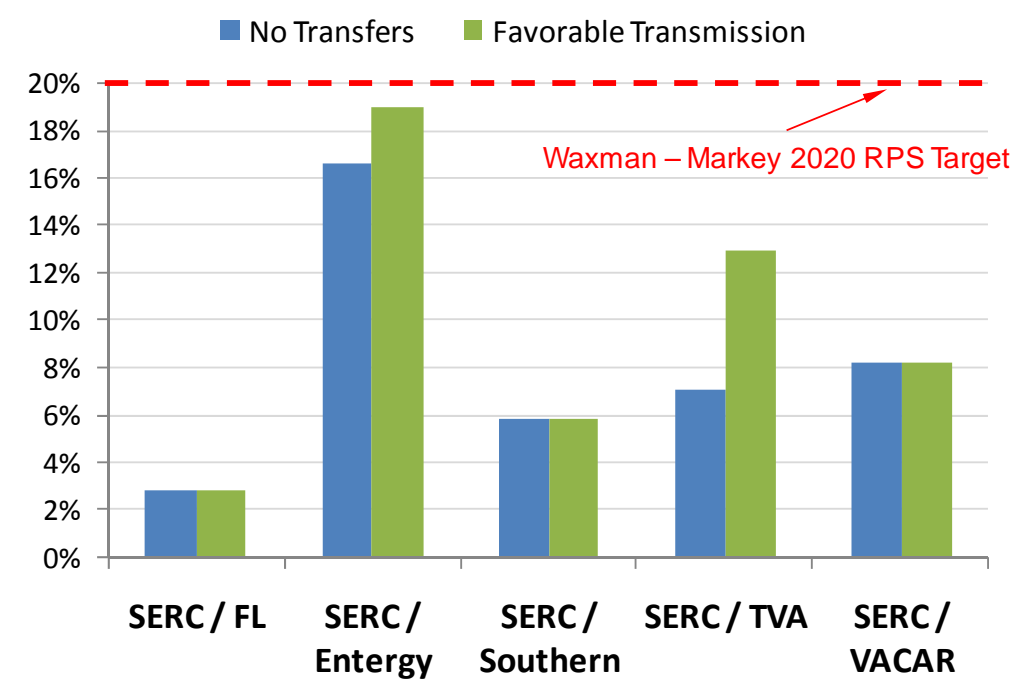

Figure 17. 2020 Renewable Generation as Percent of Total Generation in the Southeast before and after Wind Energy Transfers, under the Assumptions of Low Prices of Natural Gas and $\mathrm{CO} 2$ Emission Allowances.

The second sensitivity case investigated the economic value of wind energy transfers to the Southeastern US when the new installations of nuclear capacity are delayed. Figure 18 illustrates the input assumptions for nuclear capacity deployment. The figure shows the limit on the cumulative installation of new nuclear plants over time. This sensitivity case assumes a ten-year delay for construction of new nuclear plants from 2015 to 2025. Table 9 shows the economic impacts of this delay on the economic value of the wind energy transfers from SPP to the Southeastern sub-regions. The economic transfers from SPP increase to 34,000 megawatts. However, the net benefit of these transfers increases only marginally to $\$ 10.1$ billion in the favorable transmission case and to $\$ 4.4$ billion in the unfavorable transmission case, 
respectively. These net benefit gains relatively small because, while the nuclear technology is an attractive option in the NESSIE simulations, installations of other low- and non-emitting capacity increase when nuclear capacity cannot be added. The impact of the nuclear delay on achieved renewable generation percentage is positive but not significant when compared to the base case results, as shown in Figure 19. In summary, this sensitivity case produces a significant increase in the physical quantity of wind imported to the Southeast US as measured in megawatthours. However, the economic value of the wind transfers increases only marginally.

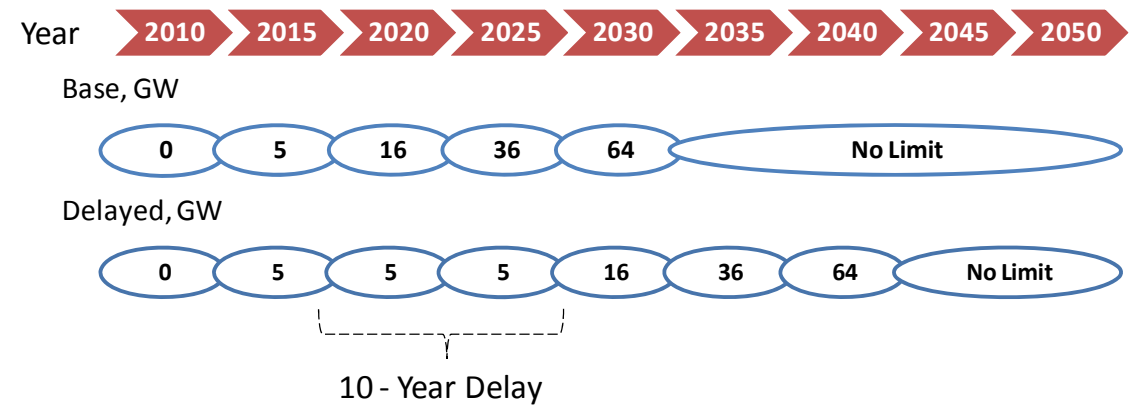

Figure 18. Cumulative Nuclear Capacity Limit on New Capacity Additions over Time 
Table 9. Value of Wind Energy Transfers under the Assumptions of Delayed Nuclear Technology

Total Cost of Generation (PV in 2010, \$2006 million)

Favorable Transmission Scenario

Florida Entergy Southern TVA VACAR SPP Total

Wind Transfers (MW)

SPP Class 5

SPP Class 4

$\begin{array}{rrrrrr}5,000 & 1,000 & 1,000 & 3,000 & 3,000 & (13,000) \\ - & 6,000 & 5,000 & 10,000 & - & (21,000)\end{array}$

Generation Cost Savings

Production Cost

$17,515 \quad 6,467$

Capital Cost

$(11,387) \quad(3,662)$

8,100

$(4,853)$

18,912

6,529

$6,128 \quad 2,805$

3,247

$(11,785) \quad(3,989)$

(126) 57,397

Total

$3,357 \quad 1,037$

2,551

$7,127 \quad 2,540$

$25(35,650)$

Less: Transmission @ \$800 / MW - mile

\section{2,772}

1,769

696

2,83

1,800

(102)

21,747

Net Value of Wind Transfers

Unfavorable Transmission Scenario

Wind Transfers (MW)

SPP Class 5

SPP Class 4

- $\quad 5,000$

$-\quad 8,000$

- $(13,000)$

Generation Cost Savings

Production Cost

Capital Cost

Total

- $\quad 5,994$

- $\quad(2,989)$

- 16,571

- $\quad(9,672)$

- $\quad 6,899$

127) 22,438

- $\quad 3,005$

Less: Transmission @ \$1,600 / MW - mile

- $\quad 1,481$

- $\quad 3,920$

105)

$(12,639)$

Net Value of Wind Transfers

- $\quad 1,524$

2,979

(105)

9,799

5,401

4,397 


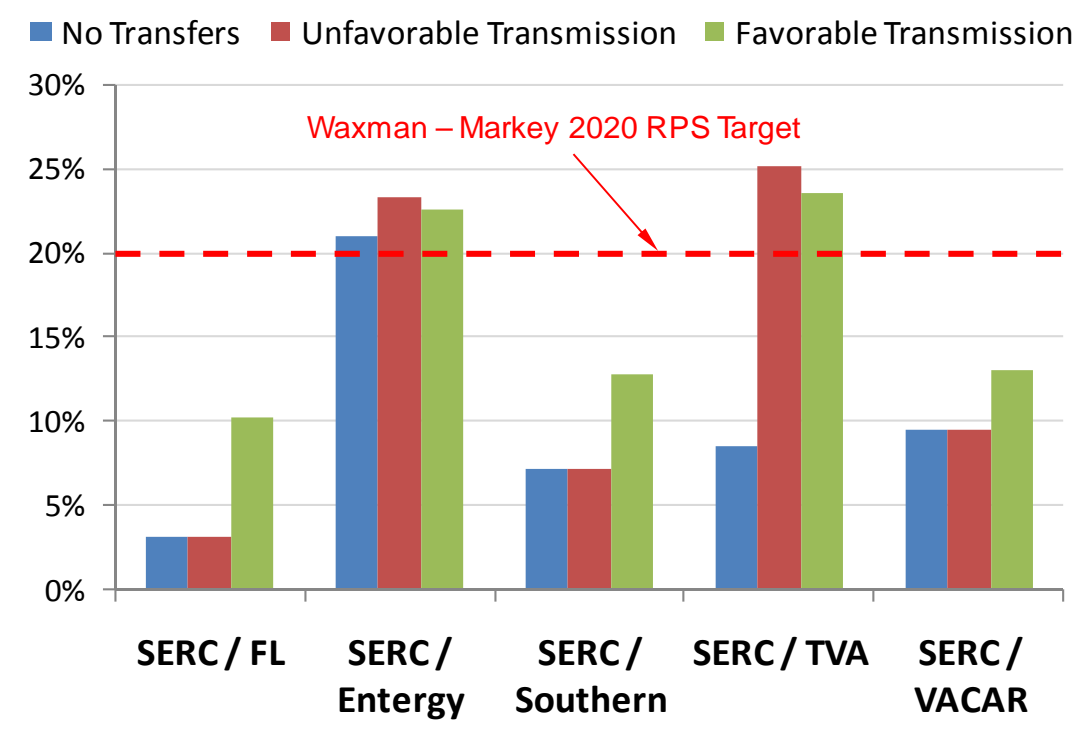

Figure 19. 2020 Renewable Generation as Percent of Total Generation in the Southeast US and SPP before and after Wind Energy Transfers, under the Assumptions of Delayed Nuclear Technology.

\subsection{Conclusions from Wind Transfer Analysis}

Several important conclusions emerge from this evaluation of wind transfers from SPP to the Southeastern US described in the section. These conclusions pertain to both the overall economics of wind energy transfers and the specific impact that environmental policy may play on the value of the transfers.

The important conclusions regarding the economics of wind energy transfers from SPP to the Southeastern US are:

- Wind energy transfers are economical under a variety of scenarios. The availability of surplus economic wind resource in SPP, and the relative scarcity of wind and other renewable technologies in the Southeast, creates a significant opportunity for economic transfers under a wide range of assumptions about generation technology cost and performance, regional electric market conditions, and future environmental policies.

- $\quad$ Economic wind transfers from SPP to the Southeastern US range from 6 gigawatts to 34 gigawatts. The potential for economic transfers varies considerably based on assumptions about the cost of transmission, the price of $\mathrm{CO} 2$ and natural gas, and the availability of new nuclear generating capacity.

- The value of transfers is highly sensitive to transmission capital cost. Understanding the required investment in new transmission capacity is critical to understanding the value of wind transfers, particularly to sub-regions with longer distances from surplus wind resources.

- Most of the economic benefits flow to the regions with a relatively short transmission distance (TVA and Entergy). Due to the higher cost of transmission to Southern, VACAR, and Florida, the regions closer to SPP receive most of the economic benefit of the wind transfers, particularly if transmission costs are high. 
- Wind deployment in windy areas depends on new transmission. Because the available wind resource in windy regions such as SPP is much greater than can be deployed in the Southeastern US to meet its own generation requirements, transmission capacity to support inter-regional transfers is needed before many of these wind sites can be developed.

The key conclusions pertaining to the potential impact of environmental policy on the value of wind transfers are:

- Moderate CO2 policy will change electricity generation and transmission. High CO2 prices will result in coal-fired generation being much less attractive, and will significantly reduce the value of inter-regional transfers of coal-fired generation to displace oil- and gas-fired generation. This could open up existing transmission capacity for inter-regional transfers of wind generation.

- $\quad \mathrm{CO} 2$ policy will significantly impact the value of wind transfers. Monetizing the cost of emitting a metric ton of CO2 significantly increases the operating costs of technologies that emit CO2, such as coal- and gas-fired power plants. These higher costs translate into higher marginal prices in regions with significant emitting generation, which greatly enhances the value of importing non-emitting technologies such as wind.

- $\mathrm{CO} 2$ policy causes the Waxman - Markey RPS targets to be met nationally, therefore, the price of renewable energy credits (RECs) is expected to be zero. Although shortfalls from the federal RPS targets will continue to exist in most Southeastern regions even with wind transfers, sufficient surplus of renewable generation is produced in other regions to ensure that the targets are met nationally. 


\section{Stakeholder Workshop and Feedback}

\subsection{Plan, Participation and Agenda (see appendix B)}

The project team conducted a workshop to obtain input from electric utilities in the Southeast. The issues considered were around meeting a possible future RPS requirement and considering the important energy market provided by the southern areas of SERC for the windy areas in SPP and MISO. A key concern of many utilities in SERC has been that the region is not blessed with as many cost-effective renewable resources as other regions. Therefore the region may need to import significant quantities of power from elsewhere, such as wind energy. Other options may be available but at potentially higher-costs. For example local generation of renewable resources, purchase of renewable energy credits without actually transmitting the energy, or payment of an alternative compliance payment to the U.S. Treasury.

The workshop was held August 18, 2009 at ORNL. The specified purpose was to review the study results and allow the participants to discuss the operational opportunities and challenges trying to meet a possible RPS. Time was allotted for participants to present there viewpoints as well as to evaluate what work has been done, hear feedback from others and participate in discussion on what further work needs to be done. Key issues that came up were related to fulfilling an RPS mandate and to transmission requirements.

Invites were limited to those with regional interests and the project team. We exceeded our expectation of participants, with 28 attending. Nine utilities and the Southwest Power Pool were represented. See appendix B of this document for a list of attendees and an agenda.

\subsection{Key Results}

The workshop confirmed that moving wind into the SE is a topic garnering significant interest for affect utilities. Future economics and the best methods for transporting wind energy are critical unanswered questions. Participants expressed their on going interest in this topic and committed to continue their engagement in follow on activities.

At the end of the meeting we discussed the follow on study (with future DOE funding in 2010) to model specific transmission flows and to revisit questions on cost and integration of significant wind imports. We will also look at the issues of balancing for regions exporting and for regions importing wind energy. The following specific presentations were made at the workshop:

Tom Key, EPRI, presented the workshop background and objectives. Main points were to describe the motivation for moving wind energy to markets in the SE. Also data were presented that show significant wind resource, beyond practical electrical needs in SPP, must be considered along with the challenge of balancing variability and delivering wind to market once large deployment occur. In the background there is anticipation that $\mathrm{CO} 2$ policy will change the opportunities and economics of moving wind energy.

Stan Hadley, ORNL, provided an overview of the previous work on moving wind to the southeast supported by DOE. He covered the relationship of this work with other studies as shown in figure XX. Also cover was the long list of references of related work that have been considered in this project. 


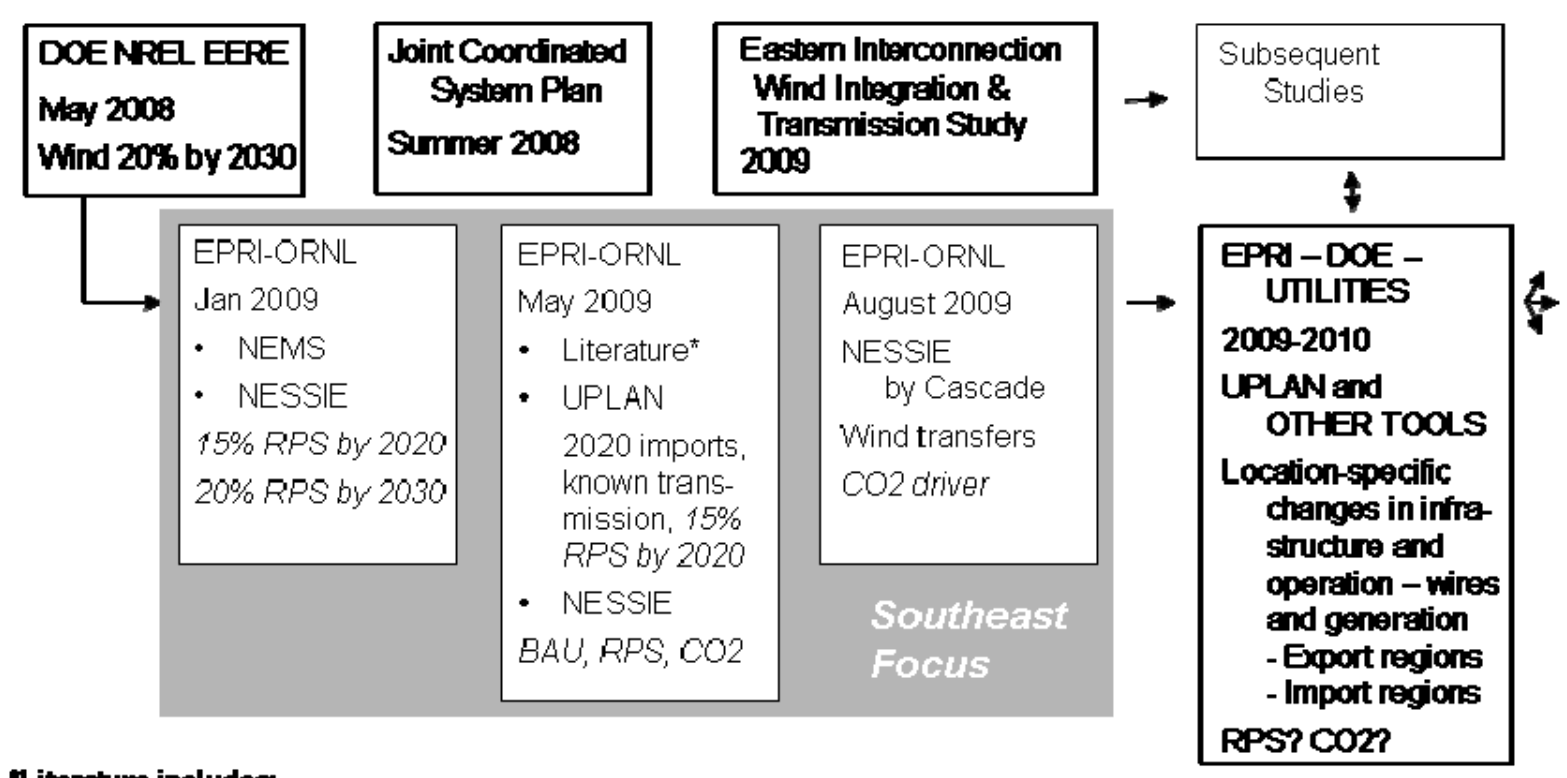

\section{'Uterature includes:}

1. AEO 08009 March 2000

2. EIA Lieberman-Wamer Bill Analysis March 2008

3. Southem Aliance for Clean Energy February 2009
4. NRE biomass Dec 2005

5. NREL PV Feb 2008

6. Nevigant FL Dec 2008

7. Energy Foundation HORL SEReneweables 2009
8. ElA Waoman-Markey RPS Analysis April 2009

9. NREL RPS Proposal Analysis May 2009

10. EPRI Gen Options Role March 2009

Key points were that AEO 2008 estimates show that none of the 13 reliability regions of the US will produce $15 \%$ energy from renewable resources and the Southeast regions was the furthest from achieving a $15 \%$ level. The only way to achieve $15 \%$ for SE is significant development of biomass and solar resources. Otherwise import would be required to achieve these levels.

Lynn Coles of NREL provided an update on the Eastern Wind Integration and Transmission Study (EWITS). This study is an important reference for moving wind to southeast. Results of the EWITS are well documented in several reports and at http://wind.nrel.gov/public/EWITS/ The key issues addressed in the study were:

- System operational impacts and costs imposed by wind generation variability and uncertainty

- Benefits from long distance transmission that accesses multiple wind resources that are geographically diverse

- Benefits from long distance transmission that move large quantities of remote wind energy to urban markets

- Remote wind resources versus local wind resources

Jay Caspary of Southwest Power Pool provided a detailed overview of plans for gathering and moving wind within the SPP. With excellent wind resources that are well beyond the local energy needs SPP is looking closely at export opportunities. Key points made in this presentation were the importance of coordinated planning and the serious and unresolved question of cost allocation. Jay pointed out that cost allocations can be a barrier to effective transmission expansion planning, but need not be. Witness EHV expansion by South Central Electric Companies in the 1960s and FERC Order 890 is forcing industry to address this topic. His final 
point was that the power industry can not afford to undervalue transmission anymore. The entire SPP presentation is provided in appendix B.

Perspectives on transferring wind to the SE were also provided by several utilities including TVA, Entergy, Southern and Duke Energy.

Gary Bullock of TVA gave an overview of TVA decisions relative to adding renewables. The main point of interest was a recent RFP for Renewable Energy that TVA issued in December, 2008. It is progressive targeted levels up to $2000 \mathrm{MW}$ by June, 2011. The solicitation had more than 7000 MW of nameplate capacity submitted. In April, 2009, the TVA Board gave advance approval to enter into long term contracts for up to $2000 \mathrm{MW}$ and prior to the time that Renewable Energy Credits are required all contracts must be competitive with forecasted market power. Of the several deals in active negotiation all the offered wind resources were outside of the Valley and to be imported by existing transmission.

TVA has a transmission plan called Pole Star 70GW, 500kV. The new 500kV transmission interconnects with existing transmission and encompasses 750 new miles of line, 10 new substations and 10 new transformer banks in existing substations. Gary also covered current TVA environmental policy, integrated resource planning and distributor/customer programs. This presentation is included in Appendix B.

Tony Waltz presented Entergy's view point on importing renewables. Compared to other large utilities in the SE region Entergy has the most inherent wind resources, primarily in NW Arkansas. On the other hand Entergy anticipates need an additional 6GW of capacity by 2018 and would be challenged to meet a significant RPS in the same time frame. Exiting qualifying facilities in the Energy service territory show a relatively high swing in output generation. These are fossil or biomass fueled, rather than variable wind or solar, generators. Given the combined variations from load swings and qualifying facilities Entergy is concerned about imbalances and flexibility requirements in the future. This presentation is provided in Appendix B.

Jeremy Bennett of Southern Company provided a summary of their planning perspectives (energy, capacity and reactive power) for importing wind energy. He also described some ramping issues and Southern Co's interest in looking at ways to accomplish dynamic scheduling and balancing. Remaining questions how wind will integrate with Nuclear, issues of over generation, forecasting, and utilization of transmission assets over short- and long-term. Jeremy also pointed out that the South has significant existing transmission assets and would like to see the option of using these assets looked as one of the options for move large amount of wind energy. Talking points are included in Appendix B.

Ed Ernst of Duke gave a Carolinas perspective on wind imports. Duke Energy Carolinas serves 2.4 million retail customers in NC and SC. Duke expects Federal Legislation/Policy to be a major driver but they are already dealing with an RPS in NC. The amount and timing of wind needs to integrate with availability of other renewable resources such as waste-wood burning facilities. Local wind resources are limited to NC mountain tops and coastline. But these resources are not large and Duke is considering imports from Midwest, etc. There have been several recent transmission studies including the NC Transmission Planning Collaborative -2008 and the SIRPP- 2008/2009. Talking points are included in Appendix B. 
Other questions that came up during the workshop were related to granularity of analysis and commercial feasibility. These included:

- Generation and transmission asset (and markets) performance - UPLAN, ISO and UTILITY studies

- What is required (wires and regional gen.) to actually meet RPS requirements - to transfer the missing $~ 9 \%$ ?

- More generally, how is balancing achieved in both exporting and importing regions?

- How is generation (including wind) affected by new wind, in both exporting and importing regions?

- How will existing and new lines of various configurations perform?

- How does fuel price (e.g., a surge in gas capacity is already projected) affect asset operations? Revenues across stakeholders? Capital cost recovery? Project financing?

- How does nuclear development affect asset performance?

- How does timing of different major steps affect impacts (wires, retirements, new capacity, etc.) 


\section{Study Conclusions and Follow on Activities}

\subsection{Broad Conclusions}

Policies will have a big effect on the generation mix and the cost of electricity across the country. Some regions would build additional renewable capacity to meet their RPS, even though it may be higher cost than that generated elsewhere. However, with transmission constrained, regions with higher potential low-cost renewable capacity may not fully exploit that capacity and build for export. Similarly regions that do not have renewable resources are not likely to plan for imports.

Deployment of renewable generation is expected to increase significantly because of favorable policies and improvements in technology. This is true in all regions of the US. However, alternatives are limited for the Southeast to generate more than $10 \%$ of electricity consumption from renewable resources. The two main reasons are lack of renewable energy resources and relatively high consumption of electricity. Florida has the biggest challenge in this regard.

A policy for tradable renewable energy credits would provide one alternative for SERC and Florida to make up a shortfall in renewable energy. However this will be limited by the ability of other regions to produce and balance the higher percentage of variable renewable resources. It also represents a fairly large transfer of wealth in the case of the Southeast.

Several studies using different modeling tools point to the need to import significant quantities of renewable power into the Southeast. Because of the magnitude involved, this would likely include both the energy and the balancing responsibility. This creates a rather substantial paradigm change in the way different regions plan to meet future demand. These massive imports and exports will also require new transmission infrastructure to enable the transfers. Such a paradigm shift will depend on related regulatory changes and expansions of energy markets.

\subsection{Follow-on Research Plan}

A related follow-on scope of work project was proposed in response to DOE FOA DE-PS3609G099009, Topic 4: Transmission Analysis, Planning and Analysis. The primary objective of this project is to determine the benefits and costs of balancing area collaboration between the SPP region with very large and undeveloped wind resources and southern SERC with a very large electricity market and few wind resources.

This future work will augment existing utility participant capabilities to consider wind integration and will promote collaborative planning, analysis, and renewable integration project implementation. Based on the work that has been accomplished to date it is expected that the best integration solution paths will involve new transmission corridors, closer cooperation among balancing authorities, dynamic scheduling of wind power across interties, pooling integration responsibility and services, and adopting new transmission scheduling, practices and procedures.

Scenarios will be defined, modeled and investigated to address production variability and balancing of large quantities of wind power in the Southwest Power Pool (SPP) and delivery to 
energy markets in the southern regions of the Southeastern Electric Reliability Council (SERC). Currently four scenarios are planned as follows:

1 - SPP schedules wind hourly to SERC utilities.

- SPP deals with all wind variability and uncertainty internally

- This case is expected to be expensive at least and unworkable at worst

2 - SPP dynamically schedules wind plant output to each SERC utility

- Each SERC utility deals with the variability and uncertainty of the wind that is dynamically scheduled to it internally with its own generation and load

3 - SPP coordinates operational scheduling with each SERC utility separately

- SERC BA and SPP load variability and generation response capability are coordinated for each SERC BA.

4 - SPP and all participating SERC BAs coordinate operational scheduling

- SPP and SERC BAs aggregate load and wind variability and coordinate generation response capability to meet net variability and uncertainty

The key elements of the scope for this follow on work includes:

- Evaluate wind import cases considering transmission details

- Determine transfer cases....what is reasonable transfer

- Run base case simulation, analyze results and report outputs

- Finalize alterative cases with different BA collaboration assumptions

- Review draft study findings and report

This scope will be accomplished using systems modeling tools and by interacting directly with balancing authorities. Participants are Southwest Power Pool (SPP), Entergy, Southern Company (SC), Tennessee Valley Authority (TVA), and Oglethorpe Power Corp. NREL is managing this work and ORNL will also participate as a reviewer and in associated workshops, The research team for the project includes EPRI, LCG Consulting, and Brendan Kirby Consulting. The schedule is a shown below:

\begin{tabular}{|l|l|l|l|l|}
\hline PROJECT GANNT CHART & \multicolumn{2}{|c|}{ Month 1- 12 } & \multicolumn{2}{c|}{ Month 13 - 24} \\
\hline CONTRACT START & & & \\
\hline TASK 1: Develop Base Case Scenario 1st UBA Workshop & & \\
TASK 2: Define Altemative Scenarios & & & \\
TASK 3: Run Base Case Scenarios and Report (Uplan) \\
TASK 4: Analysis of Base Case 2nd UBA Workshop
\end{tabular}




\section{References}

EPRI 2007, Assessment of Waterpower Potential and Development Needs, EPRI 1014762, March. http://mydocs.epri.com/docs/public/000000000001014762.pdf

EIA 2008, Energy Market and Economic Impacts of S. 2191, the Lieberman-Warner Climate Security Act of 2007, EIA, March.

http://www.eia.doe.gov/oiaf/servicerpt/s2191/index.html

EIA 2009a, Annual Energy Outlook 2009 With Projections to 2030, DOE/EIA-0383(2009), Energy Information Administration, March.

http://www.eia.doe.gov/oiaf/aeo/index.html

EIA 2009b, Impacts of a 25-Percent Renewable Electricity Standard as Proposed in the American Clean Energy and Security Act Discussion Draft, SR/OIAF/2009-04, Energy Information Administration, April.

http://www.eia.doe.gov/oiaf/servicerpt/acesa/index.html

EPRI 2009, Role of Future Generation Options for the U.S. Electric Sector, Report 1015805, Electric Power Research Institute, March.

Federal Energy Regulatory Commission (FERC), 2008, FERC eForms - Form 714 Data, Federal Energy Regulatory Commission. http://www.ferc.gov/docs-filing/eforms/form-714/data.asp

Hadley, Stanton W., and Thomas Key, 2009, Power Transfer Potential to the Southeast in Response to a Renewable Portfolio Standard: Interim Report 1, ORNL/TM-2008/222, Oak Ridge National Laboratory, March.

Hadley, Stanton W., Thomas Key, Rajat Deb, 2009, Power Transfer Potential to the Southeast in Response to a Renewable Portfolio Standard: Interim Report 2, ORNL/TM-2009/102, Oak Ridge National Laboratory, May.

Milbrandt, A. 2005, A Geographic Perspective on the Current Biomass Resource Availability in the United States, NREL/TP-560-39181, National Renewable Energy Laboratory, December. http://www.nrel.gov/docs/fy06osti/39181.pdf

Paidipati, J., L. Frantzis, H. Sawy;er, and A. Kurrash 2008, Rooftop Photovoltaics Market Penetration Scenarios, NREL/SR-581-42306, National Renewable Energy Laboratory, February. http://www.nrel.gov/docs/fy08osti/42306.pdf

NREL 2009, Eastern Interconnection Wind Integration \& Transmission Study (Draft), NREL, Midwest ISO, and Enernex, 2009.

http://wind.nrel.gov/public/EWITS/ 
Navigant 2008, Florida Renewable Energy Potential Assessment, Navigant Consulting, Dec.

SACE 2009, Yes We Can: Southern Solutions for a National Renewable Energy Standard, Southern Alliance for Clean Energy Feb. 2009

Sullivan, Patrick, Jeffrey Logan, Lori Bird, and Walter Short, 2009, Comparative Analysis of Three Proposed Federal Renewable Electricity Standards, NREL/TP-6A2-45877, National Renewable Energy Laboratory, May 


\section{Appendix A Available renewable resources in the Southeast}

The Southeast has a number of renewable resources that can be used to meet a RPS. However, the total amount economically available is likely less than $15 \%$ of total generation. Several studies have been done that look at renewable energy resources in all or part of the southeast. The key studies used for the amounts described below are:

Annual Energy Outlook 2009 by the Energy Information Administration, March 2009 Energy Market and Economic Impacts of S. 2191, the Lieberman-Warner Climate Security Act of 2007 by EIA, March 2008

Yes We Can: Southern Solutions for a National Renewable Energy Standard, Southern Alliance for Clean Energy Feb. 2009

EPRI analysis of Wind capacities Feb. 2009

A Geographic Perspective on the Current Biomass Resource Availability in the United States, NREL/TP-560-39181, National Renewable Energy Laboratory, December 2005.

Rooftop Photovoltaics Market Penetration Scenarios, NREL/SR-581-42306, NREL, Feb. 2008.

Florida Renewable Energy Potential Assessment, Navigant Consulting, Dec. 2008. Eastern Interconnection Wind Integration \& Transmission Study (Draft), NREL, Midwest ISO, and Enernex, 2009.

A separate study is underway at ORNL funded by the Energy Foundation that will conduct a more thorough literature review of the amounts of each renewable energy category that is potentially available in the SE.

\section{A.1 Wind}

Onshore wind capabilities in the Southeast are relatively modest. Less than 20 TWh of power could potentially be generated in the SE states (Table 10) using data from EPRI. The table shows the amounts if capacity factors for wind turbines vary between $18 \%$ and $37 \%$ depending on the class of wind. The wind resource estimates for in states that have some territory in other reliability regions have been downscaled to reflect the amounts within the SERC and FRCC borders. Note that half of the potential production in SERC comes from Missouri, with its northwestern portion having the best quality of wind potential. This region is still rather distant from the rest of the SERC region and load centers.

Table 10. Potential Onshore Wind Capacity in SERC region by state (EPRI)

$\begin{array}{lcccccccccccc} & \text { AL } & \text { AR } & \text { FL } & \text { GA } & \text { LA } & \text { MO } & \text { MS } & \text { NC } & \text { SC } & \text { TN } & \text { VA } & \text { Total } \\ \text { Potential Capacity (GW) } & 0 & 0.3 & 0 & 0 & 0 & 6.0 & 0 & 1.9 & 0.3 & 1.1 & 1.8 & 11.4 \\ \text { Expected prod. (TWh) } & 0.0 & 0.5 & 0.0 & 0.0 & 0.0 & 9.6 & 0.0 & 3.5 & 0.5 & 2.1 & 3.3 & 19\end{array}$

Additionally, offshore wind capacity is potentially available. However, this form of wind energy has not yet been tapped within the US. It is beginning to be developed in Northern Europe, in the North Sea and in the Atlantic off the coast of Ireland and England. The EWITS study developed estimates of wind capacity along the Atlantic coast. These were largely along the Virginia and North Carolina coasts, as shown in Figure 20. The total amount in the SERC region was 4,000 
MW, even in the aggressive penetration scenario. At a capacity factor of $40 \%$, this totals to 14 TWh per year.

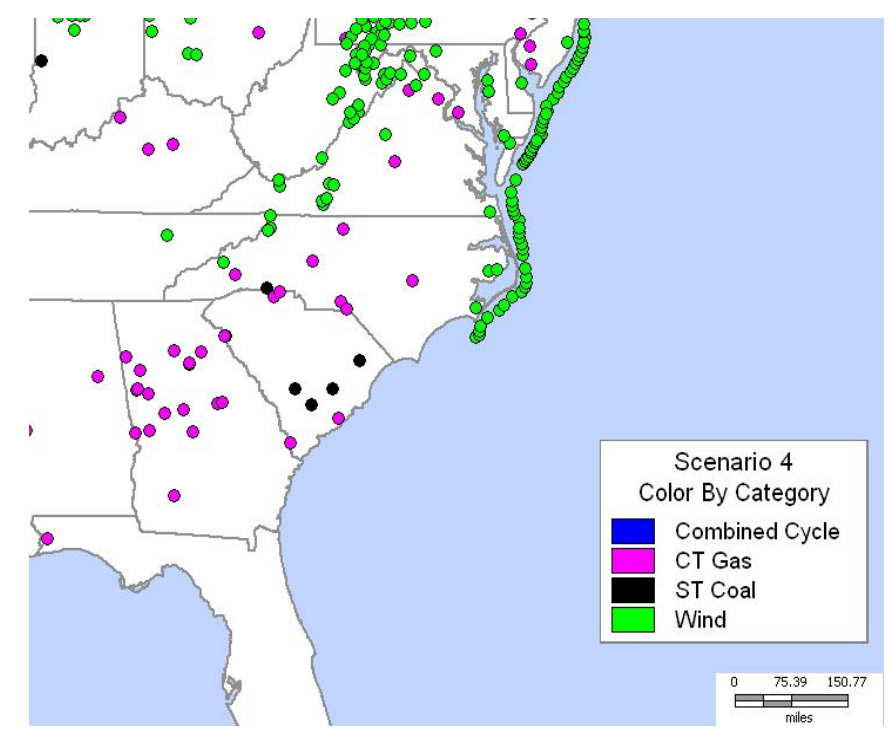

Figure 20. Locations of Southeast Offshore Wind in EWITS study

Combined, the total amount of potential wind capacity for the southeast is roughly $15 \mathrm{GW}$, with a production amount of $33 \mathrm{TWh}$. This includes a speculative $4 \mathrm{GW}$ of offshore wind plus $6 \mathrm{GW}$ in upstate Missouri.

Separately, Navigant Consulting performed an analysis of renewable energy potential in the state of Florida (Navigant 2008). Their analysis projected $67 \mathrm{MW}$ of onshore wind and $105 \mathrm{MW}$ of offshore wind by 2020 in the most favorable circumstances. These contribute 0.5 TWh of generation to the region.

\section{A.2 Solar}

Solar capacity could be extensive in the southeast, depending on the cost of deployment. One study of rooftop PV potential from NREL shows much of Florida (and small parts of the rest of the Southeast) with solar prices below residential electricity prices in 2015 (Figure 21) (Paidipati et al. 2008). The technical potential (regardless of cost) is on the order of $200 \mathrm{GW}$, but actual deployment will be much smaller. 


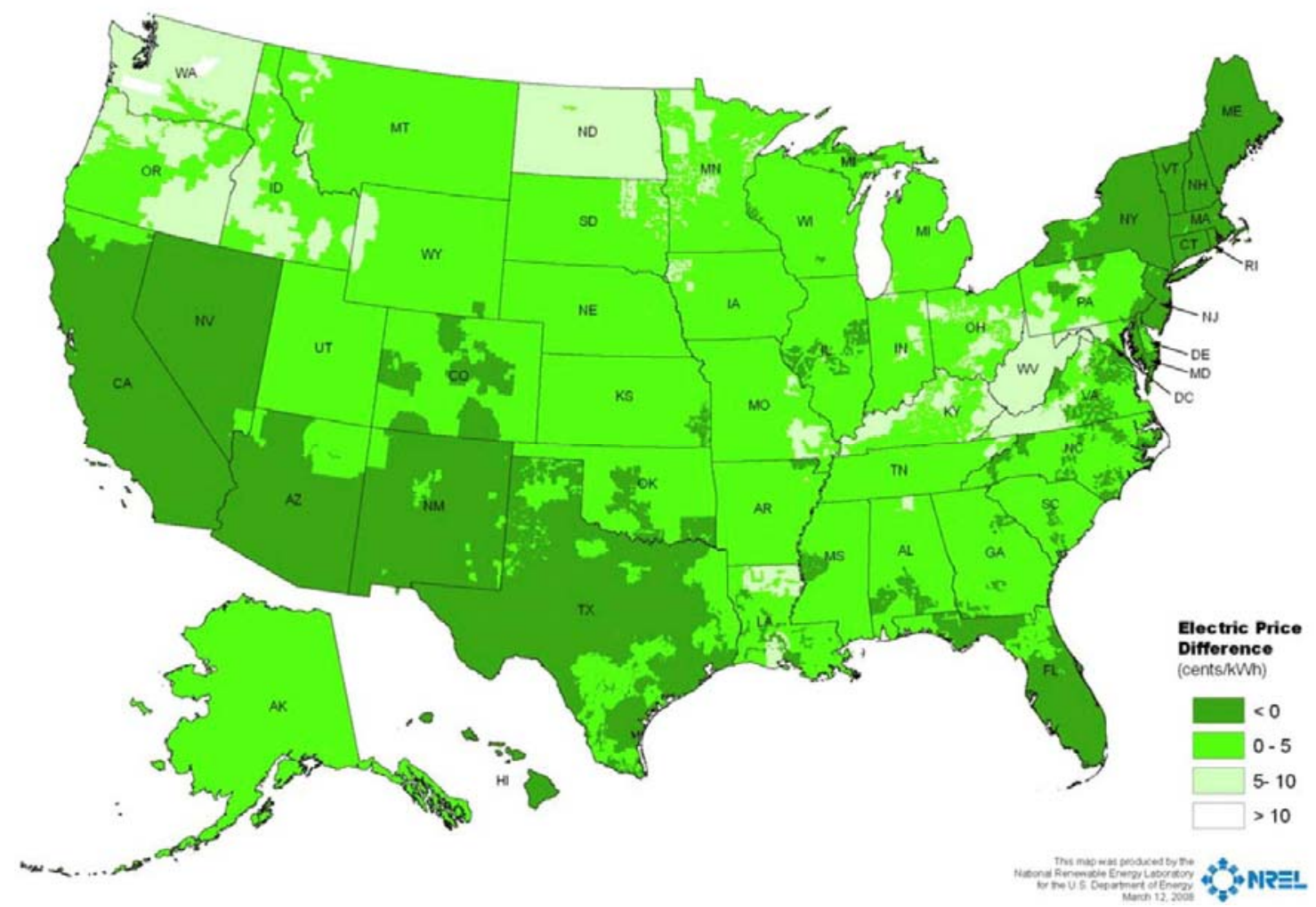

Figure 21. Price difference between solar PV levelized costs and residential electricity in 2015 with a 13\% increase in residential prices and no incentives (Paidipati et al. 2008)

The authors of the study made state-by-state analyses of existing policies and the effect of potential changes to policies. Under their Business as Usual scenario, they projected cumulative installations of rooftop PV for the southeast at $213 \mathrm{MW}$. Under their best-case assumptions, they forecasted almost 1,000 MW (Table 11). Assuming a 25\% capacity factor, this works out to around 2 TWh, much less than the required 186 TWh identified in Table 1. In their analysis, they proposed various policies to encourage further solar development, most of which North Carolina already has planned (note that the amount is the same for both the BAU and best case scenarios.)

Table 11. Southeast states' cumulative rooftop PV capacity (MW) in 2015 under BAU and best case scenarios (Paidipati et al. 2008)

\begin{tabular}{|c|c|c|}
\hline State & Business as Usual & Best Cas \\
\hline Alabama & 1 & 87 \\
\hline Arkansas & 1 & 1 \\
\hline Florida & 30 & 330 \\
\hline Georgia & 11 & 41 \\
\hline Louisiana & 1 & 34 \\
\hline Mississippi & 2 & 92 \\
\hline North Carolina & 154 & 154 \\
\hline South Carolina & 3 & 43 \\
\hline Tennessee & 6 & 84 \\
\hline Virginia & 3 & 62 \\
\hline West Virginia & 1 & 8 \\
\hline Total & 213 & 936 \\
\hline
\end{tabular}


A separate study by Navigant of the potential for renewable energy in Florida included an analysis of the potential for ground-mounted PV in the state. They projected a technical potential of 37 GW in 2020, representing 600 square miles or $\sim 1 \%$ of the state's area. Depending on the renewable energy policies (including renewable energy credits) they projected between 0 and 9.5 GW of ground-mounted PV by 2020 (producing up to 21.6 TWh), roughly one fourth of the technical potential. The Southern Alliance for Clean Energy extrapolated these results to the eleven states of the southeast and came up with a total technical potential of $346 \mathrm{GW}$ and feasible capacity of $74 \mathrm{GW}$. The feasible generation was $160 \mathrm{TWh}$, assuming favorable renewable energy policies and RECs. With the higher price differential for solar in the rest of the southeast (Figure 21) it is less likely that this solar amount could be feasible by 2020 .

\section{A.3 Biomass}

Biomass generation may be the largest supply of renewable production in the southeast.

According to the NREL report A Geographic Perspective on the Current Biomass Resource Availability in the United States (Milbrandt 2005) the total potential biomass resources available in the southeast is around 120 million metric tonnes per year. Assuming $16 \mathrm{mmbtu} / \mathrm{tonne}$ and a heat rate of 10,000 btu/kWh (34\% efficiency) the total potential electricity from these resources is 145 TWh, a significant fraction of the required 186 TWh identified in Table 1 . With a capacity factor of $70 \%$, this translates into a total potential electric capacity of around $24 \mathrm{GW}$. However, even if this total potential were utilized, some portion of it would be used for liquid biofuels rather than electricity production. As such, it would not qualify for the renewable portfolio standard, which only applies to electricity production. Figure 22 shows the split of resources by type of fuel.

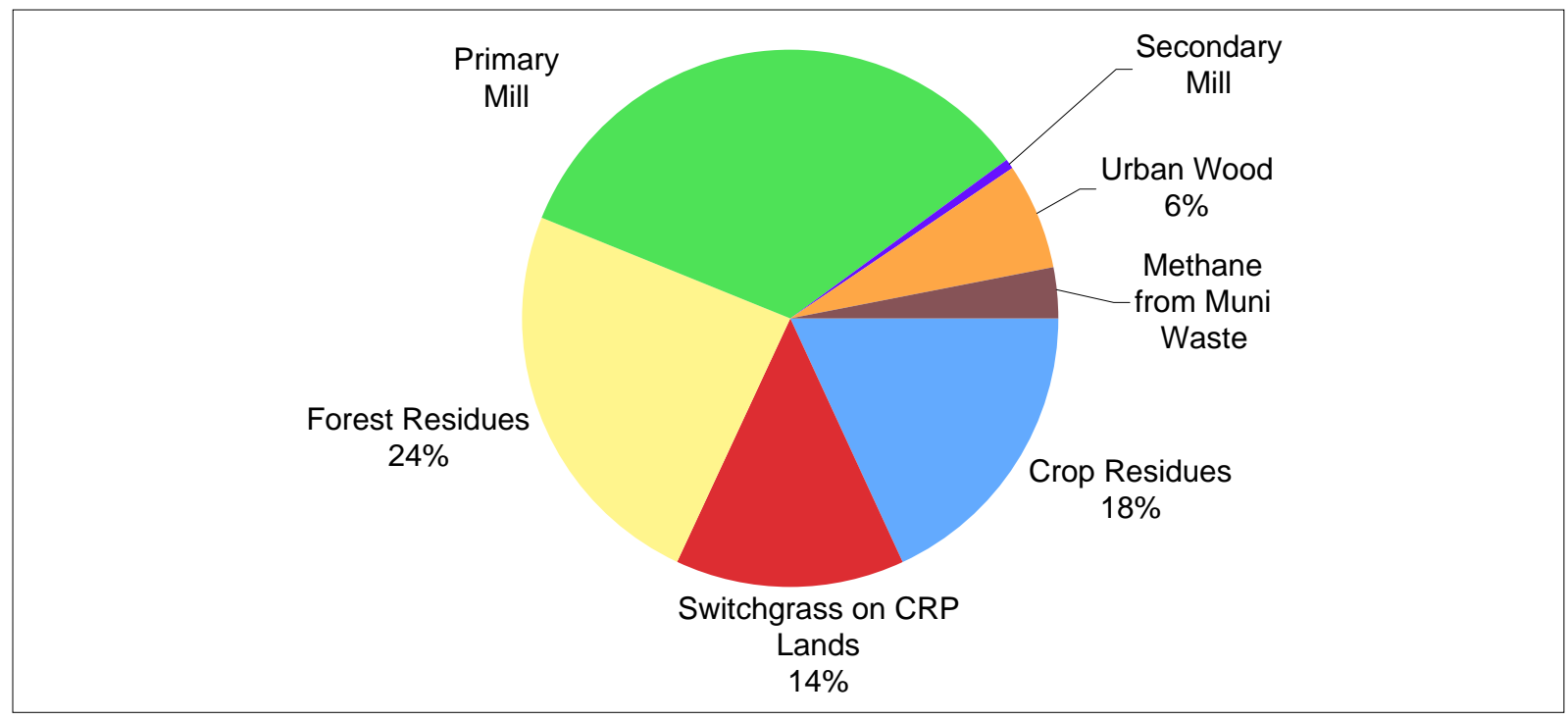

Figure 22. Total potential biomass resources in the southeast by type (Milbrandt 2005)

The AEO2009 projects 12 TWh of wood and other biomass production in 2020 in the southeast. Much of this generation is from cofiring in a coal-fired power plant, rather than as dedicated biomass capacity. In addition, it lists another 3 TWh from biogenic municipal waste, but this does not qualify for the RPS according to Bingaman's proposed bill. The analysis by EIA of Senate bill 2191 (the Lieberman-Warner Climate Security Act) placed biomass generation in the 
southeast at 55 TWh by 2020, while an analysis of the RPS within the American Clean Energy and Security Act of 2009 reported 34 TWh of production.

\section{A.4 Hydro}

Hydroelectricity is currently the most widely used renewable resource within the southeast. The resources have been developed by the TVA, the US Army Corps of Engineers, and other utilities mainly in the central part of the southeast (Figure 23). Total resources in the SERC and FRCC region are between $12 \mathrm{GW}$ and $13 \mathrm{GW}$ with a typical production of $35 \mathrm{TWh}$. (Wet and dry years, such as the drought in 2006 and 2007, will cause hydropower output to vary by as much as 50\%.) Most major resources have been developed although some additional incremental generation may be realized by upgrading existing hydro turbines and improving operating efficiency at existing facilities. Nameplate capacity in SERC rose from 12.3 GW in 2004 to 12.7 GW in 2007.

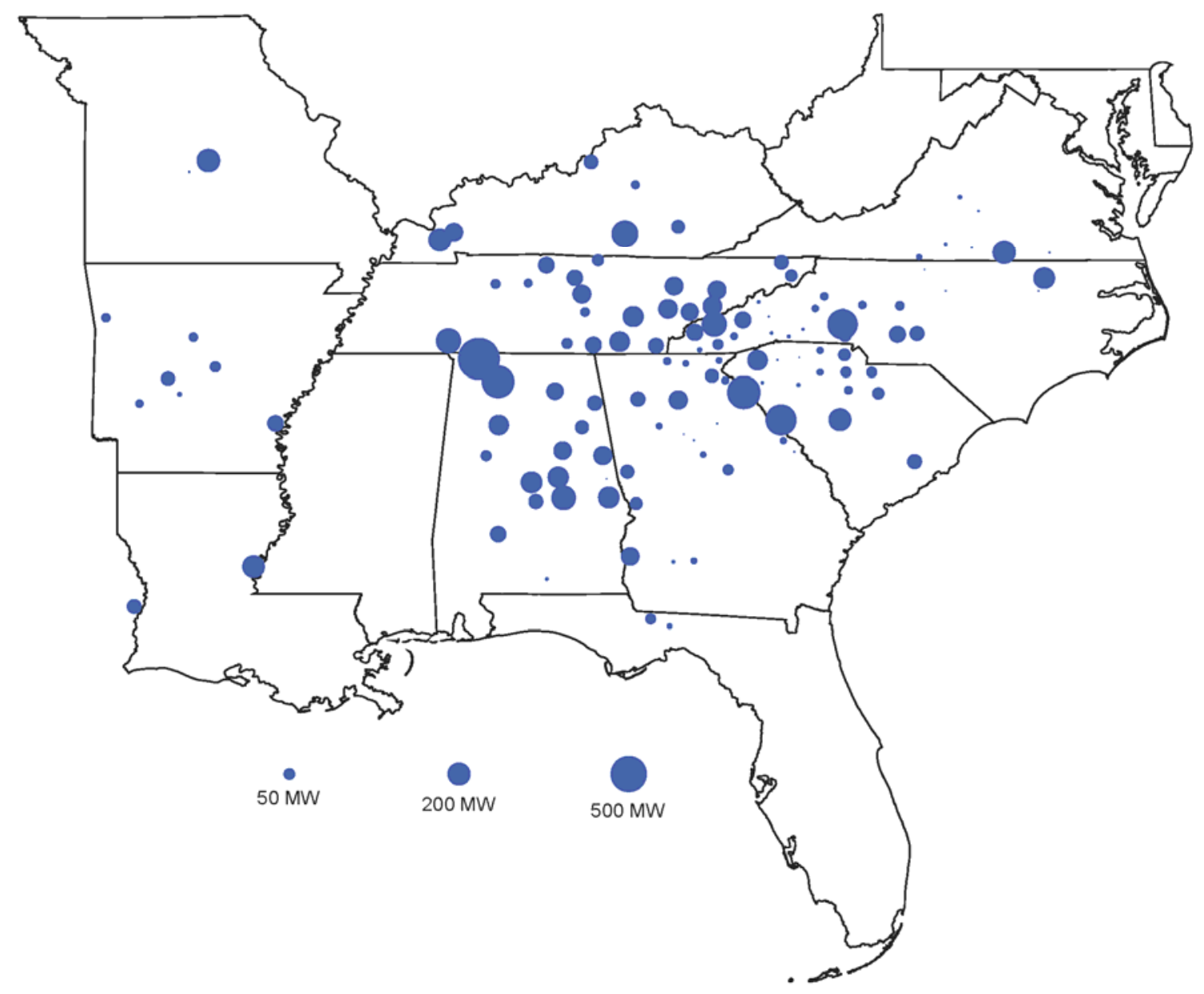

Figure 23. Location of Hydroelectric facilities in the Southeast (EPA 2008)

In many RPS proposals, including the Bingaman proposal described above, existing hydropower does not count towards meeting the standard, but is also removed from the total generation to which the percentage is applied. 
Another new technology with potential is hydrokinetic machines that operate in free-flowing rivers or ocean currents. Tidal and wave power equipment are also under research. However, these technologies are currently only at the developmental or pilot-scale level and are unlikely to provide a significant portion of the needs under an RPS.

EPRI has identified a nationwide potential for hydro capacity gains of 3.7 GW by 2015 and 23 GW by 2025, with a total potential of 85 - 95 GW (EPRI 2007). However, they provide no geographic breakdown of this amount. Some $10 \mathrm{GW}$ of this potential is at existing facilities or small hydro and so may be applicable to southeastern rivers and dams (Table 12). Between this new capacity and increased efficiency at existing dams, they project a potential nationwide generation of 40-50 TWh from conventional hydro. The southeast would only capture a fraction of that. Hydrokinetic capabilities are largely from tidal in-stream operations, which are not being pursued currently in the southeast but rather in the Pacific Northwest, Hawaii, and New York.

Table 12. Estimated National Waterpower Capacity Gains (MW) by 2025 (Source EPRI 2007)

\begin{tabular}{|c|c|c|c|c|c|}
\hline Waterpower Technology & 2006 & Potential & By 2010 & By 2015 & By 2025 \\
\hline \multicolumn{6}{|l|}{ Conventional hydropower } \\
\hline Large Hydro (>30 MW) & 66,536 & & 0 & 0 & 0 \\
\hline $\begin{array}{l}\text { Capacity gains at existing large } \\
\text { and small hydro }\end{array}$ & $\sim 100$ & 4,300 & 375 & 1,000 & 2,300 \\
\hline New small hydro $(>1 \mathrm{MW}<30)$ & 8,023 & 36,000 & 25 & 500 & 2,000 \\
\hline New low power hydro <1 MW & 313 & 22,000 & 100 & 350 & 700 \\
\hline New hydro at existing dams & - & & 25 & 500 & 5,000 \\
\hline Conventional hydro potential realized & & & 525 & 2,350 & 10,000 \\
\hline \multicolumn{6}{|l|}{ Hydrokinetic } \\
\hline Tidal instream & Demos & 300 & 115 & 300 & 3,000 \\
\hline $\begin{array}{l}\text { Instream and constructed } \\
\text { waterways }\end{array}$ & - & 12,500 & 0 & 30 & ? \\
\hline Hydrokinetic potential realized & & & 115 & 330 & 3,000 \\
\hline Ocean energy (wave) & Demos & $10,000-20,000$ & 84 & 1,000 & 10,000 \\
\hline TOTAL & 74,972 & $85,100-95,100$ & 724 & 3,680 & 23,000 \\
\hline
\end{tabular}

\section{A.5 Amount deployed under different scenarios}

Under the newest Annual Energy Outlook 2009 Reference scenario (released in April and including the impact of the recent stimulus funds), only $18 \mathrm{GW}$ of renewables are used in the southeast, generating 68 TWh (Table 13). Of this amount, only 29 TWh of generation is from qualified renewables; the remainder is from hydroelectric and municipal waste. It does include 3.6 GW of wind (3.57 GW in Florida onshore and the $30 \mathrm{MW}$ existing in Tennessee). The biomass generation amount of 19 TWh includes both dedicated biomass plants $(1.4 \mathrm{GW})$ plus cofiring in some of the region's coal-fired plants. 
Table 13. Southeast 2020 electricity capacity, generation and load from AEO2009 poststimulus (EIA 2009)

\begin{tabular}{lrr}
\hline & $\begin{array}{c}\text { Capacity } \\
\text { (GW) }\end{array}$ & $\begin{array}{c}\text { Generation } \\
\text { (TWh) }\end{array}$ \\
\hline Coal & 149.7 & 572 \\
Oil \& Gas & 232.5 & 188 \\
Nuclear & 38.7 & 334 \\
Pumped Storage/Other & 7.7 & -1 \\
Conventional Hydropower & 12.2 & 35 \\
Geothermal & 0.0 & 0 \\
Biogenic Municipal Waste & 0.8 & 4 \\
Wood and Other Biomass & 1.4 & 19 \\
Solar Thermal & 0.0 & 0 \\
Solar Photovoltaic & 0.0 & 0 \\
Wind & 3.6 & 11 \\
Offshore Wind & 0.0 & 0 \\
less gen for own use & & -10 \\
Electric Gen for Customers & 285.4 & 1152 \\
Net imports from other regions & & 77 \\
Purchase from CHP & & 1240 \\
Net Energy for Load & & \\
\hline
\end{tabular}

The amounts in this scenario expand the amount of renewables when compared to earlier reference cases due to the policies in the American Reinvestment and Recovery Act. Other recent NEMS scenarios by EIA had even more development. The analysis by EIA of the renewable energy standard within the proposed American Clean Energy and Security Act of 2009 (EIA 2009) placed qualified renewable generation in the southeast at 44 TWh by 2020 (Table 14). Biomass production increased from 19 TWh to $34 \mathrm{TWh}$; other renewables essentially stayed the same. Even this scenario has only a fourth of what is needed for the region to supply its own share of a $15 \%$ RPS requirement. 
Table 14. Southeast electricity capacity, generation and load from EIA evaluation of RPS policy in American Clean Energy and Security Act (Source EIA2009b)

\begin{tabular}{lrr}
\hline Coal & $\begin{array}{c}\text { Capacity } \\
\text { (GW) }\end{array}$ & $\begin{array}{c}\text { Generation } \\
\text { (TWh) }\end{array}$ \\
Oil \& Gas & 148.9 & 558 \\
Nuclear & 230.2 & 184 \\
Pumped Storage/Other & 38.7 & 334 \\
Conventional Hydropower & 7.7 & -1 \\
Geothermal & 12.2 & 35 \\
Biogenic Municipal Waste & 0.0 & 0 \\
Wood and Other Biomass & 0.8 & 4 \\
Solar Thermal & 1.6 & 34 \\
Solar Photovoltaic & 0.0 & 0 \\
Wind & 0.0 & 0 \\
Offshore Wind & 3.6 & 11 \\
less gen for own use & 0.0 & 0 \\
Electric Gen for Customers & & -10 \\
Net imports from other regions & 284.1 & 1149 \\
Purchase from CHP & & 79 \\
Net Energy for Load & & 1240 \\
\hline
\end{tabular}

A recently released study by NREL on RPS proposals (Sullivan 2009) includes a table that shows the state-by-state generation by different renewable technologies (Table 15). The analysis was done using their ReEDS model and the data shown in the table is the sum for the eleven states in the southeast (as opposed to the SERC and FRCC regions). The data represents their modeling of the Markey's bill H.R. 890, the American Renewable Energy Act for the year 2030. Even though this bill required the most renewable generation of the three studied, 25\% by 2025, the southeast states did not generate the required amounts. Instead, they were expected to import renewable power and/or purchase renewable energy credits from states with surpluses.

Table 15. Southeastern renewable generation in 2030 under Markey Bill (TWh) (Source Sullivan 2009)

\begin{tabular}{lrrrr}
\hline & Wind & Solar & \multicolumn{1}{c}{ Bio } & Total \\
\hline Alabama & 0 & 0 & 1.4 & 1.4 \\
Arkansas & 0.4 & 0 & 0.7 & 1.1 \\
Florida & 2.9 & 3.2 & 11 & 17.1 \\
Georgia & 2.1 & 0 & 1.6 & 3.7 \\
Louisiana & 3.9 & 2.8 & 0.7 & 7.4 \\
Mississippi & 0 & 0 & 1.2 & 1.2 \\
Missouri & 13.4 & 0 & 0.8 & 14.2 \\
North Carolina & 10.8 & 7.0 & 7.0 & 24.8 \\
South Carolina & 0.4 & 1.5 & 2.2 & 4.1 \\
Tennessee & 1.0 & 0 & 1.5 & 2.5 \\
Virginia & 2.5 & 1.7 & 1.4 & 5.6 \\
Total & 37.4 & 16.2 & 29.5 & 83.1 \\
\hline
\end{tabular}


The amounts above represent only the electricity generated by the electricity sector and does not include industrial or other sectors' generation for their own end-use. Particularly in the southeast, generation from biomass through cogeneration at paper mills provide significant quantities of electricity. These are not greatly affected by changes in plans and do not qualify for tradable renewable energy credits in some of the bills under discussion. Under the AEO2009 with stimulus package scenario by 2030 there is 37 TWh of qualified renewable resources from endusers while in the Waxman RPS the total is only 36 TWh (Table 16).

Table 16. Renewable resources in 2030 from different scenarios and models

\begin{tabular}{l|r|r|r|r|r|r|r}
\hline & Markey RPS & \multicolumn{4}{|c|}{ AEO2009 with Stimulus (NEMS) } & \multicolumn{3}{c}{ Waxman RPS (NEMS) } \\
& (ReEDS) & Elec Sector & EndUse & Total & Elec Sector & EndUse & \multicolumn{1}{c}{ Total } \\
\hline Wind & 37 & 11 & 0 & 11 & 11 & 0 & 11 \\
Solar & 16 & 0 & 5 & 5 & 0 & 7 & 7 \\
Biomass & 30 & 18 & 32 & 50 & 129 & 28 & 157 \\
Total & 83 & 29 & 37 & 66 & 139 & 36 & 175 \\
\hline
\end{tabular}

Another point to be made from this table is that different models and associated assumptions can give large differences in the amount and type of generation developed. The ReEDS model analysis of the Markey RPS develops a large amount of solar and wind resources while the NEMS analysis supply most renewable generation in the southeast from biomass. 


\section{Appendix B Workshop Invitation, Agenda and Participants}

\section{B.1 Invitation}

Study on the Feasibility of Importing Wind Electricity to the Southeast U.S.

Researchers at the Oak Ridge National Laboratory (ORNL) and the Electric Power Research Institute (EPRI) are conducting a study on the feasibility of importing large quantities of wind energy into the southeastern U.S. We want to obtain input from utilities in the region and would like to invite you or someone in your organization to participate as a reviewer over the next four months. In August we are planning a one-day review and workshop related to this work, to be held at ORNL in Oak Ridge, TN. We would like to invite you or a representative of your company to participate in this workshop.

The issues considered in this work are to meet a possible future RPS requirement, and also to provide an important market from southern SERC for windy areas in SPP and MISO. A key concern of many utilities in SERC is that we are not blessed with as many cost-effective renewable resources as other regions. Utilities may need to import significant quantities of power from elsewhere, such as wind energy. Other options may be available but at higher-cost such as local generation of renewable resources, purchase of renewable energy credits without actually transmitting the energy, or payment of an alternative compliance payment to the U.S. Treasury.

The status of this work is we have drafted two interim reports: one on regional estimates of renewable resource projections compared to RPS needs, and one on current transmission and generation estimates of renewables for the Southeast. We are currently examining the issues at the subregion level in SERC, and under varying scenarios that include the economics of wind generation and transport from SPP.

We expect about 20 from utility transmission operations and planning to attend the workshop. It will be held August 18, 2009 at ORNL. The purpose is to review the study results and allow the participants to discuss the operational opportunities and challenges trying to meet a possible RPS. You will be able evaluate what work has been done, hear feedback from others and participate in discussion on what further work needs to be done. We want to hear about, and discuss your major issues and challenges for fulfilling an RPS mandate.

If you or someone in your organization would be willing to participate in this workshop, please let us know. You can contact us via the website we have established for the project, Renewables in the Southeast. Or you can contact either Tom Key of EPRI (tkey@epri.com, 865-218-8082) or Stan Hadley of ORNL (hadleysw@ornl.gov, 865-574-8018) directly for further information.

After we hear from you we will begin to provide the results to date and the plans for work over the summer.

Sincerely,

Stanton W. Hadley

Oak Ridge National Laboratory
Thomas S. Key

Electric Power Research Institute 


\title{
B.2 Agenda
}

\author{
Agenda \\ Workshop on Importing Wind to Southeast \\ ORNL, Oak Ridge, TN \\ Visitor’s Center Cumberland Conference Room
}

August 18, 2009

- 7:30 Obtain Badge and Refreshments in Meeting Room (visitor’s center)

- 8:30 Welcome/Introductions/Framework and Objectives Tom Key, EPRI

- 8:45 Regional Settings and Background Studies

o JCSP/EWITS Studies Summary

o ORNL-EPRI Wind Transfer Potentials Overview

o Southwest Power Pool Wind/Transmission Overview

Lynn Coles, NREL Stan Hadley, ORNL Jay Caspary, SPP

- 10:00 Break

- 10:30 Utility Planning/Procurement Perspectives on Wind Import/Export
o TVA Gary Bullock/ Dennis Chastain
o Entergy
o Southern Company
o Oglethorpe Tony Waltz
o Duke Power Jeremy Bennett
o Other
Rich Clark
Ed Ernst

- 12:00 Lunch (in the meeting room)

- 12:45 Tour of VERDE Real-time Transmission Visualization John Stovall, ORNL

- 1:30 Scenarios, Sensitivities and Comparison of Wind Transfer Analysis

o Transfers w/o Major Interregional Enhancements

o Approach and Scenarios for EPRI Transfer Cases Jeremy Platt, EPRI Tom Key, EPRI

- 2:30 Discussions of Results, Identify Issues/Opportunities

Participants

- 3:00 Break

- 3:30 Stakeholder Input Daniel Brooks, EPRI

o Identify remaining (burning) Issues

o Review Open or Unanswered Questions, Uncertainties

o Discuss Future Plans and Next Steps

- 4:30 Adjourn 


\section{B.3 Attendees}

\section{Wind to Southeast Workshop, ORNL, OakRidge,}

\begin{tabular}{|c|c|c|c|c|c|}
\hline \multicolumn{3}{|c|}{ First Name Last Name } & \multicolumn{2}{|c|}{ :onfirme Company } & \multirow{2}{*}{$\begin{array}{l}\text { Email Address } \\
\text { erwilcox@aep.com }\end{array}$} \\
\hline 1 & Evan & Wilcox & $x$ & American Electric Power & \\
\hline 2 & Stan & Calvert & $x$ & DOE/EERE & Stan.Calvert@ee.doe.gov \\
\hline 3 & Ryan & Elwell & $x$ & DOE/EERE & Ryan.Elwell@ee.doe.gov \\
\hline 4 & Ed & Ernst & $x$ & Duke Energy Corporation & Ed.Ernst@duke-energy.com \\
\hline 5 & Charles & DeGeorge & $x$ & Entergy Services, Inc. & cdegeor@entergy.com \\
\hline 6 & Tony & Walz & $x$ & Entergy Services, Inc. & awalz@entergy.com \\
\hline 7 & Daniel & Brooks & $x$ & EPRI & dbrooks@epri.com \\
\hline 8 & Tom & Key & $x$ & EPRI & tkey@epri.com \\
\hline 9 & Jeremy & Platt & $x$ & EPRI & jplatt@epri.com \\
\hline 10 & Jeff & Smith & $x$ & EPRI & jsmith@epri.com \\
\hline 11 & Lielong & Hsue & $x$ & LCG Consulting & llh@energyonline.com \\
\hline 12 & Lynn & Coles & $x$ & NREL & Iynn.coles@nrel.gov \\
\hline 13 & Jake & Langthorn IV & $x$ & Oklahoma Gas \& Electric & langthis@oge.com \\
\hline 14 & Stan & Hadley & $x$ & ORNL & hadleysw@ornl.gov \\
\hline 15 & Brennan & Smith & $x$ & ORNL & smithbt@ornl.gov \\
\hline 16 & Grant & Blume & $x$ & Progress Energy & grant.blume@pgnmail.com \\
\hline 17 & Jeremy & Bennett & $x$ & Southern Company Services, Inc. & jbennett@southernco.com \\
\hline 18 & Todd & Wall & $x$ & Southern Company Services, Inc. & Itwall@southernco.com \\
\hline 19 & Jody & Holland & $x$ & Southwest Power Pool & jholland@spp.org \\
\hline 20 & Jay & Caspary & $x$ & Southwest Power Pool, Inc. & jcaspary@spp.org \\
\hline 21 & Gary & Bullock & $x$ & Tennessee Valley Authority (TVA) & gcbullock@tva.gov \\
\hline 22 & Dennis & Chastain & $x$ & Tennessee Valley Authority (TVA) & dwchastain@tva.gov \\
\hline 23 & Dejim & Lowe & $x$ & Tennessee Valley Authority (TVA) & dclowe@tva.gov \\
\hline 24 & K. W. & Morris & $x$ & Tennessee Valley Authority (TVA) & morriskw@tva.gov \\
\hline 25 & Kamren & Ali & web & AEP & kali@aep.com \\
\hline 26 & Brendan & Kirby & web & Consultant & kirbybj@ieee.org \\
\hline 27 & Alberto & Del Rosso & web & EPRI & adelrosso@epri.com \\
\hline 28 & Charlie & Clark & web & Cascade Consulting & cclark@contractor.epri.com \\
\hline
\end{tabular}


B.4 Workshop Presentations - Southwest Power Pool
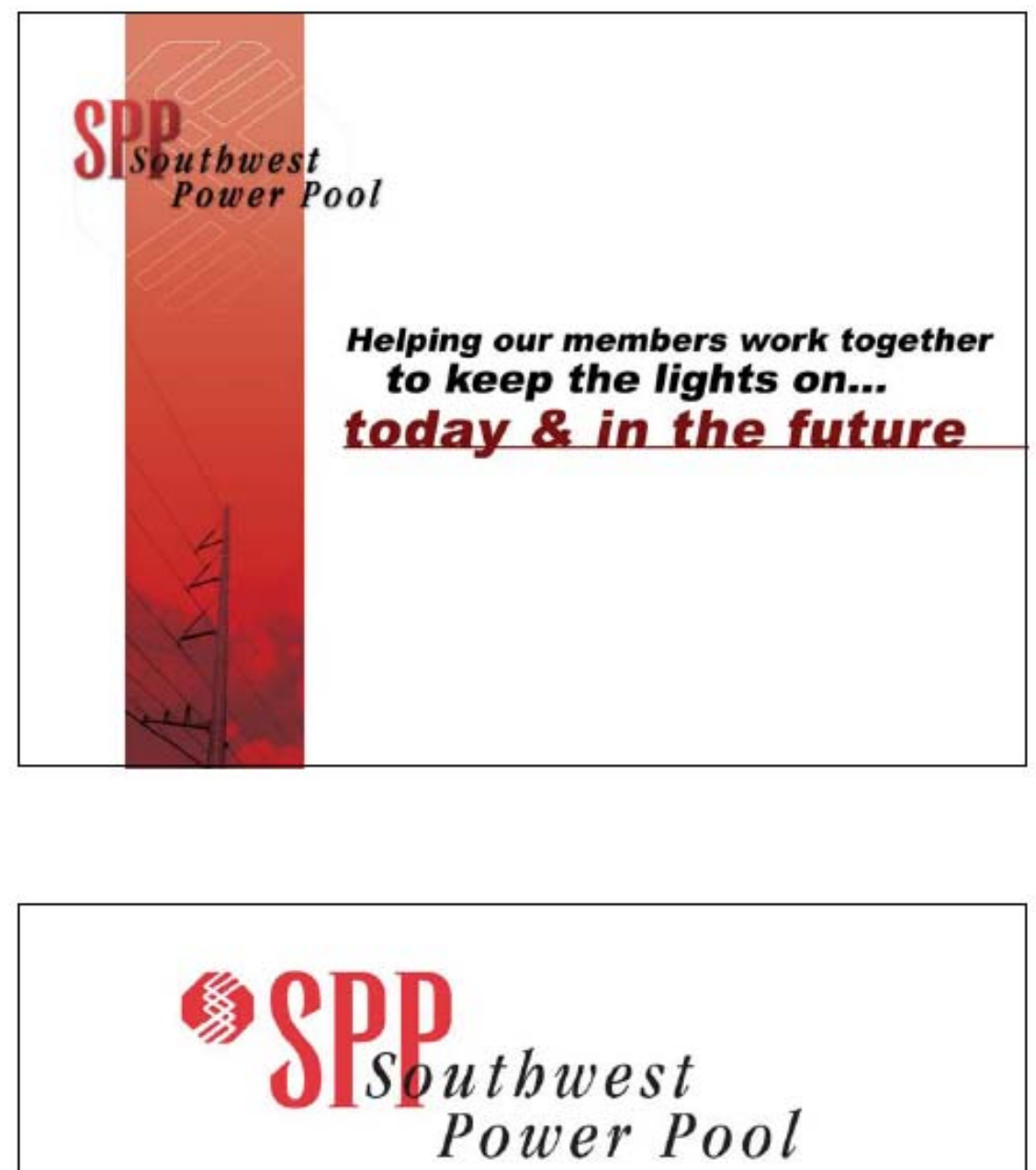

SPP Wind/Transmission Overview

Knoxville, TN

August 18, 2009 


\section{Overview}

- SPP Background

- Eastern Interconnection Planning Collaborative

- Expansion Planning

- Wind Integration Issues

- SPS Wind Penetration Study

- How we Plan is Changing

- Cost Allocation is Key

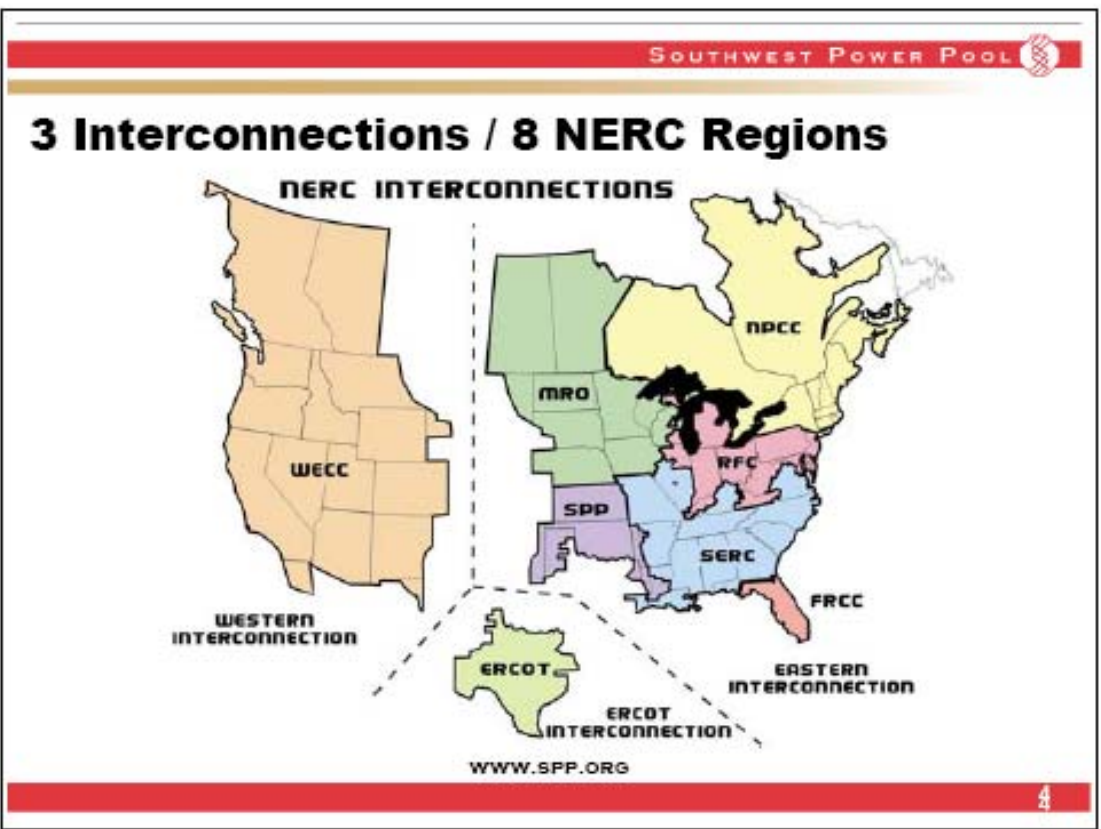




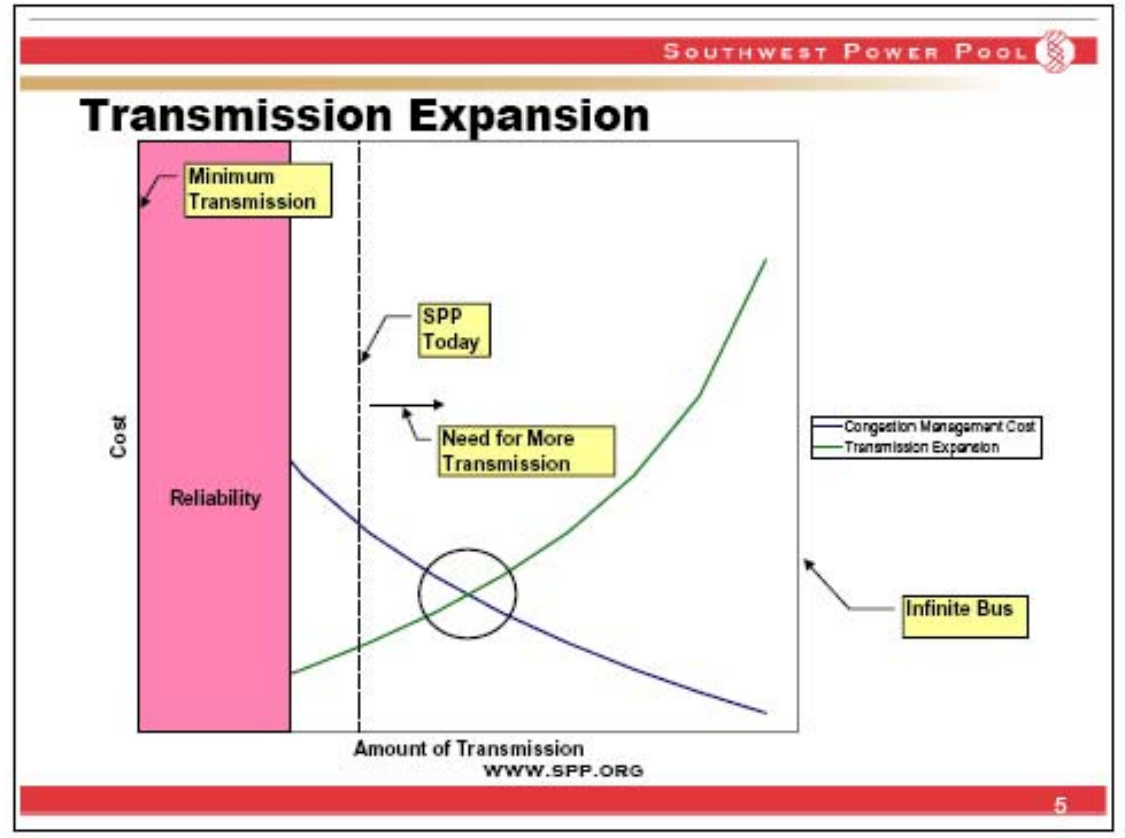

SOUTHWEST POWER POOL

\section{Transmission Planning}

- Expansion planning has been effective

- Transparent, inclusive processes in place

- Efforts underway to enhance collaboration

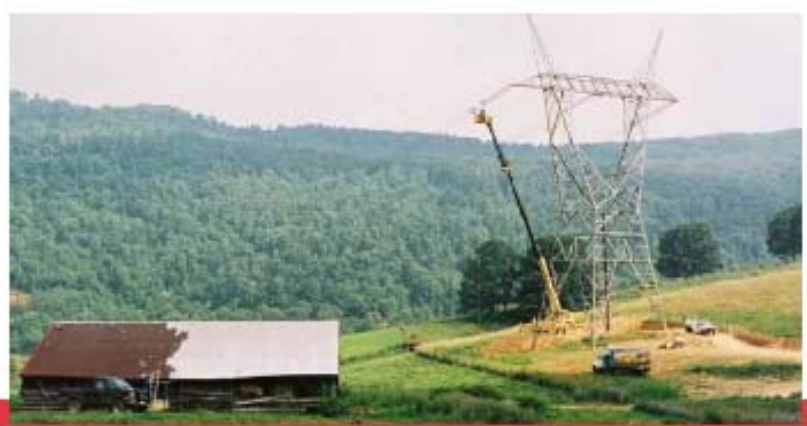




\section{Long-term Planning is Challenging,} but Essential -Uncertainty about energy and environmental policies
make planning difficult

$>$ Economic growth

$>$ Demand response

> Energy efficiency

$>$ Aging infrastructure

> Carbon constraints

$>$ Resource planning with (and without) state mandates

$>$ Cost Allocations / Seams Agreements

-Siting issues for major projects across several jurisdictions require very long lead times WWW.SPP.ORG

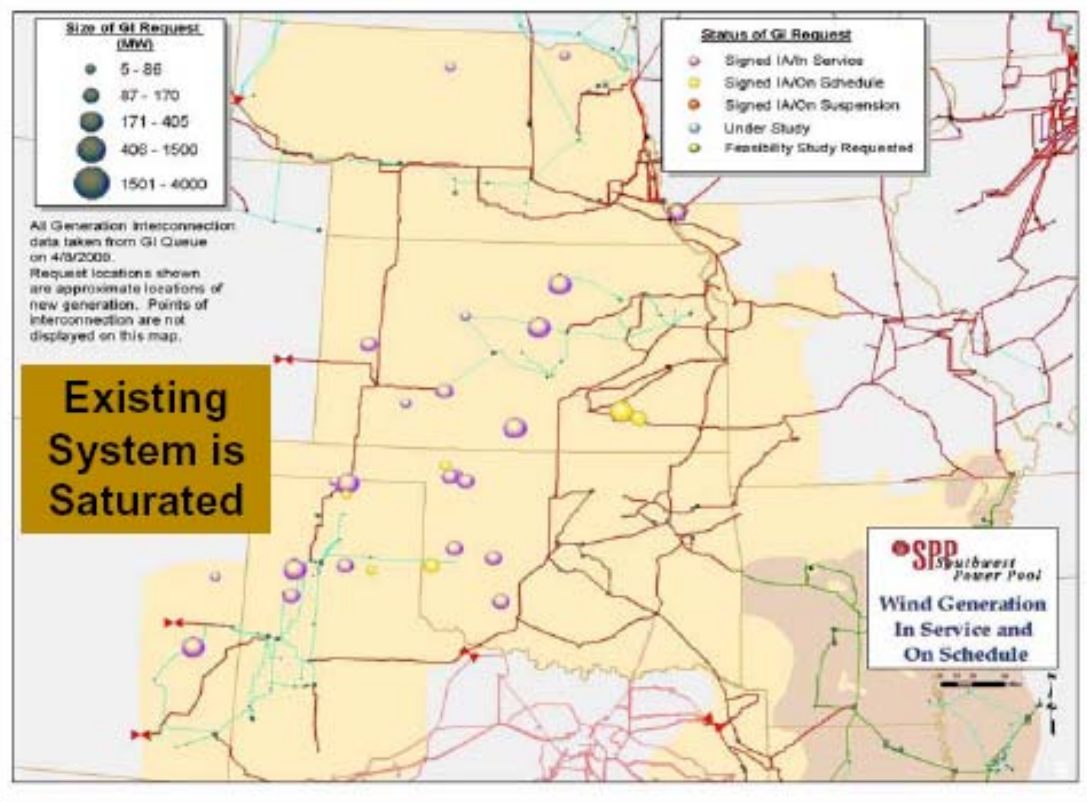



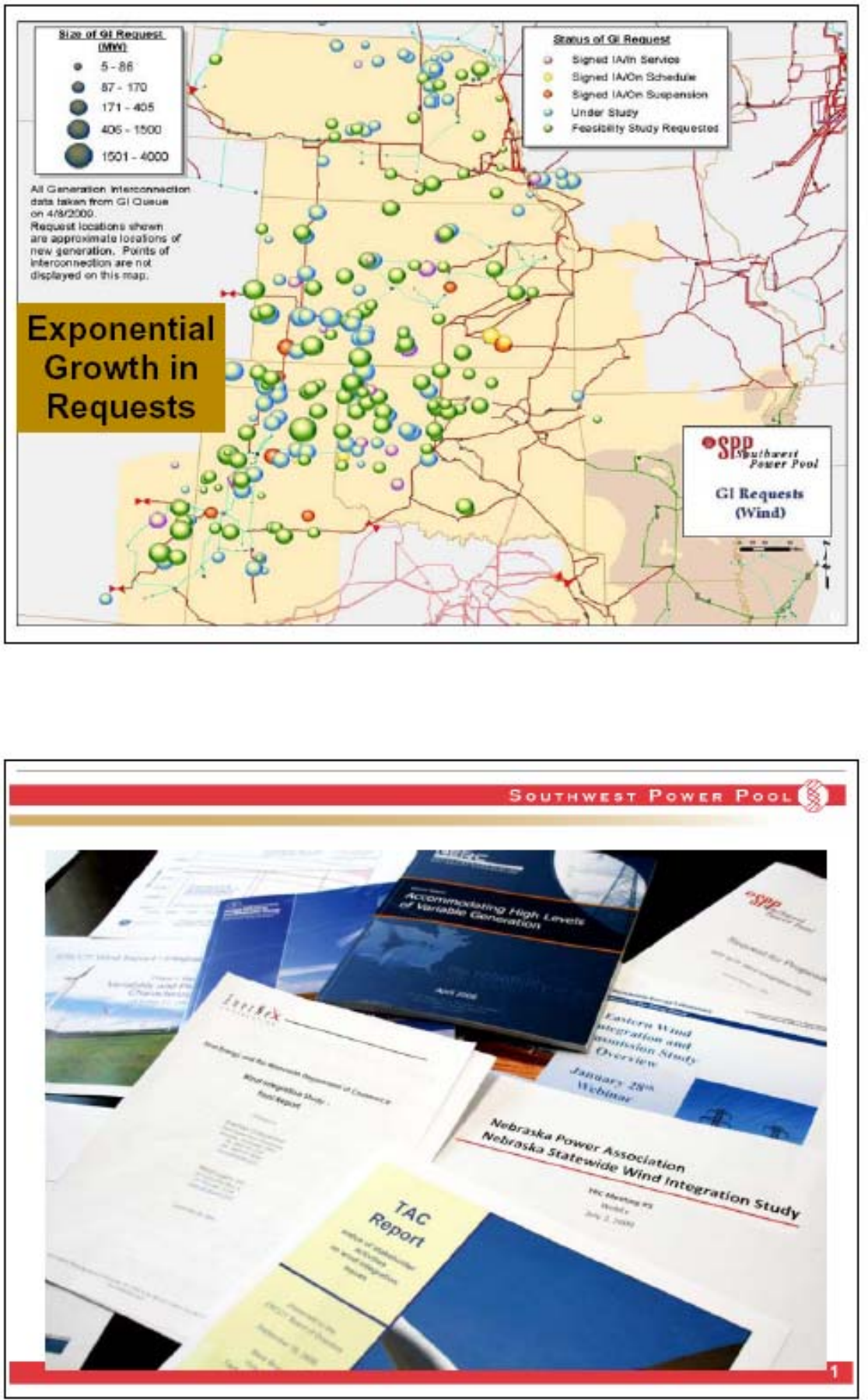


\begin{tabular}{l}
\hline Need for Eastern Interconnection \\
Planning Collaborative (EIPC) \\
>New energy policies are driving the need to create a \\
framework to analyze transmission scenarios on a broad \\
multi-regional scale considering the entire interconnection \\
- Transmission expansion plans in the Eastern \\
Interconnection are developed today and coordinated on a \\
regional and super-regional basis, but could be better \\
coordinated on an interconnection basis \\
>Any new expanded process must build upon, not restrict, \\
existing regional planning processes \\
www.spe.ore
\end{tabular}

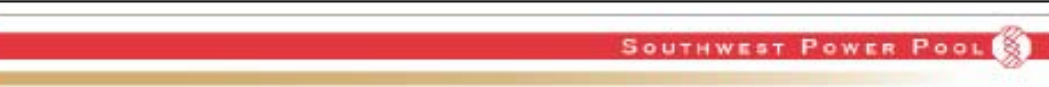

\section{Challenge to the Industry}

-Existing generation connection queues and transmission development plans must be respected

-Expanding existing regional processes to cover the entire Eastern Interconnection and reach consensus will require:

$>$ "Grassroots" approach

> Broad stakeholder involvement

> Significant role for state and provincial representatives

> Federal acceptance of the process

$>$ U.S. DOE announced funding opportunity to facilitate development and strengthen study efforts in the three U.S. interconnections

> Proposals due September 14, 2009 WWW.SPP.ORG 


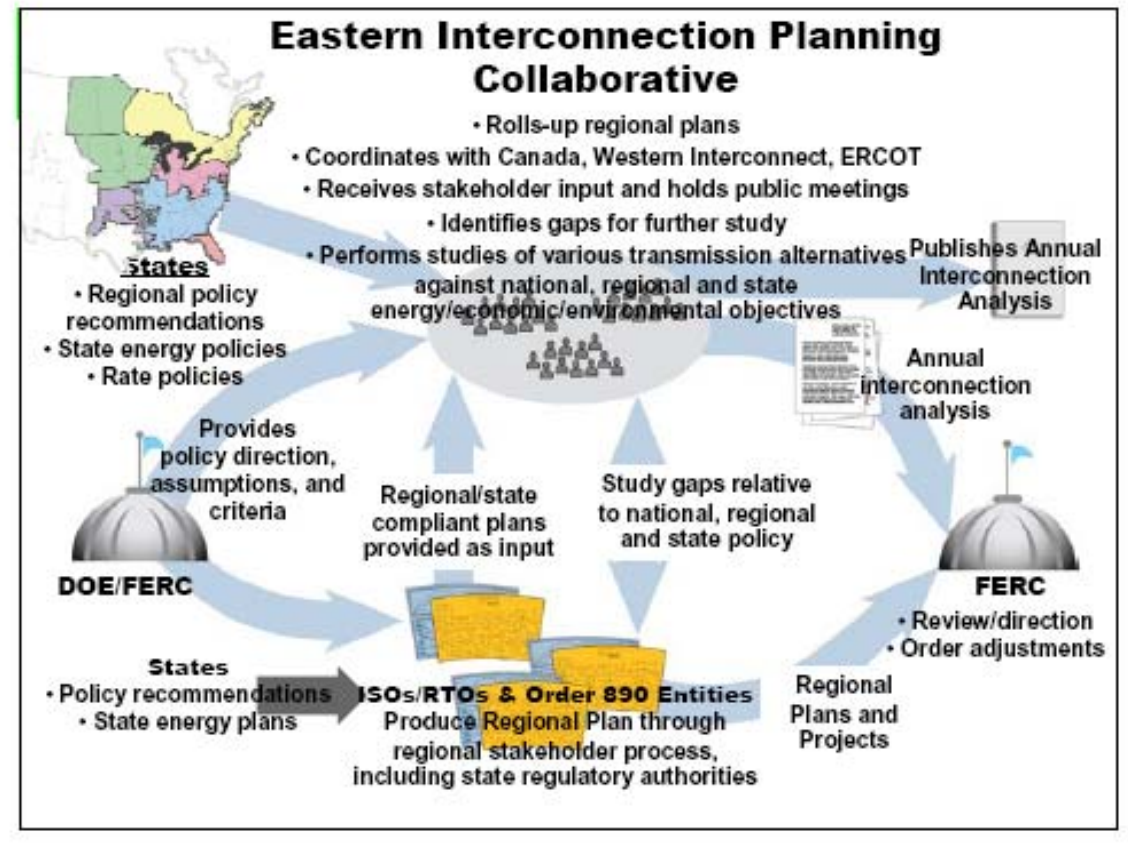

SOUTHWEST POWER POOL \&

\section{EIPC Next Steps}

$>40$ states/District of Columbia are working together on funding request to DOE to enable their active support of EIPC

>Steering Committee (SC) with sector voting will drive modeling assumptions and scenarios/futures with state regulators/staff filling at least $33 \%$ of SC

$>$ EIPC proposal will include gap analysis of existing plans, as well as development of base line model and several scenarios / assessments to inform future policy decision.

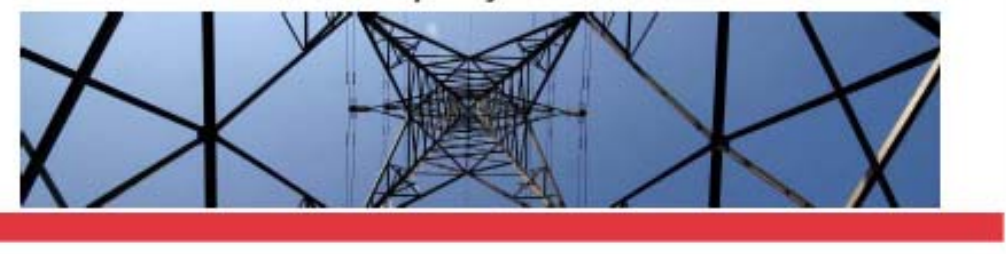



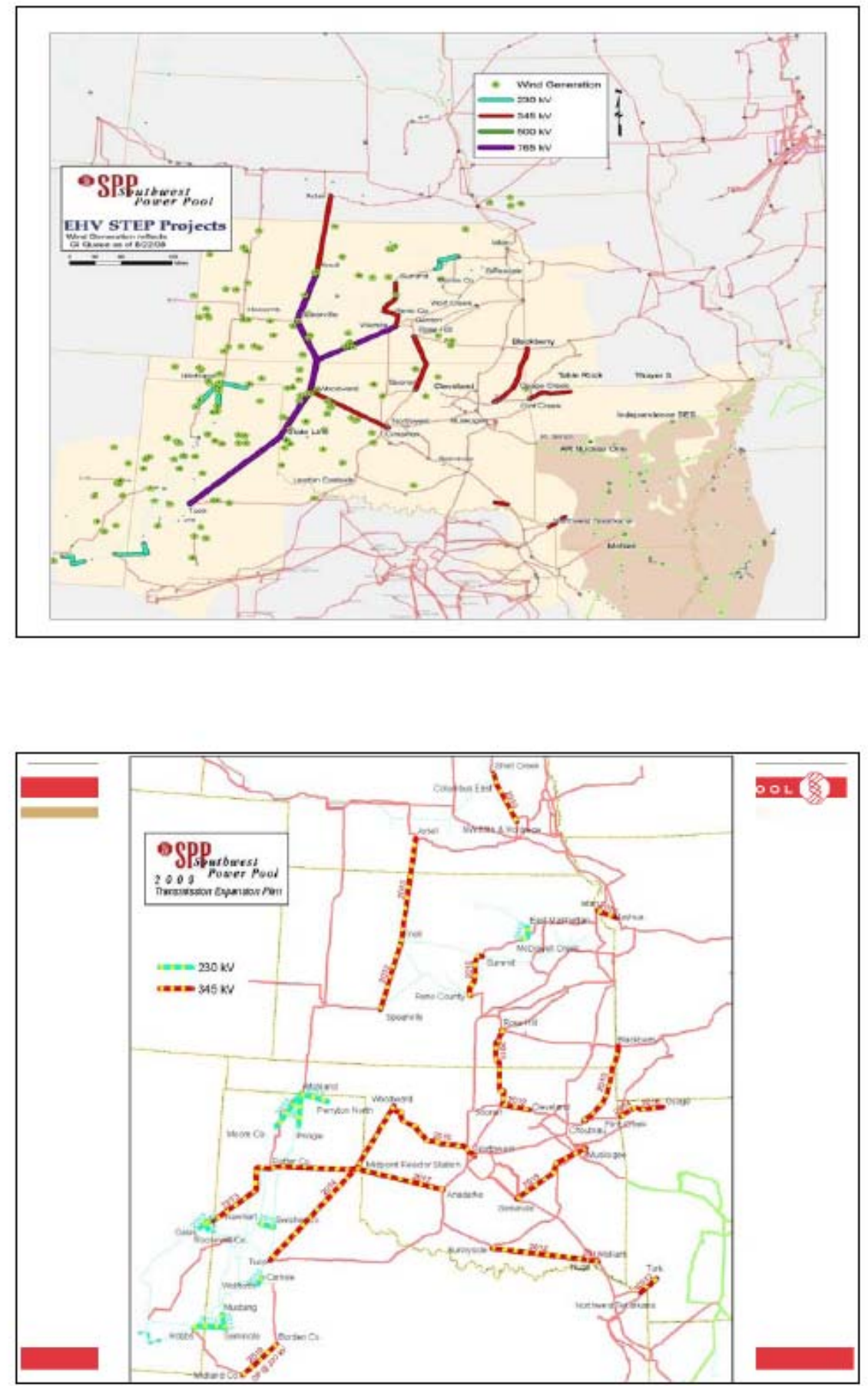


\begin{tabular}{l}
\hline Economic Planning \\
Reliability and Economics are Inseparable \\
Economic Upgrades - sponsored under existing \\
tariff but eligible for credits based on new service \\
sold \\
Balanced Portfolio \\
Postage stamp cost allocations for a portfolio of \\
Economic Upgrades which benefit SPP as a whole, and \\
for which each zone realizes benefits in excess of their \\
costs \\
Tariff language has been approved and filed at FERC \\
\$700M Balanced Portfolio approved by BOD in April \\
$\quad$ www.spp.ore
\end{tabular}

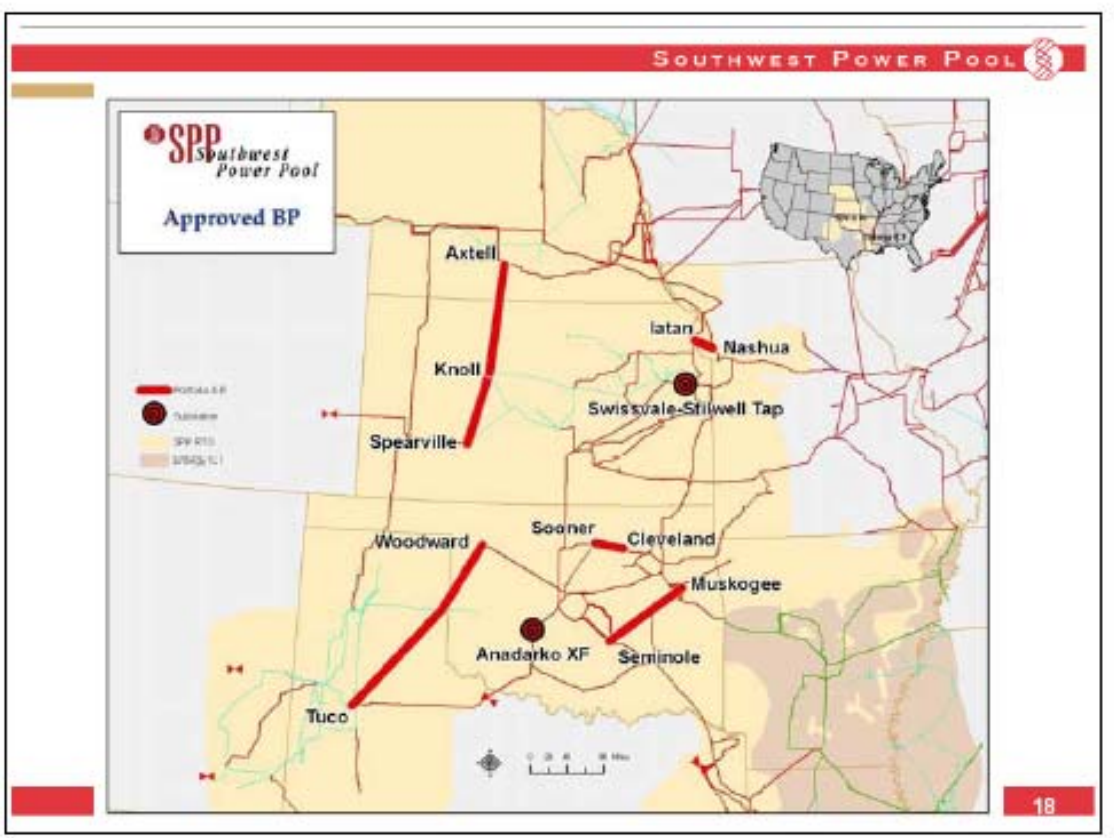



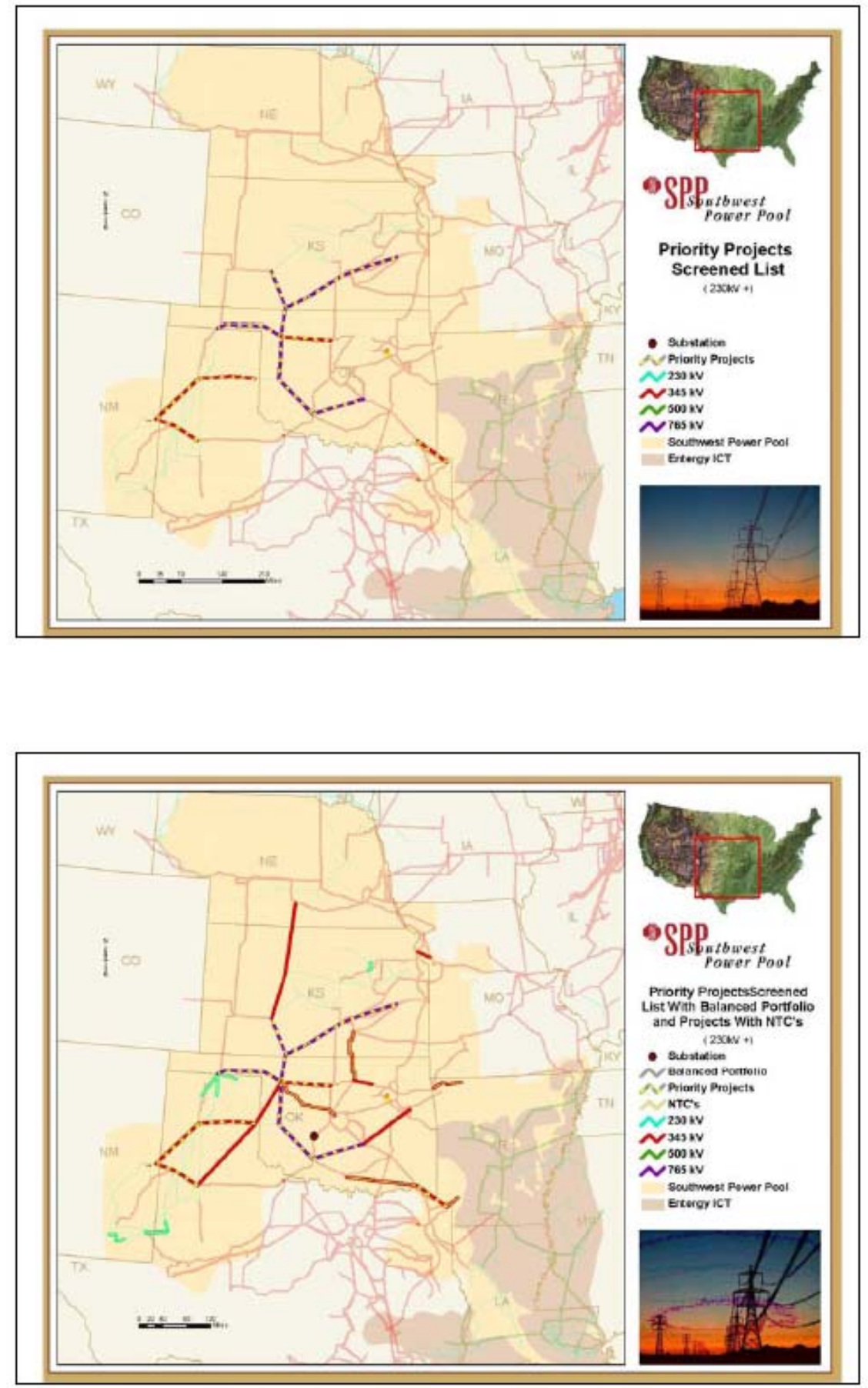


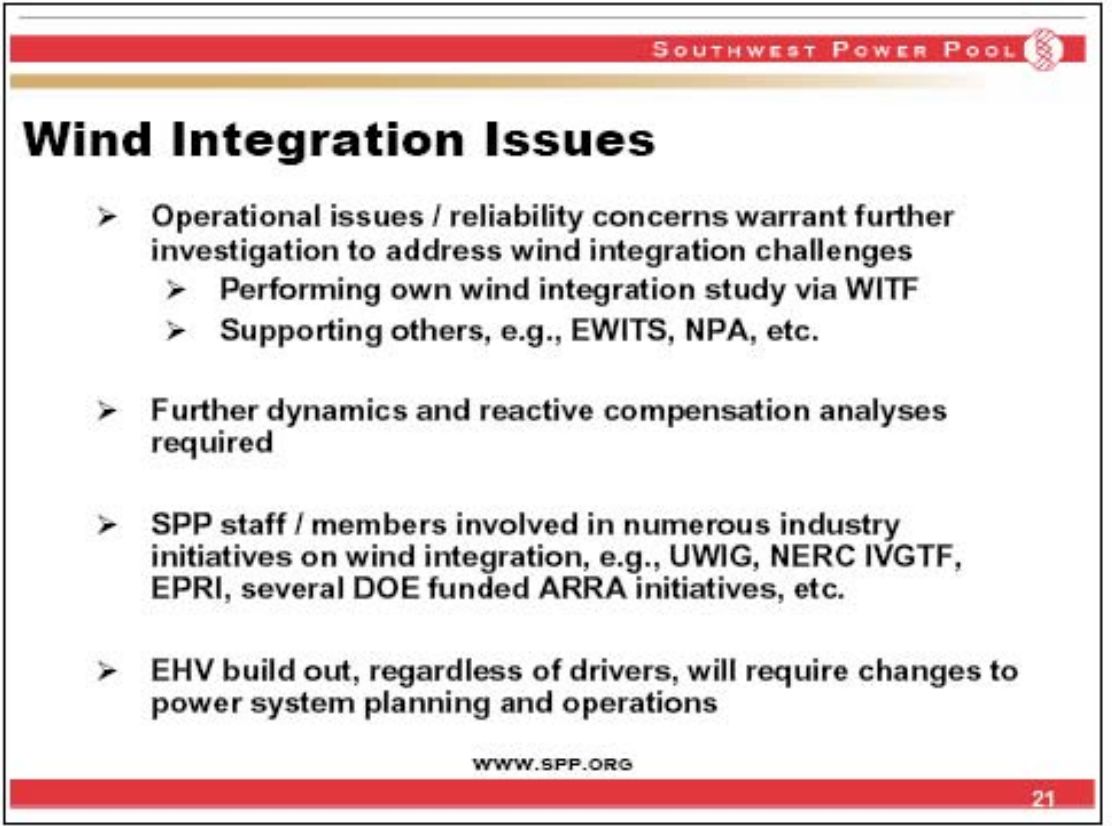

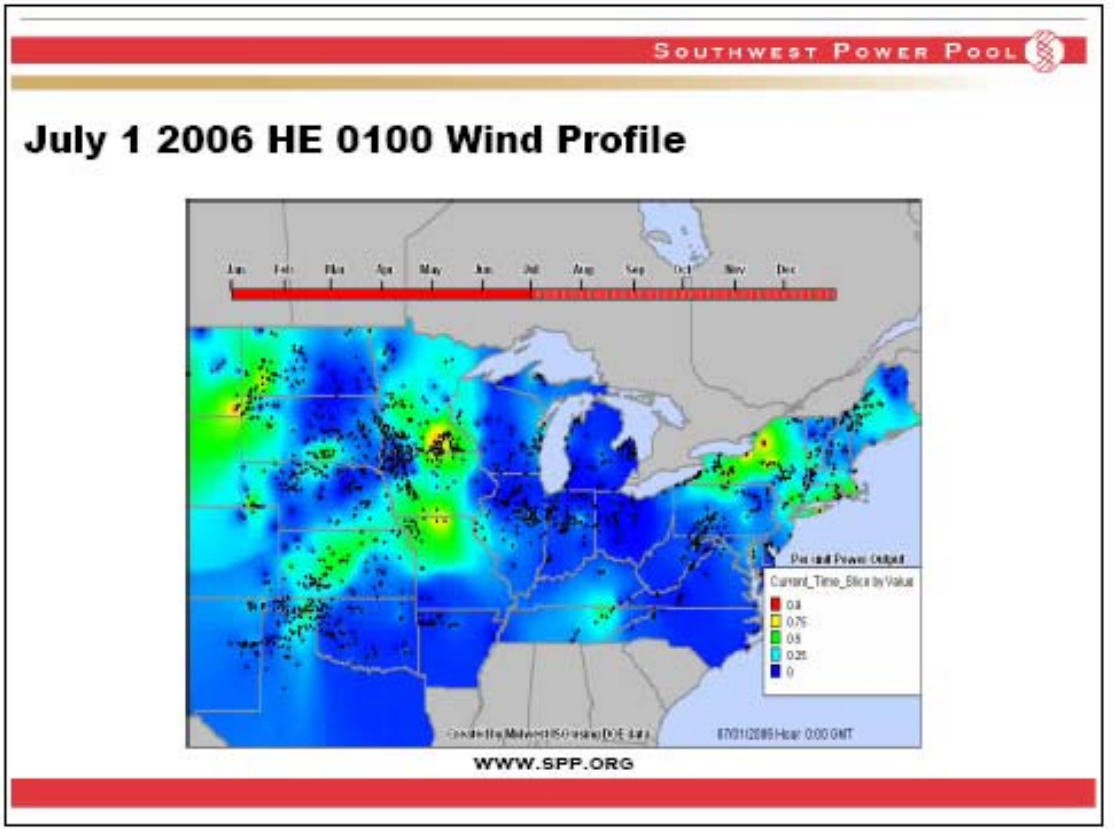




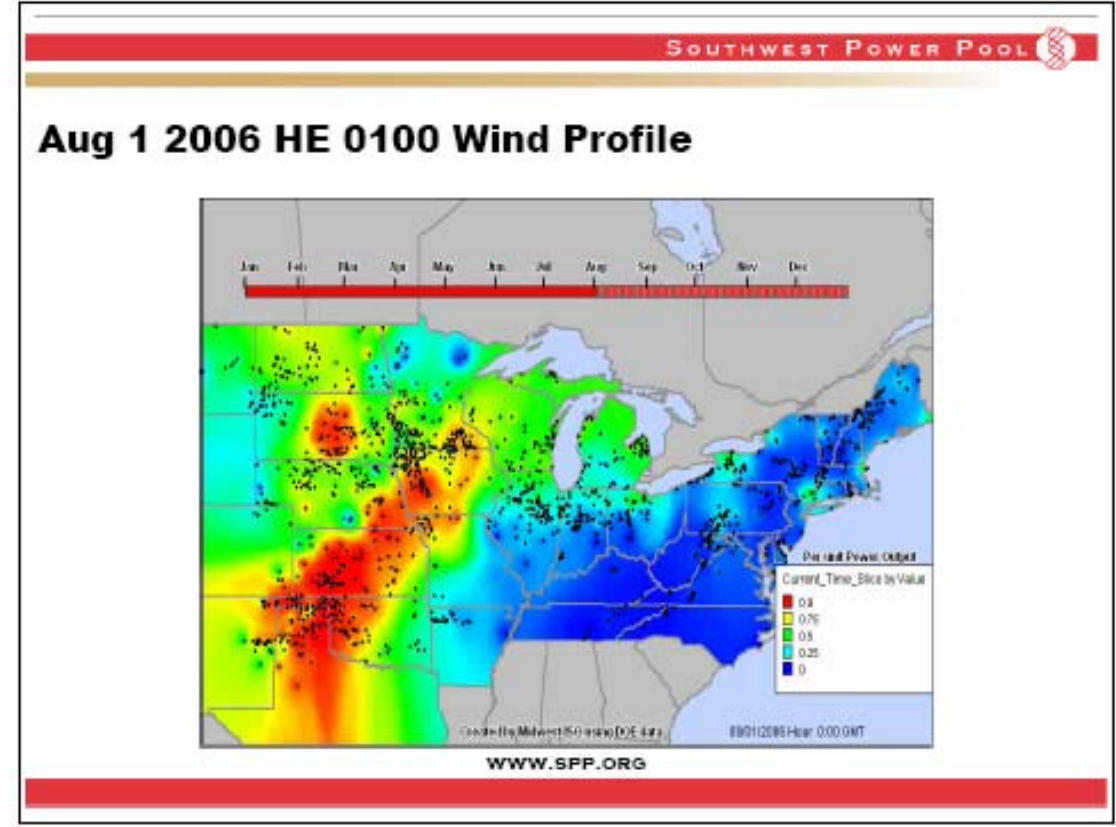

\section{SOUTHWEST POWER POOL \&}

\section{SPS Wind Penetration Study}

>Concern that Southwestern Public Service (SPS) system was likely at immediate reliability risk

> Many wind providers see SPS system a prime opportunity because of combination of high wind, load and existing network, despite IImited Interface capablilty.

$>$ Many behind the meter distribution turbines not studied.

$>$ "Qualifying Facilities"

$>$ EIS Market

$>$ AMEC contracted to assess expected operating conditions in upcoming spring seasons. 


\section{Wind Data}

NREL/DOE 2004-2006 wind data for every 2 square kilometers every 10 minutes at 80 and $100 \mathrm{~m}$ heights Diversity exists, but expected range is 0 to $100 \%$ of nameplate capacity for wind farms within SPS

\section{$>$ Ramps are noteworthy}

> Maximum 10 minute change ranges from $+26 \%$ to $-23 \%$

> Maximum hourly change ranges from $+57 \%$ to $-52 \%$

Energy output in spring is impressive. Capacity factors of aggregate wind farms range from $49.0 \%$ in 2004 to $58.2 \%$ in 2006

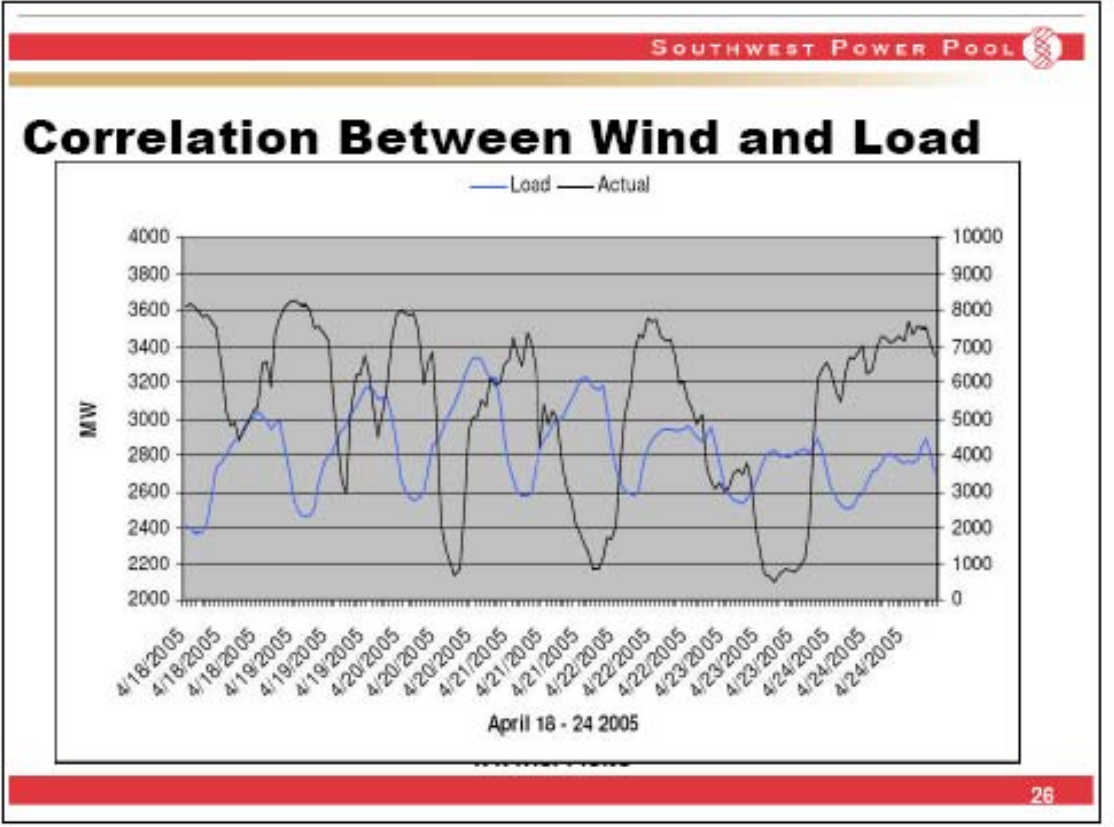




\begin{tabular}{l}
\hline Operating Margins \\
> Results are sensitive to many factors, most of \\
which are related to unit characteristics and \\
temporal constraints. Limits to wind penetration \\
include: \\
$>$ Unit Ramp Rates \\
$>$ Must Run Requirements \\
$>$ Interchange Performance \\
$>$ Margin Requirements \\
$>$ Unit On-Off Cycle Times \\
\end{tabular}

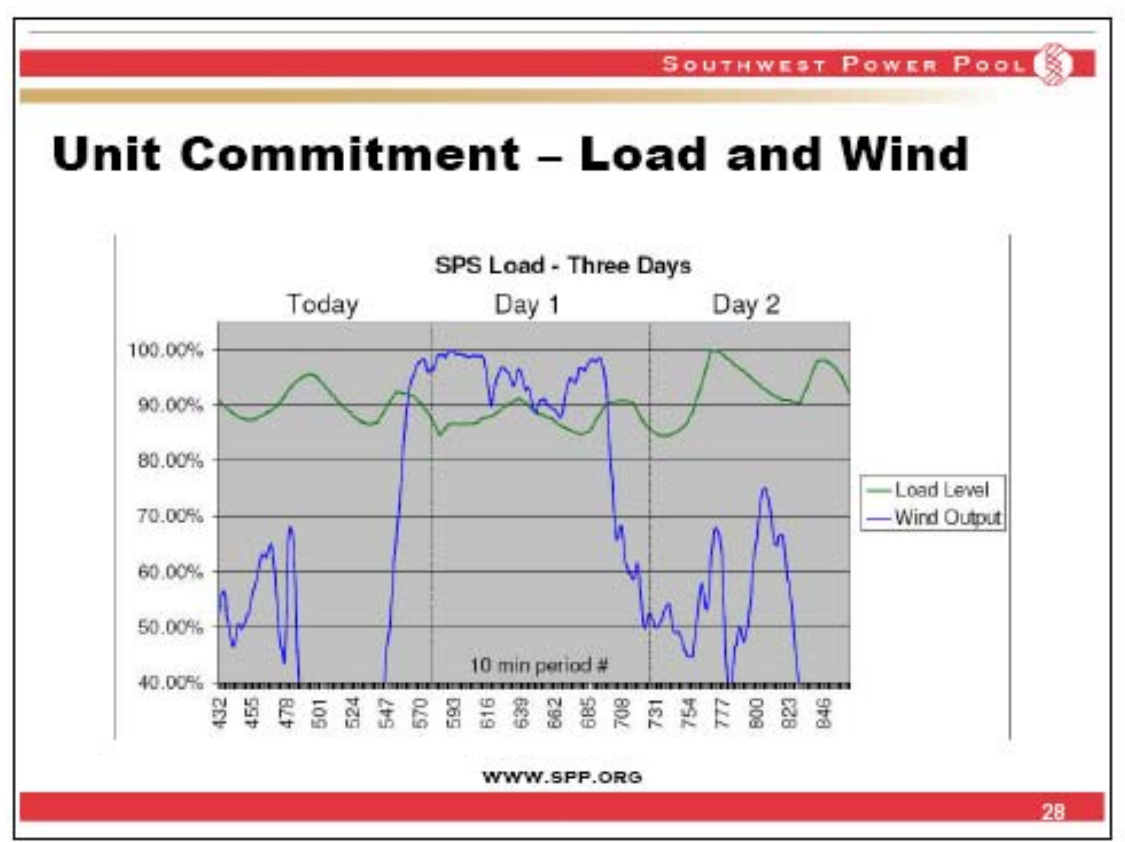



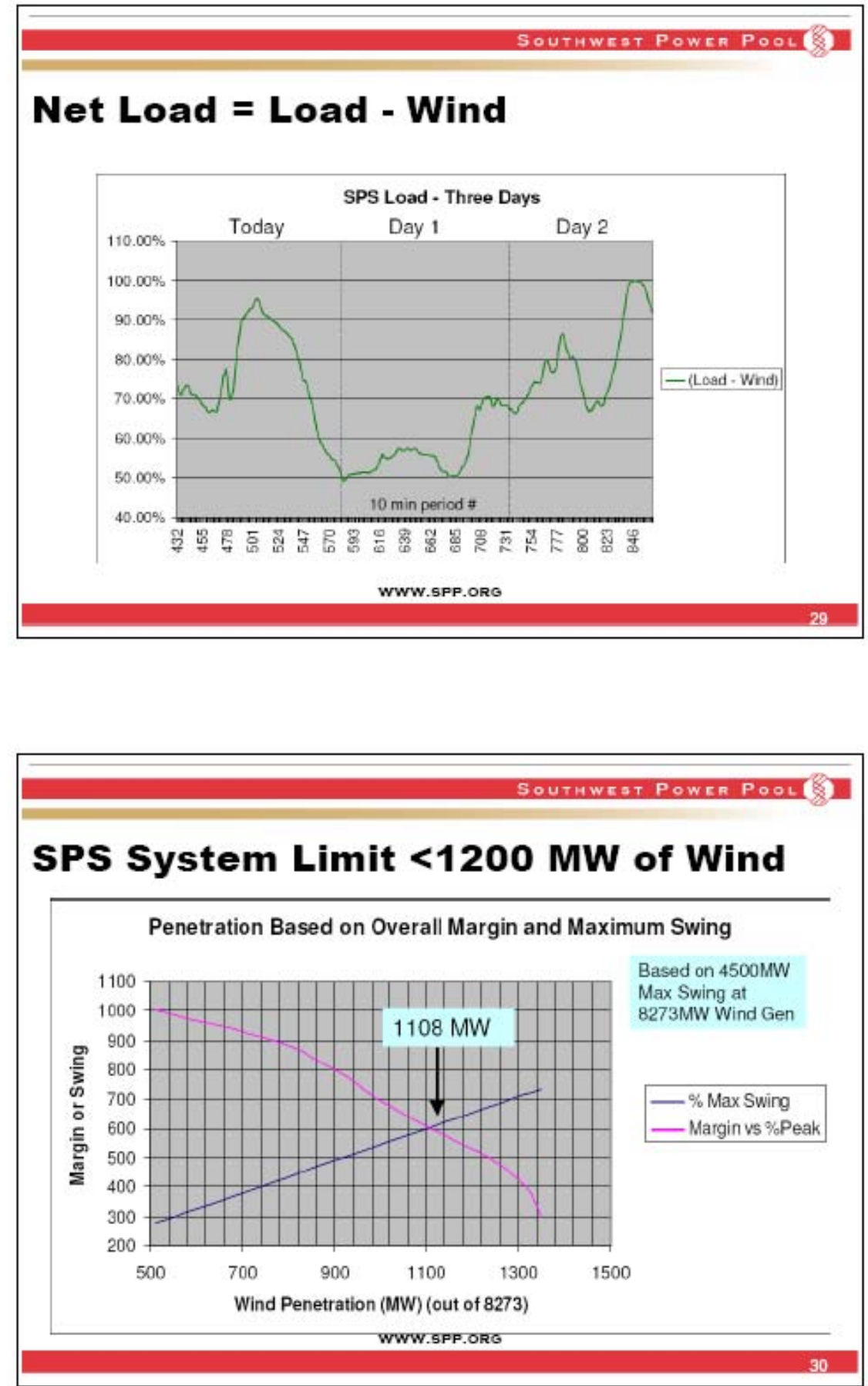


\section{SPS Wind Next Steps}

SPS has almost $900 \mathrm{MW}$ of wind interconnected to their system today with another 2,000 MW with signed Interconnection Agreements. Wind curtailments have occurred and can be expected to increase in the future. New operating procedures and changes to tariff / interconnection agreements may be required.

SPP is working with SPS who is the Balancing Authority to determine next steps and create an Action Plan and Curtailment Policy

$>$ Potential of further studies to refine analyses

$>$ Share results and next steps with stakeholders

WWW.SPP.ORG

\section{Generation Interconnection in SPP}

$>$ Current Status (as of April 1, 2009*)

278 Active $^{* *}$ Requests totaling $61,128 \mathrm{MW}$

$>228$ are for Wind totaling 50,868 MW

$>50$ are for Fossil or Other totaling 10,260 MW

*Includes Nebraska utilities

${ }^{*}$ Active Requests do not include requests with an IA that have not yet been built (suspension or construction pending ) 

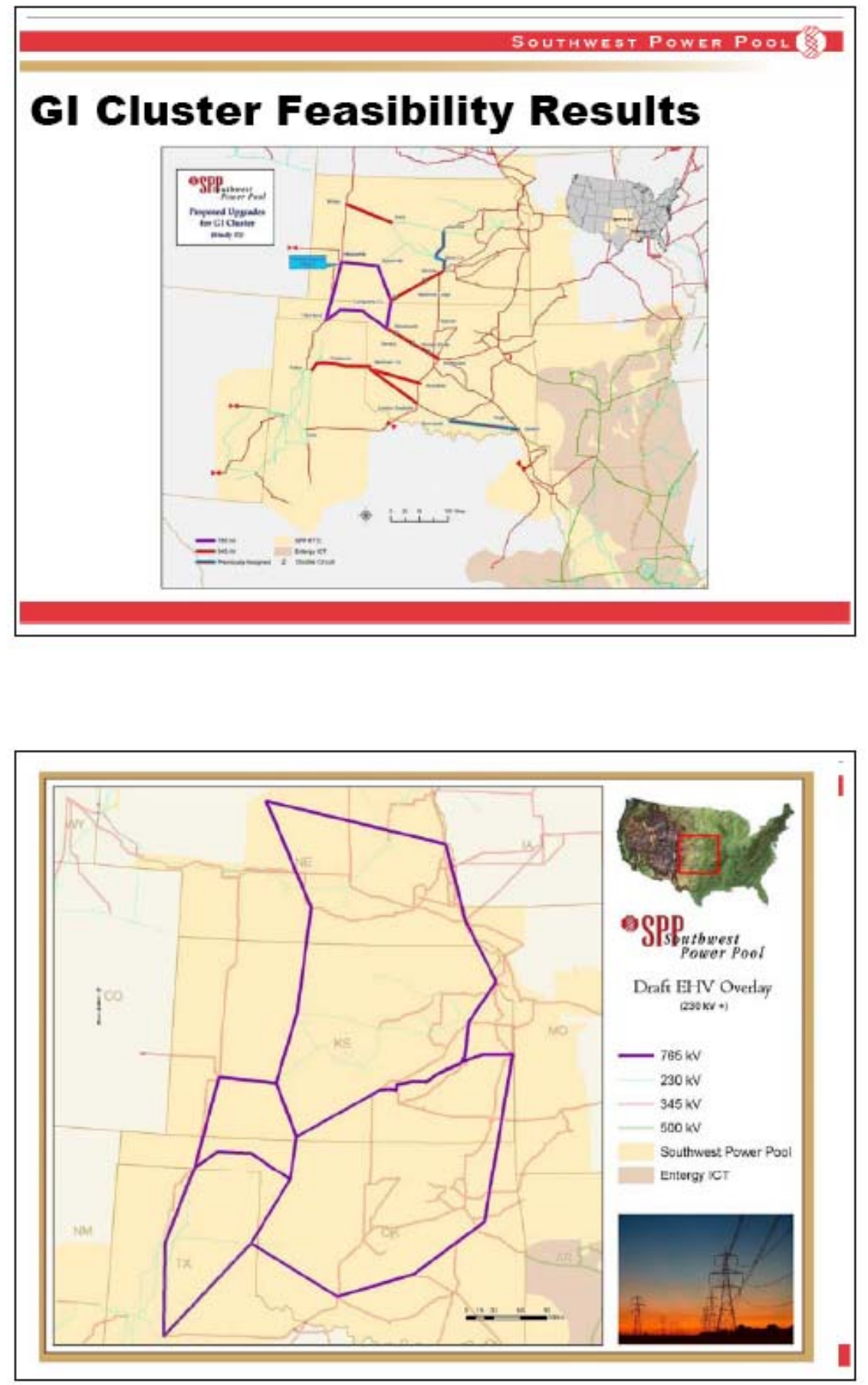


\begin{tabular}{l}
\hline What's a National RES mean to SPP? \\
-Eastern Wind Integration and Transmission Study \\
(EWITS) sponsored by DOE/NREL is refining Joint \\
Coordinated System Plan 2008 (JCSP'08) models to \\
investigate transmission needs and operational \\
impacts for a $3-20 \%$ and a single $30 \%$ National RES \\
scenario. \\
- Latest projections show $60-95 \mathrm{GW}$ of incremental \\
wind development in SPP with up to 25 GW in \\
Nebraska. Transmission expansion limited to 765 \\
kV AC and 800 kV HVDC. \\
> Current OATT, Markets, Criteria, and JOAs may \\
work for 15 GW of wind in SPP. How to handle next \\
$45-80$ GW of wind in SPP to support exports? \\
www.spr.oro
\end{tabular}

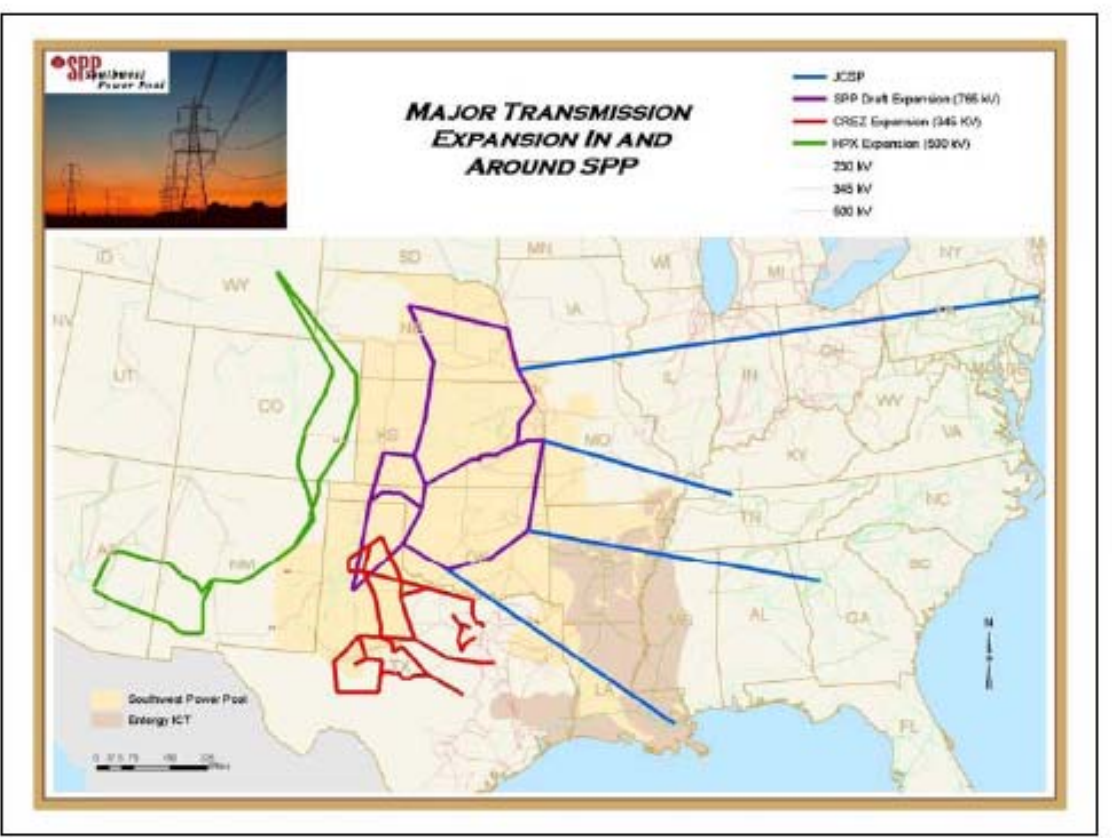




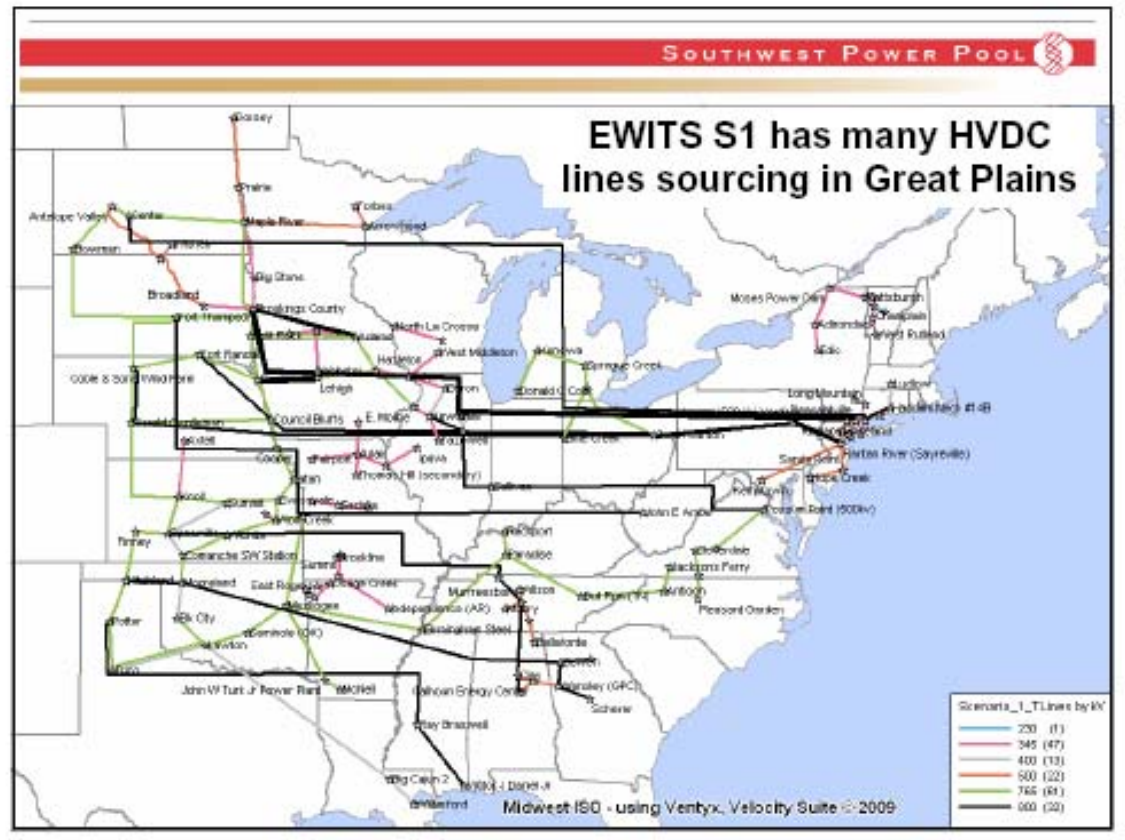

SOUTHWEST POWER POOL

\section{Next Steps}

>Integrated Transmission Plan (ITP) will define SPP long range needs with 20 year models and focus on 40 year economics to demonstrate robustness and flexibility for any future

$>$ Incorporate latest approved plans including Balanced Portfolio of economic upgrades with postage stamp cost recovery which was approved by FERC in October 2008

$>$ Support interconnection-wide and national grid planning needs and coordinate with efforts in ERCOT and WECC

$>$ Finalize EHV Cost Allocation targeted end 2009 


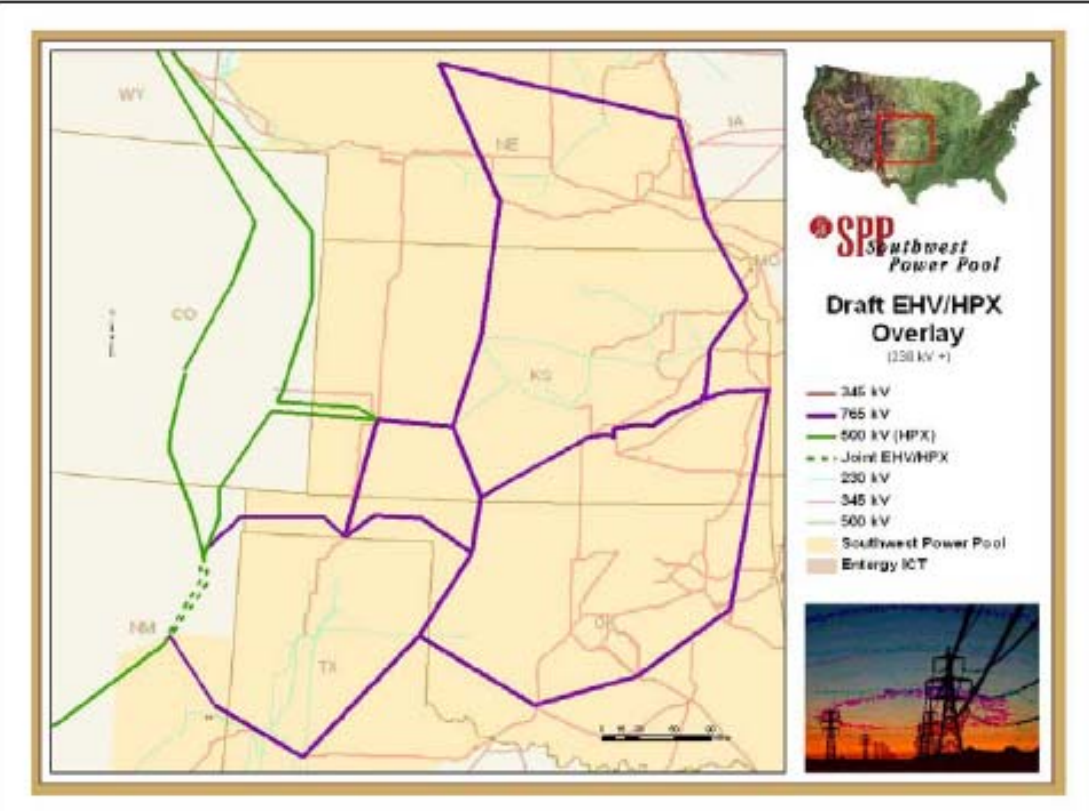

\section{Cost Allocations Are Key}

$>$ Cost allocations can be a barrier to effective transmission expansion planning, but need not be. Witness EHV expansion by South Central Electric Companies in the 1960s.

$>\quad$ FERC Order 890 is forcing industry to address this topic

Power industry can not afford to undervalue transmission anymore. 

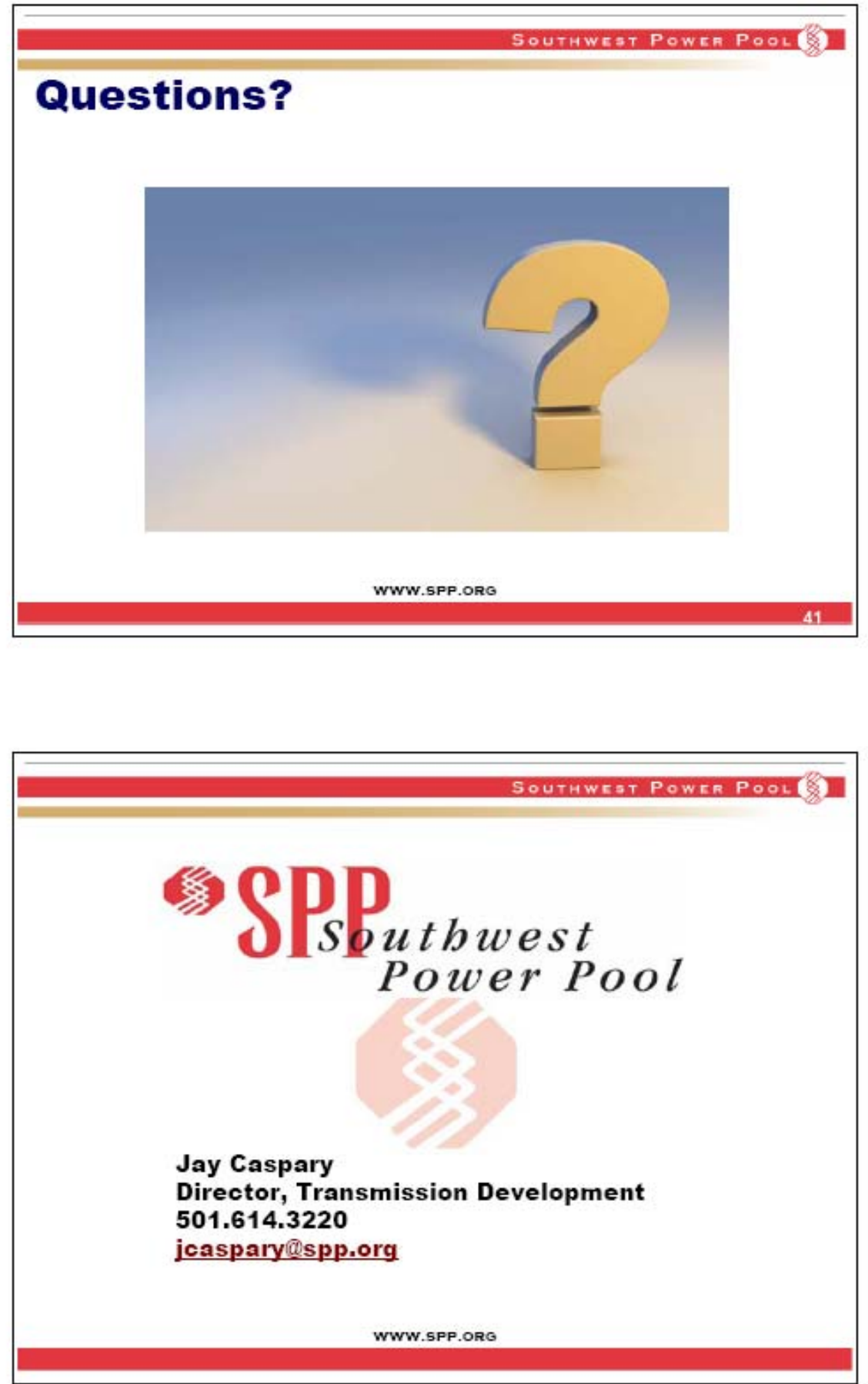


\section{B.5 Workshop Presentations - Entergy}
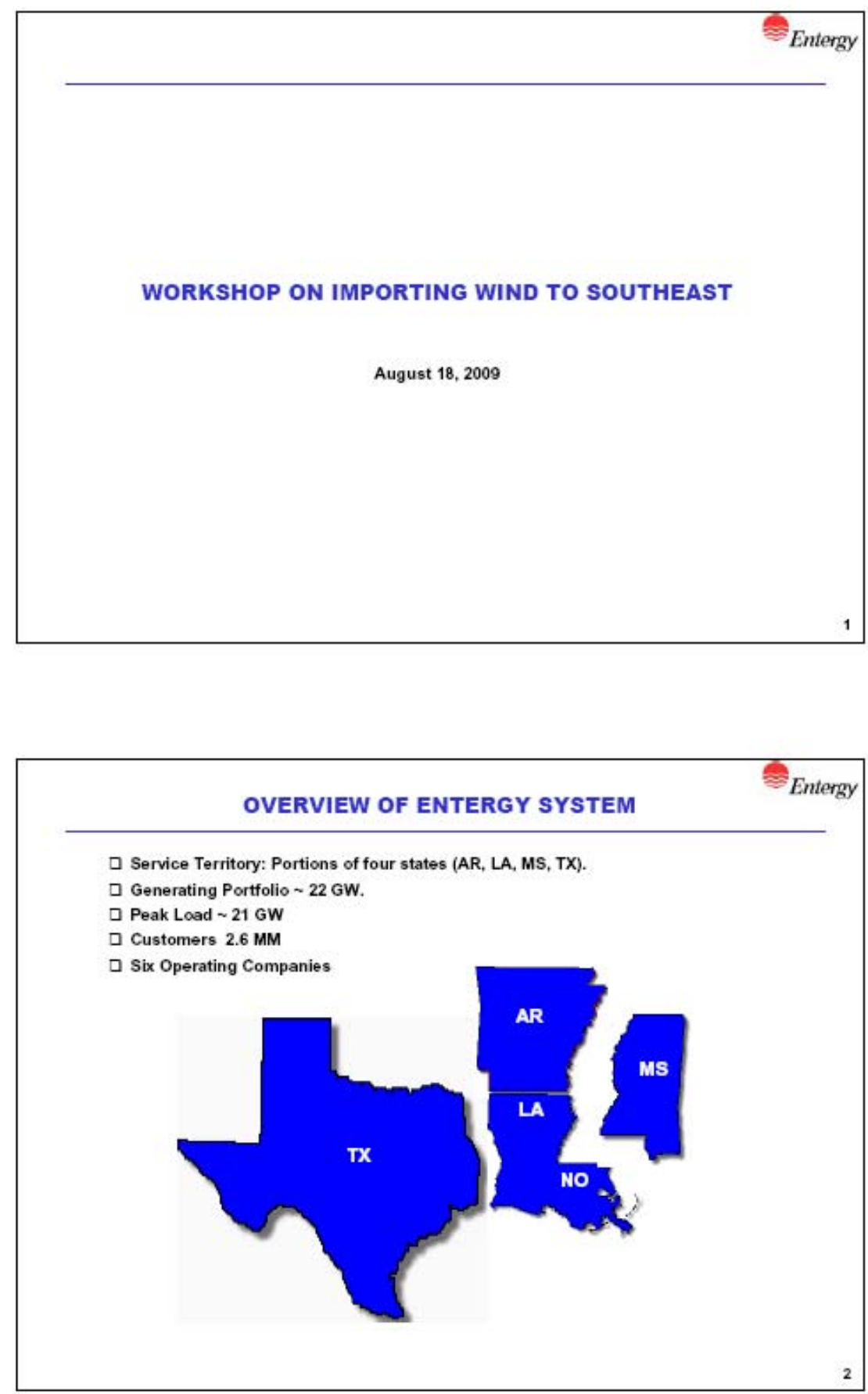

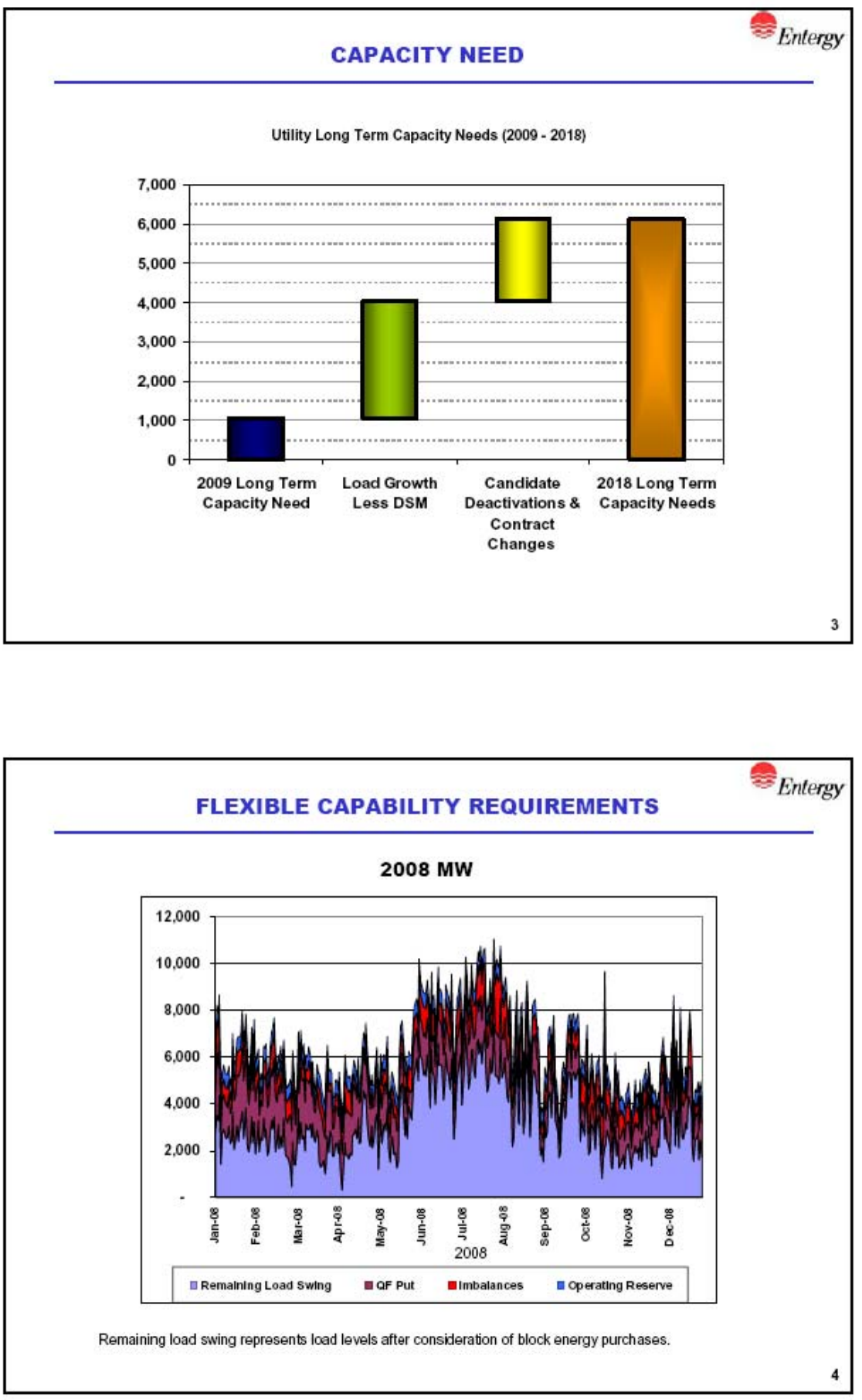

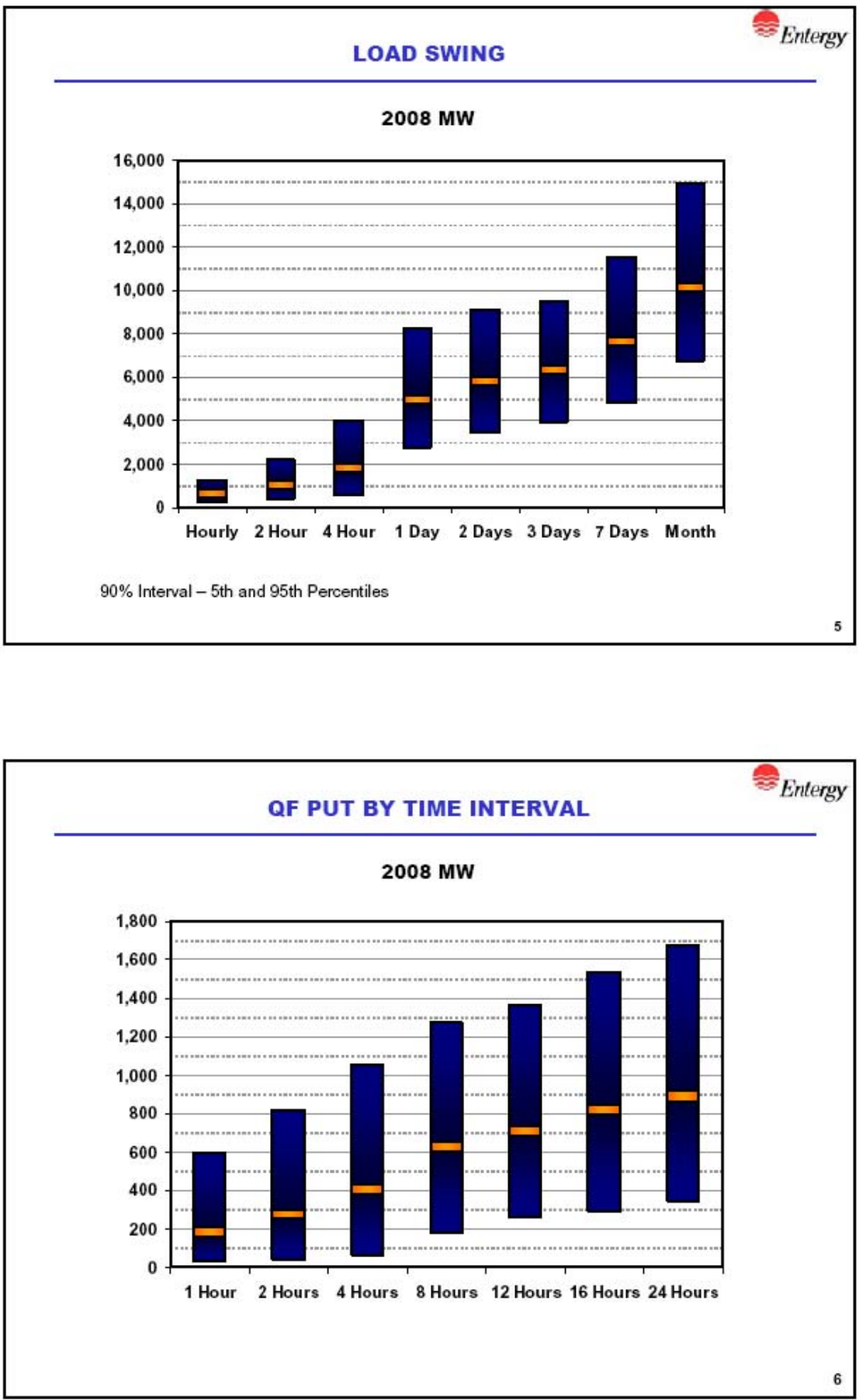


\section{B.6 Workshop Presentations - Southern}
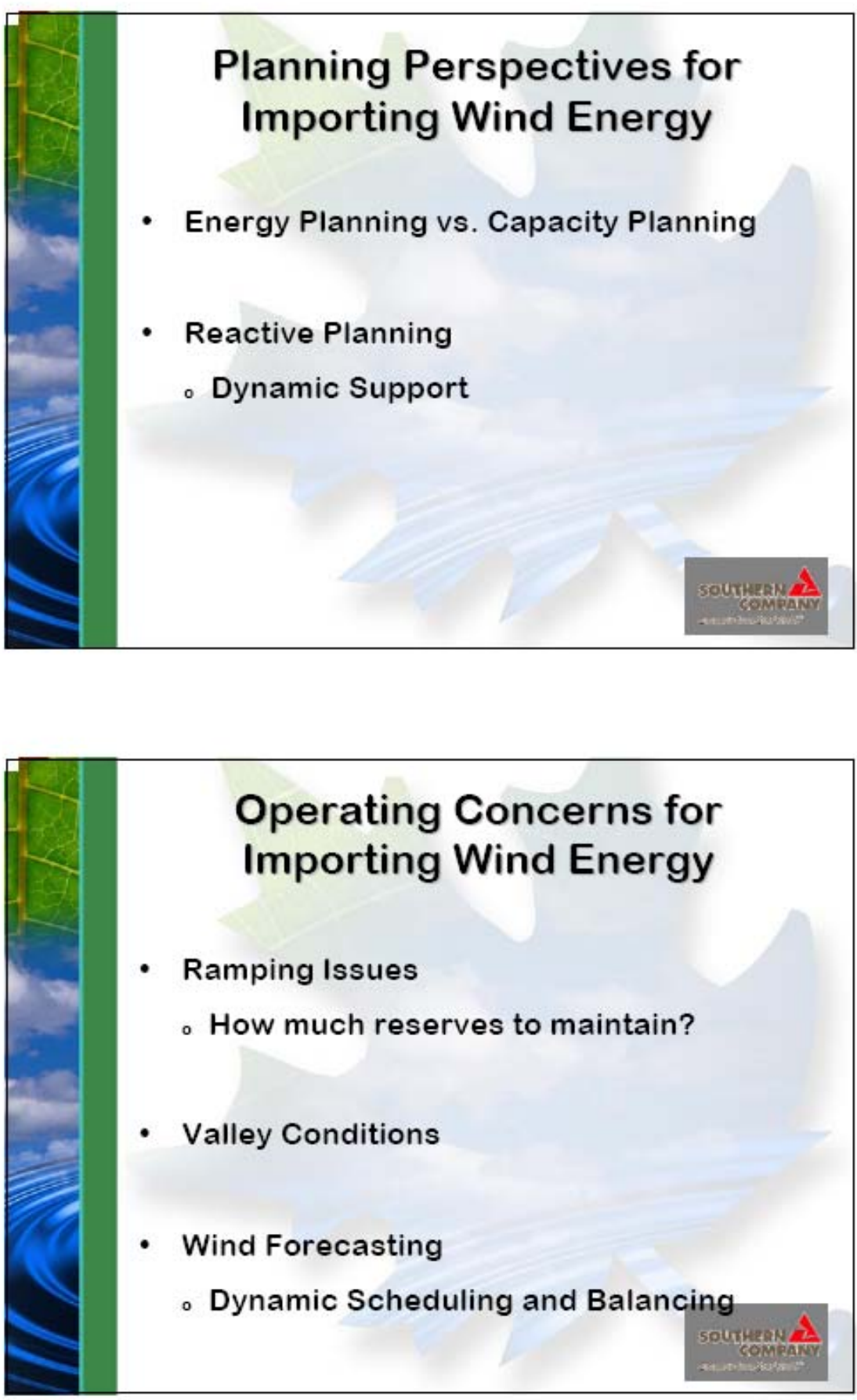


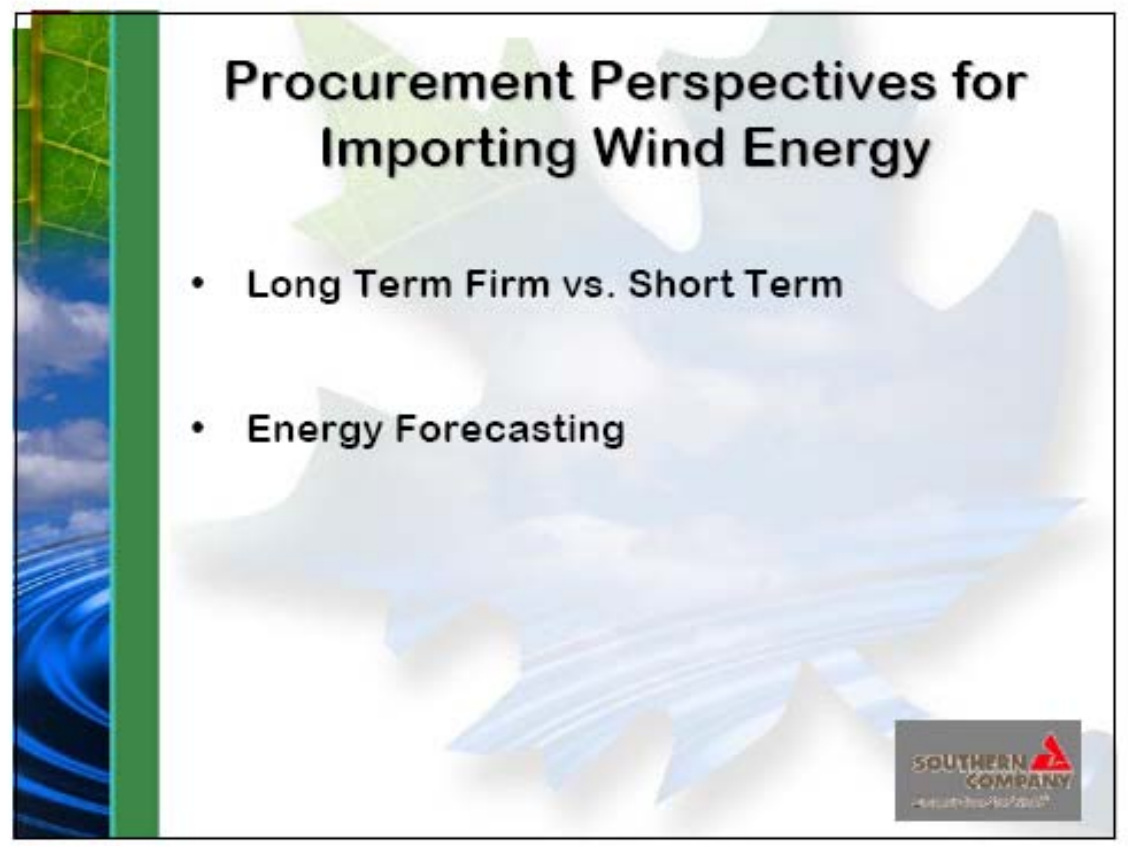




\title{
B.7 Workshop Presentations - TVA
}

\author{
Tennessee Valley Authority \\ Presented at: Workshop on Importing Wind to Southeast \\ ORNL, Oak Ridge, TN \\ August 18, 2009
}

- RFP for Renewable Energy

- TVA issued an RFP for renewable energy in December, 2008.

- Progressive targeted levels were up to 2000 MW by June, 2011.

- More than $7000 \mathrm{MW}$ of nameplate capacity was submitted.

- In April, 2009, the TVA Board gave advance approval to enter into long term contracts for up to $2000 \mathrm{MW}$.

- Up until Renewable Energy Credits are required, all contracts must be competitive with forecasted market power

- Several deals are in active negotiation

- All of the offered wind resources were outside of the Valley

Tennessee Valley Authority

Presented at: Workshop on Importing Wind to Southeast

ORNL, Oak Ridge, TN

August 18, 2009

Future Vision (CPPP Meeting, July 28, 2009)

Pole Star 70 GW 500 kV Plan

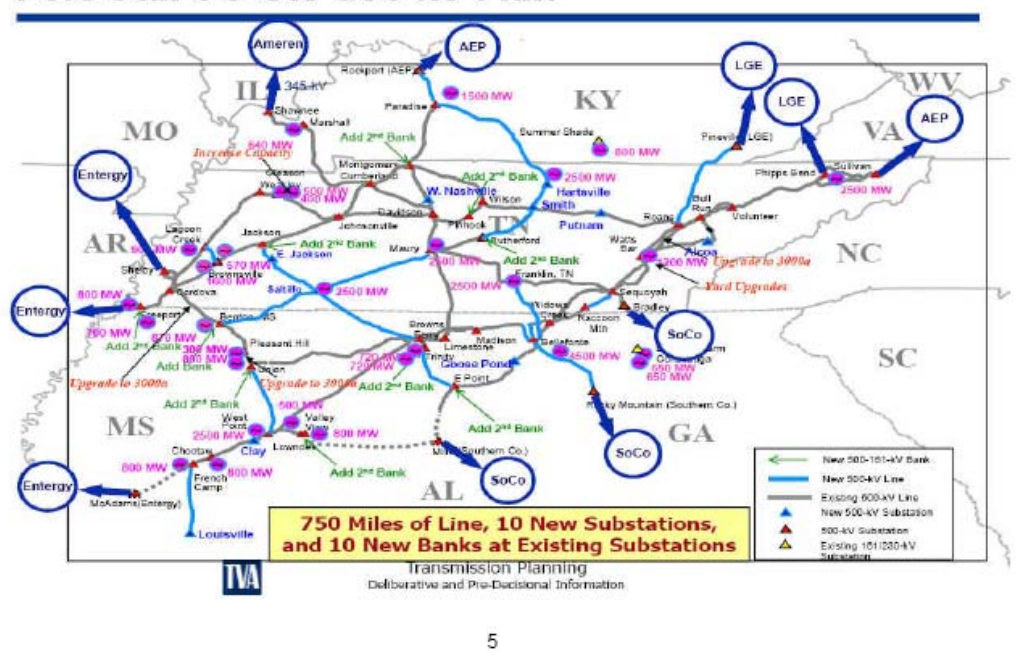




\section{B.8 Workshop Presentations - Duke}

EPRI/Oak Ridge National Lab 8/18/09 Workshop on Importing Wind to Southeast--Duke Energy Carolinas Perspective

- Duke Energy Carolinas serves 2.4 million retail customers in NC and SC

- Renewable Portfolio Standard (RPS)

- Currently have RPS in NC

- Do not currently have RPS in SC

- Federal Legislation/Policy is a potential driver

- Amount and timing of wind needs based on:

- Availability of other renewable resources such as waste-wood burning facilities

- RPS actions by state/federal government

- Wind- local vs. remote:

- Local- NC mountain tops vs. Coastline

- Remote- Midwest, etc.

- Transmission Studies done to date:

- NC Transmission Planning Collaborative -2008

- SIRPP- 2008/2009 


\section{Appendix C Alternative means to meet RPS goal in SE}

Renewable energy resources are very location specific and the most economical deployment, particularly for wind energy, is generally not near population centers. This is illustrated in Figure 24 showing wind resources in blue and population centers in red and yellow. There is very little resource in the Southeast. If there were no transmission constraints in the eastern interconnect, the most economic deployment of wind would be in the Midwest with the energy transported to the east.

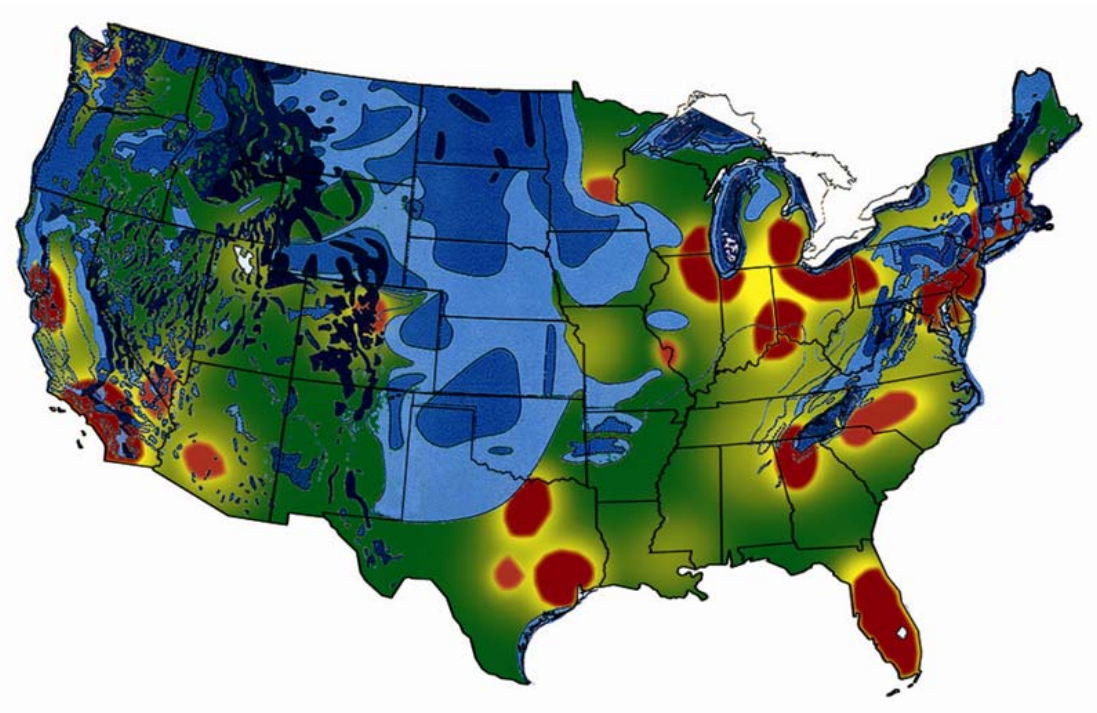

Figure 24. Wind Resources Relative to Population Centers.

Results in the JCSP and EWITS studies identify west to east transfers of wind energy that are primarily via upper Midwest to the eastern coast. Some energy transfer is expected to come from SPP to SERC Delta, and also via the Midwest to SERC Central. However, these transfers are relatively small compared to the available wind resources and compared to what would be needed to meet an RPS in the SERC and Florida regions.

\section{C.1 RPS expectation with regional balancing of supply/demand}

Federal policies, in particular related to $\mathrm{CO}_{2}$ and RPS, are expect to affect the regional cost of electricity based on models that assume the historical regional balancing of supply and demand. One policy scenario is the new Bingaman RPS requirement. In its current configuration the bill allow trading of renewable energy credits in order to meet RPS requirements. Therefore areas of the country with more abundant renewable resources are expected to over-produce in order to earn and sell credits to other areas.

Under this arrangement, utilities in the south would need to purchase RECs from other regions. For example based on EPRI's NESSIE model, with only an RPS policy (no carbon policy) the Southeast would requires 1017 TWh in 2020, and the electricity production from renewable resources would be $113 \mathrm{TWh}$, which is 91 TWh short of the 20\% RPS. External generation would provide the difference. In Florida the same EPRI model and scenario estimates that demand in 2020 is $282 \mathrm{TWh}$, and production from renewable resources is 9 TWh. With a $20 \%$ RPS goal of 56 TWh, internal production from renewable energy of 48 TWh is short of the goal. 
Applying the cap REC price of $3 \mathbb{\$} / \mathrm{kWh}$ (the ceiling in the Bingaman bill), there would be an estimated outflow of roughly \$2.7 Billion from SERC and \$1.4 Billion from Florida in 2020.

In order to better understand some of the different policy implications the EPRI NESSIE model was used to look first at the national picture and then for the Southeast and neighboring regions. Three policy cases were considered as summarized in Table 17.

Table 17. Three Possible Policy Scenarios, Source EPRI Report 1015805, March 2009 "Role of Future Generation Options for the U.S. Electric Sector"

\begin{tabular}{|l|c|c|c|c|}
\hline \multicolumn{1}{|c|}{ Future Scenario } & Name & PTC & RPS & $\mathbf{C O}_{\mathbf{2}}$ Price \\
\hline No new policy & BAU & Yes & No & No \\
\hline Federal RPS & RPS & Yes & Yes & No \\
\hline Federal carbon policy & CO2 & Yes & No & Moderate \\
\hline
\end{tabular}

- Load growth based on AEO 2008

- RPS policy assumptions based on the revised Bingaman Bill

- For carbon case, CO2 price in 2015 is approximately $\$ 27$ per ton

- Natural gas prices vary from $\$ 4.91$ to $\$ 7.28 / \mathrm{MMBtu}$

\section{C.1.1 National RPS Levels with Different Policies}

Results of modeling show that the economic deployment of renewable varies significantly depending on policies. The Figure 25, showing periods from 2010 to 2050, indicates that nationally a CO2 policy results in the highest deployment of renewable resources. It will also lead to a higher cost of electricity compared to the no policy or the RPS policy case.

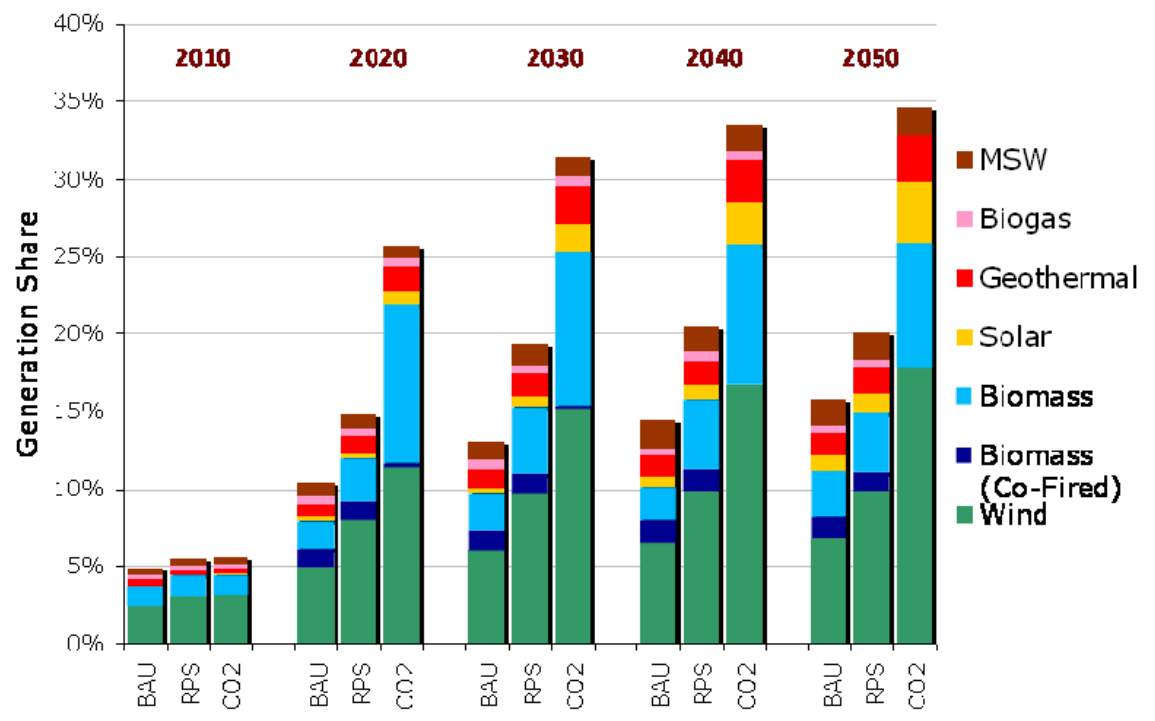

Figure 25. Renewable Share of Total Generation for Three Scenarios

A comparison of how national electricity demand would be met in the three different policy cases is provided in Figure 26. Note that the same demand is shown for each policy. A 
simplifying assumption was applied, where demand elasticity is not considered in the policy comparisons.

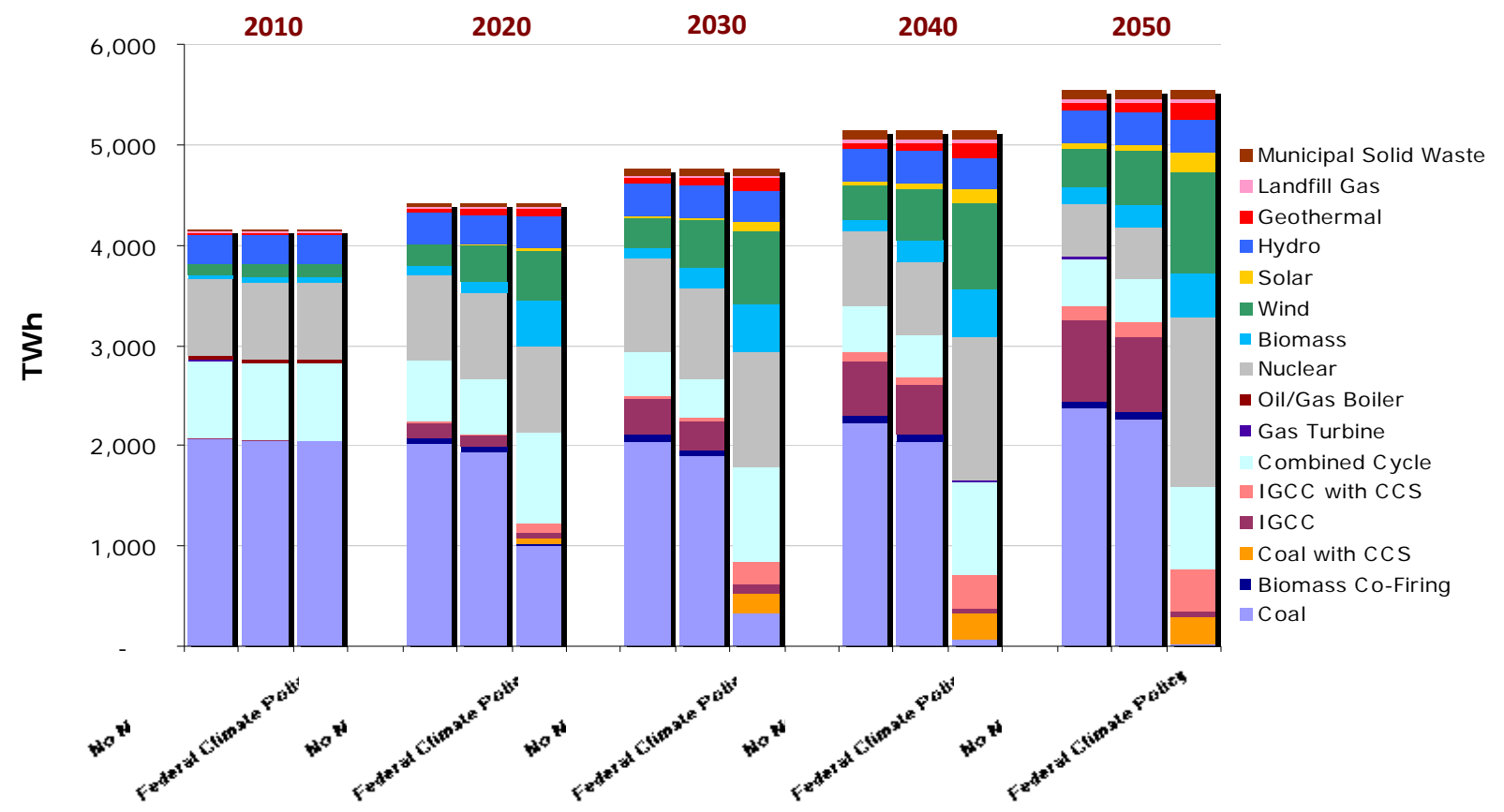

Figure 26. US Annual Electricity Generation under Different Scenarios (TWh)

NESSIE models the U.S. electric sector by carrying thirteen separate NERC regions. Nine of the 13 regions make up the Eastern interconnection. These regions are shown in Figure 27.
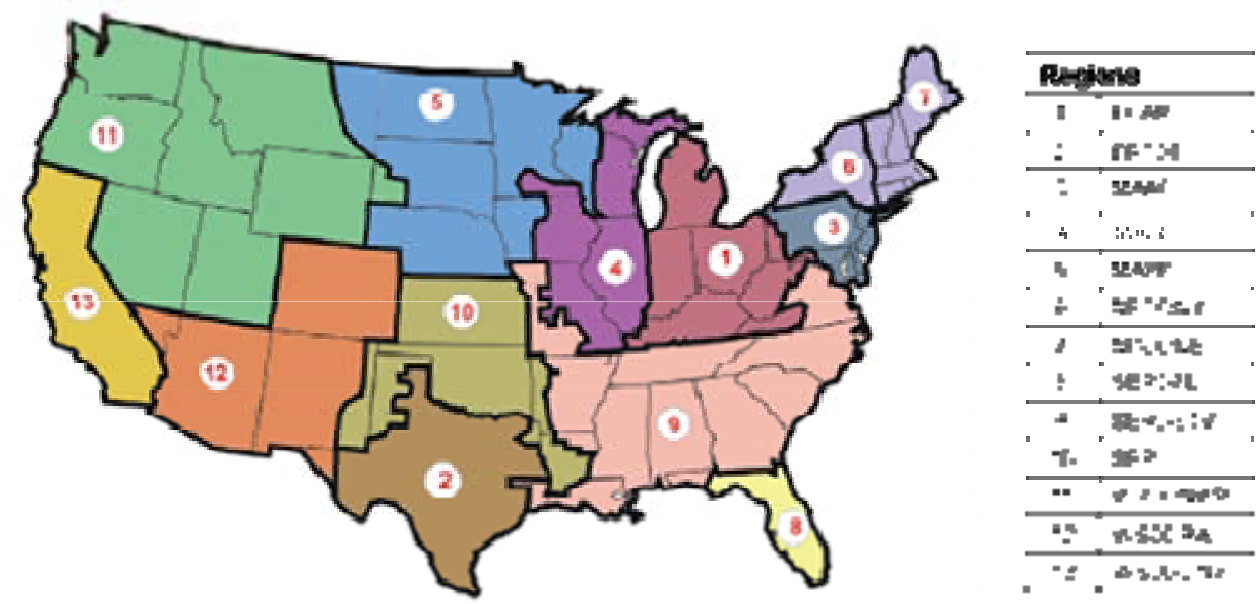

Figure 27. Thirteen NERC Regions used in NEMS and NESSIE Model.

\section{C.1.2 Eastern Interconnect and SE RPS Potential with different Polices}

Modeling future scenarios for a large electric system depends on many, often subtle, factors in addition to the scenario assumptions. Capacity expansion and system operation are sensitive to load patterns, existing capacity, and commodity prices for both fuels and emission allowances. These vary from region to region. 
In addition, renewable technologies depend on the extent and quality of wind, solar insolation, moving water suitable for hydro, and underground thermal. Also, the cost of delivered biomass fuel can vary. Differences in renewable resource availability represent an important factor for understanding the future LCOE that determines new capacity additions. In addition, the resource quality differences and the availability with respect to time of day (energy output profiles) help shape the production results for the regional systems. The deployment of renewable energy is expected to vary significantly from one region to another as shown in Figure 28. Also affecting the deployment is regional demand and competing generation options in a region.

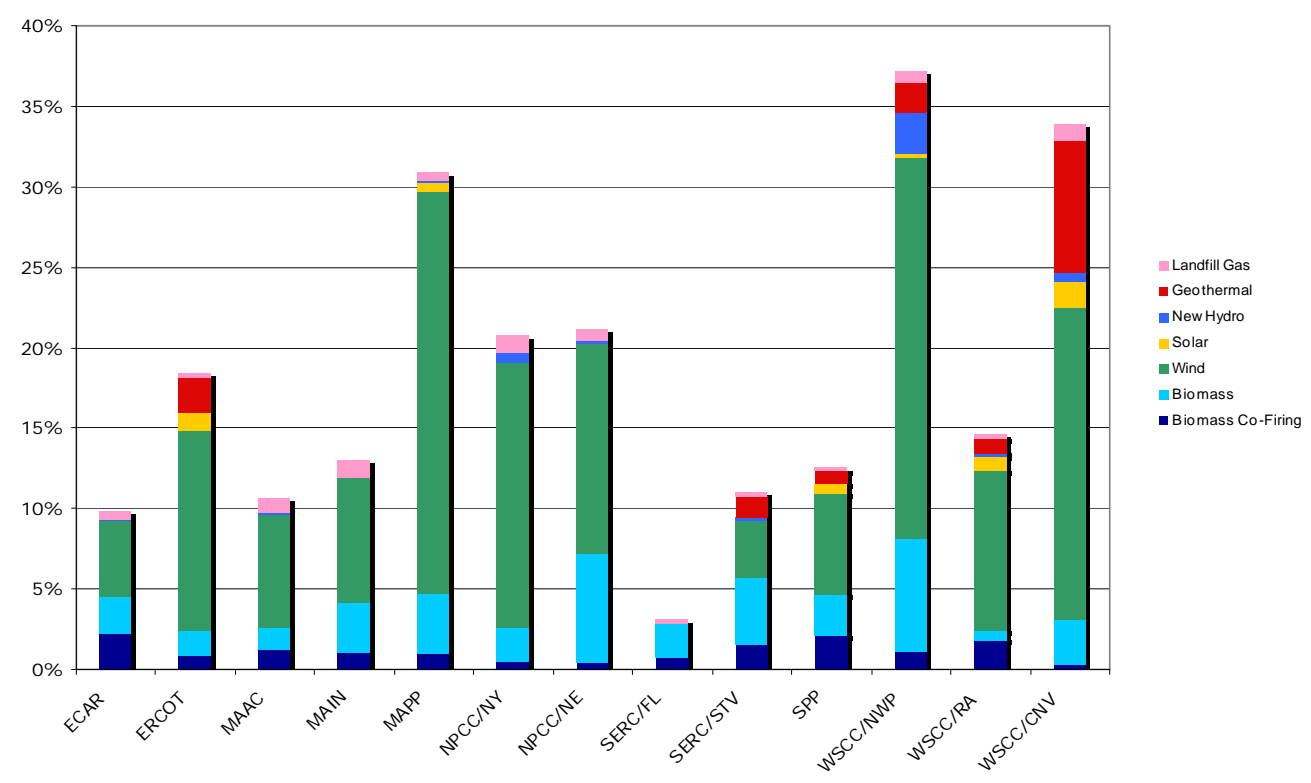

Figure 28. Regional Variation in Renewable Generation, RPS Policy Case (2020)

When considering where SERC/STV and Florida might import additional renewable energy the only apparent option in the RPS policy case shown above, is MAPP. However, most of the excess energy in MAPP and MAIN is spoken for by the east coast markets in MAAC, including PA, NJ, MD and Northern Virginia. There is abundant wind energy in SPP, however, other low cost generation options make wind investments less attractive. Also the relative size of electricity demand in the SE presents an additional challenge. As show in Figure 29 the SE plus Florida will consume about 1300 TWh in 2020, which is more than $30 \%$ of the total consumption in the US. 


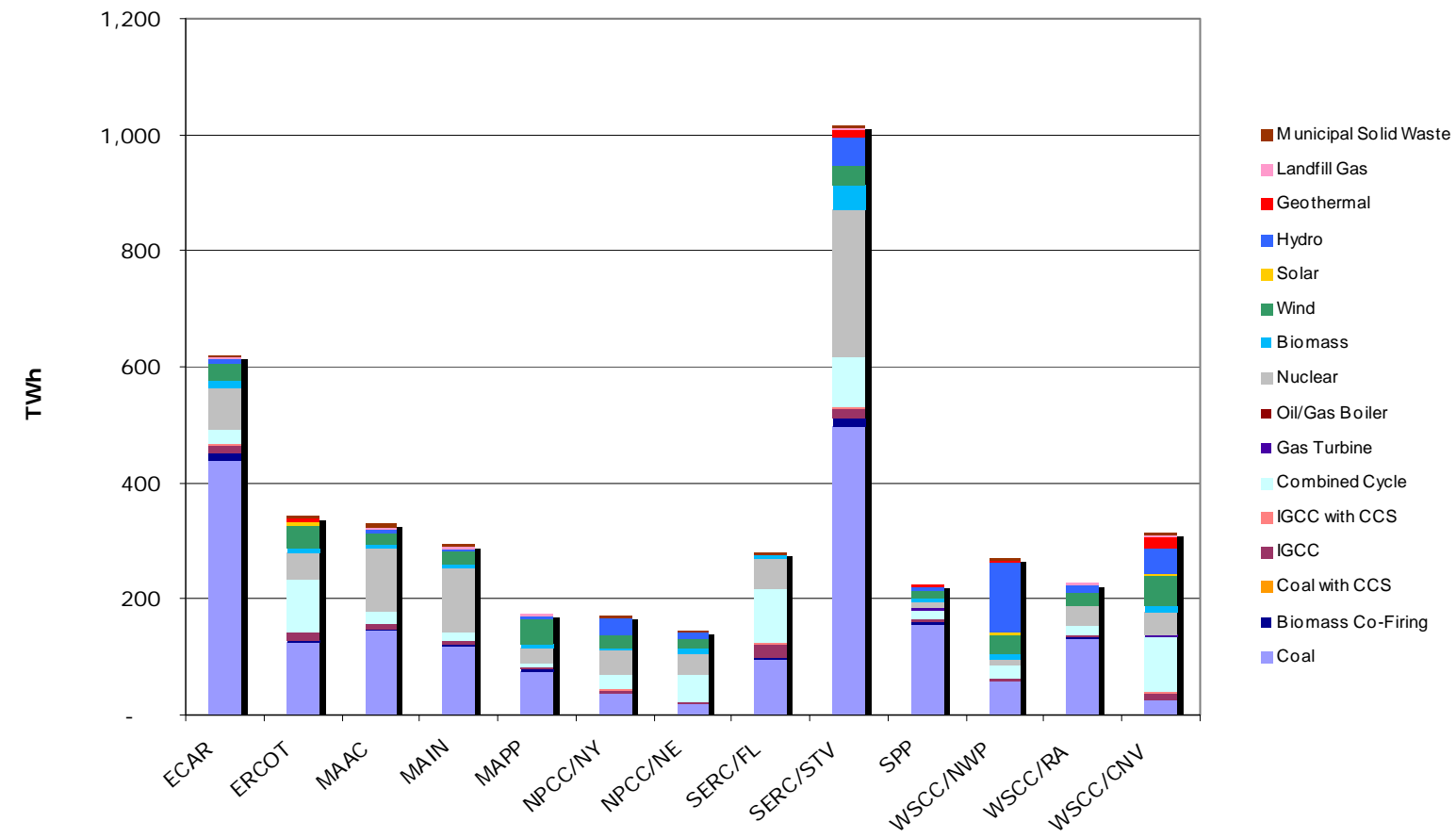

Figure 29. Regional Electricity Generation, RPS Policy Case 2020

The picture is expected to change significantly in all regions if there is a climate policy compared to the RPS case. For example in SPP almost three times more wind is deployed in the climate policy case than in the RPS case, see Figure 30.

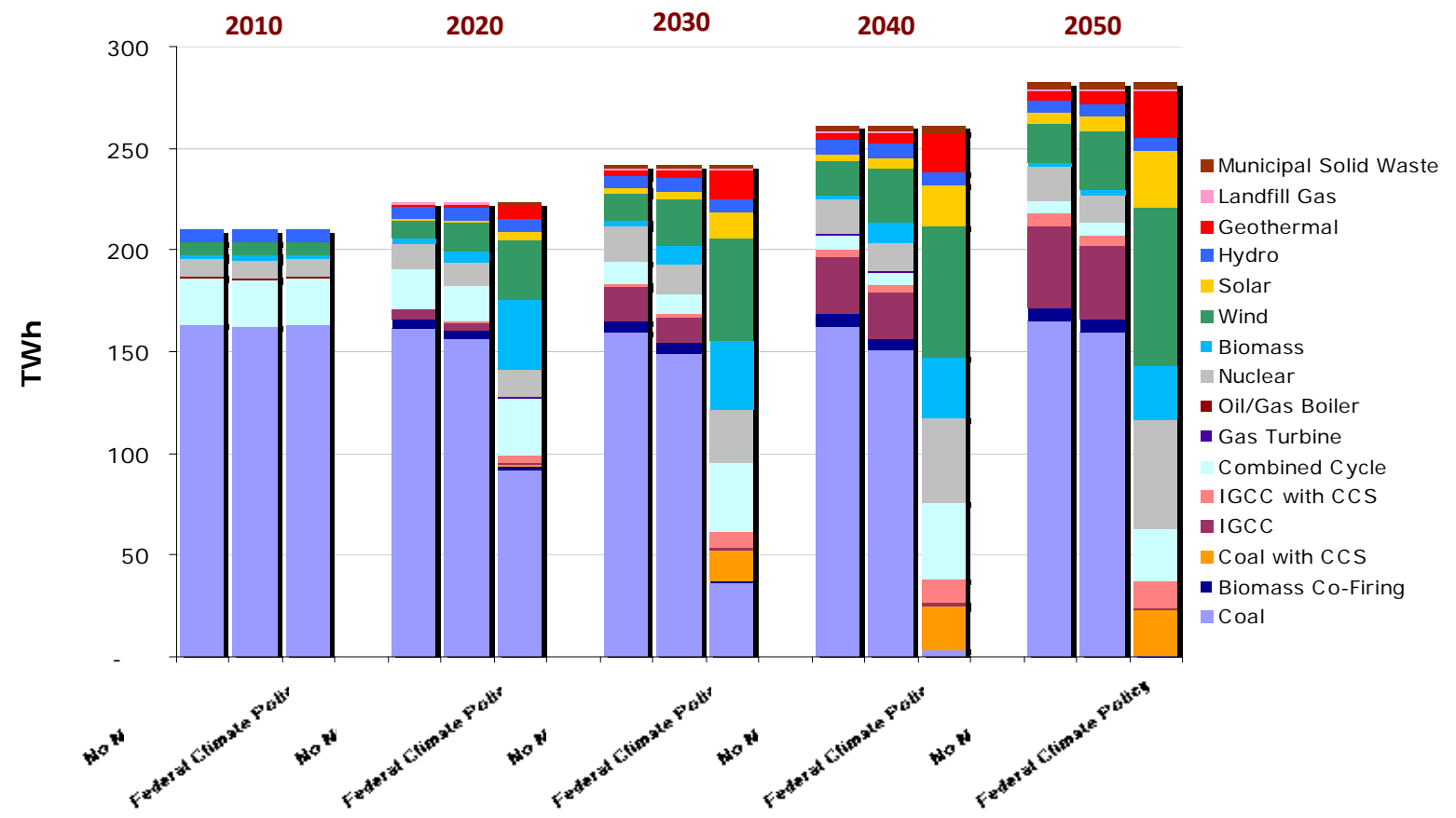

Figure 30. SPP Generation with No Policy, Federal RPS, and Federal Climate Policy 
The increase of wind generation capacity in SPP occurs without any expectation for export to other regions. Since SPP is only harvesting about $1 \%$ of the wind resources, it is apparent that building for export could make a big difference in capacity expansion and transfer of wind energy to the SE. There is also an expected change in the deployment of renewable energy in all regions of the Eastern Interconnection if a $\mathrm{CO}_{2}$ policy is enacted. Figure 31 shows the changes in generation in SERC and Figure 32 shows how the policy affects the cost of electricity in SPP, SERC/FL and SERC/STV.

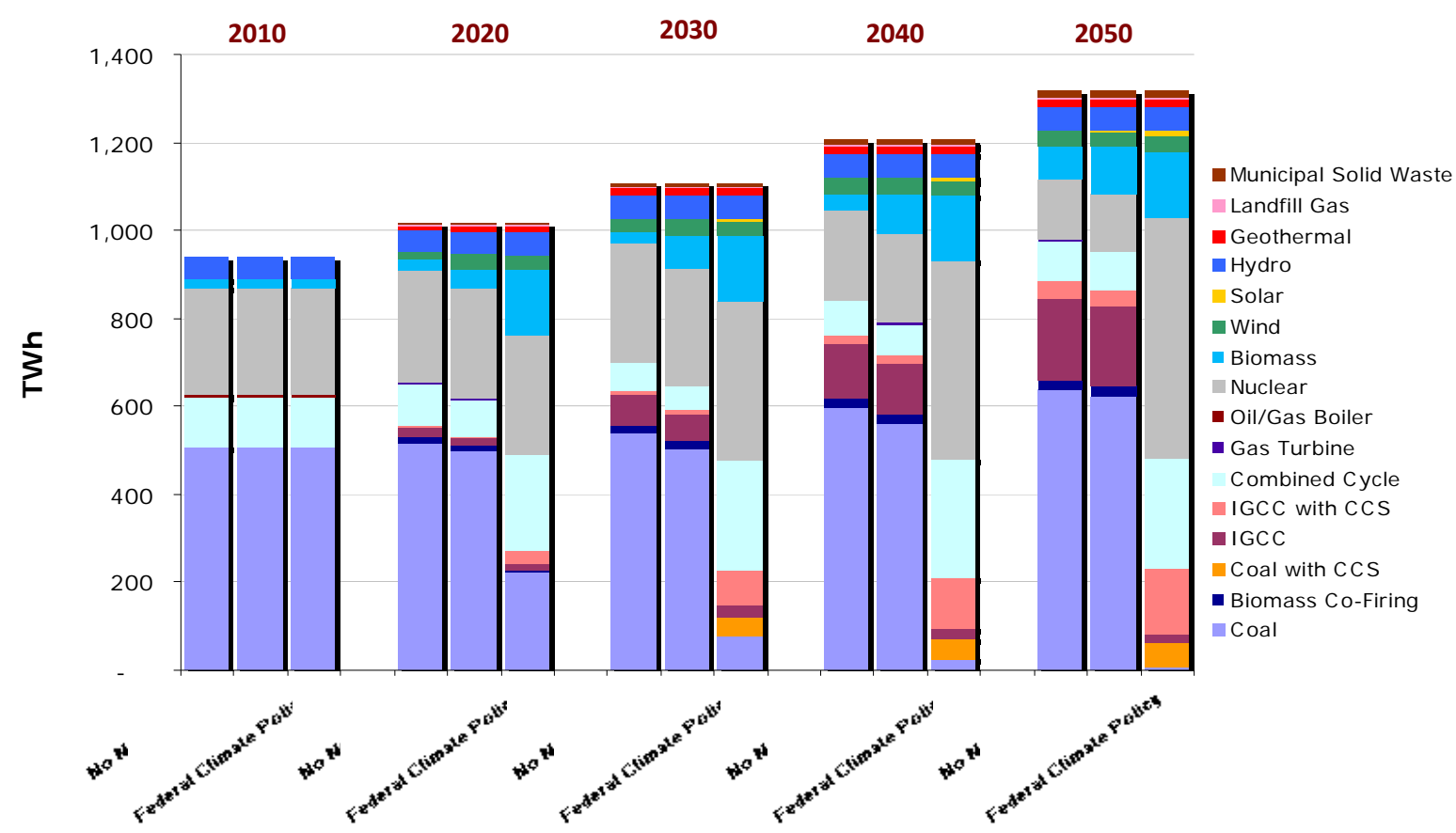

Figure 31 SERC Generation with No Policy, Federal RPS, and Federal Climate Policy

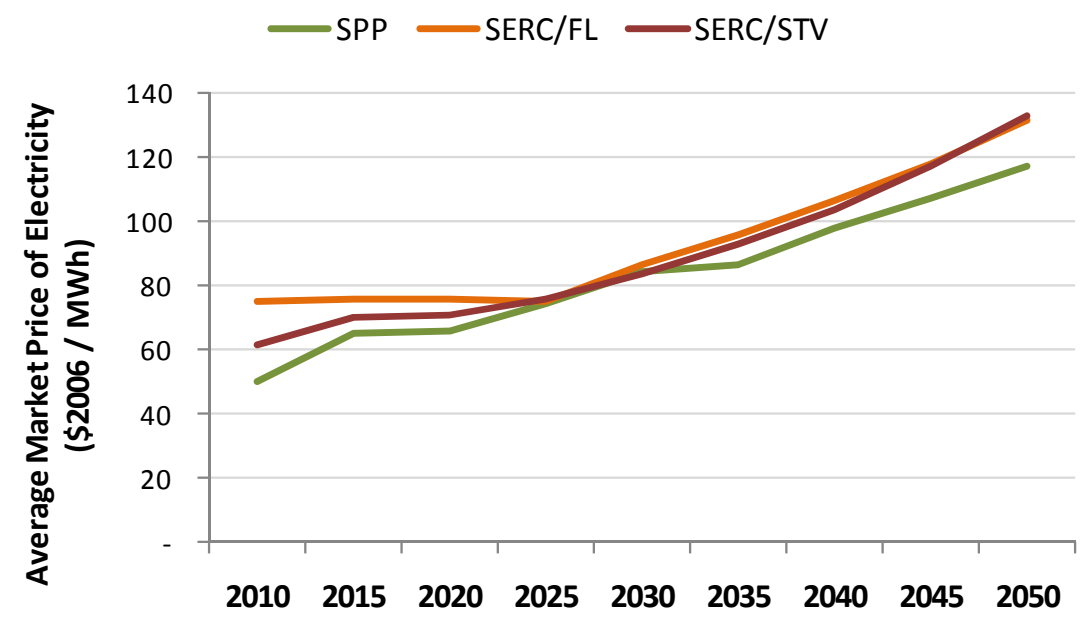

Figure 32. Comparison of Regional Cost of Electricity, $\mathrm{CO}_{2}$ Policy Case 
For the $\mathrm{CO}_{2}$ Policy Case market prices from 2010 to 2050 for three regions; the levelized prices for the three regions are \$69.58 per MWh in SPP, \$75.62 in SERC/STV, and \$81.97 in SERC/FL. These regional price differences are important for such metrics as customer satisfaction, asset values, and capacity retirements. As shown in the Figure lower prices in SPP early in the time horizon reflect good access to fuel markets and lower coal and natural gas prices; later, access to plentiful, high-quality renewable resources-especially wind, solar, and geothermal-provides an advantage as the $\mathrm{CO}_{2}$ price accounts for a larger fraction of the wholesale price. Over the long run, the SERC/STV and SERC/FL have similar price trajectories reflecting similar fuel costs and renewable resource bases. However, SERC/STV has a more economic mix in the early years, which leads to the lower levelized market price.

There are more significant impacts of $\mathrm{CO}_{2}$ policy in coal burning regions such as ECAR. In this case the cost of electricity in 2030 more than doubles from the no policy case, $\$ 40.50$ per MWh to $\$ 89.50$ per MWh with a moderate $\mathrm{CO}_{2}$ policy. The cost of the RPS, without $\mathrm{CO}_{2}$, policy is estimated to be $\$ 45.16 / \mathrm{MWh}$. Figure 33 show the significant change in the generation mix in ECAR depending on the policy.

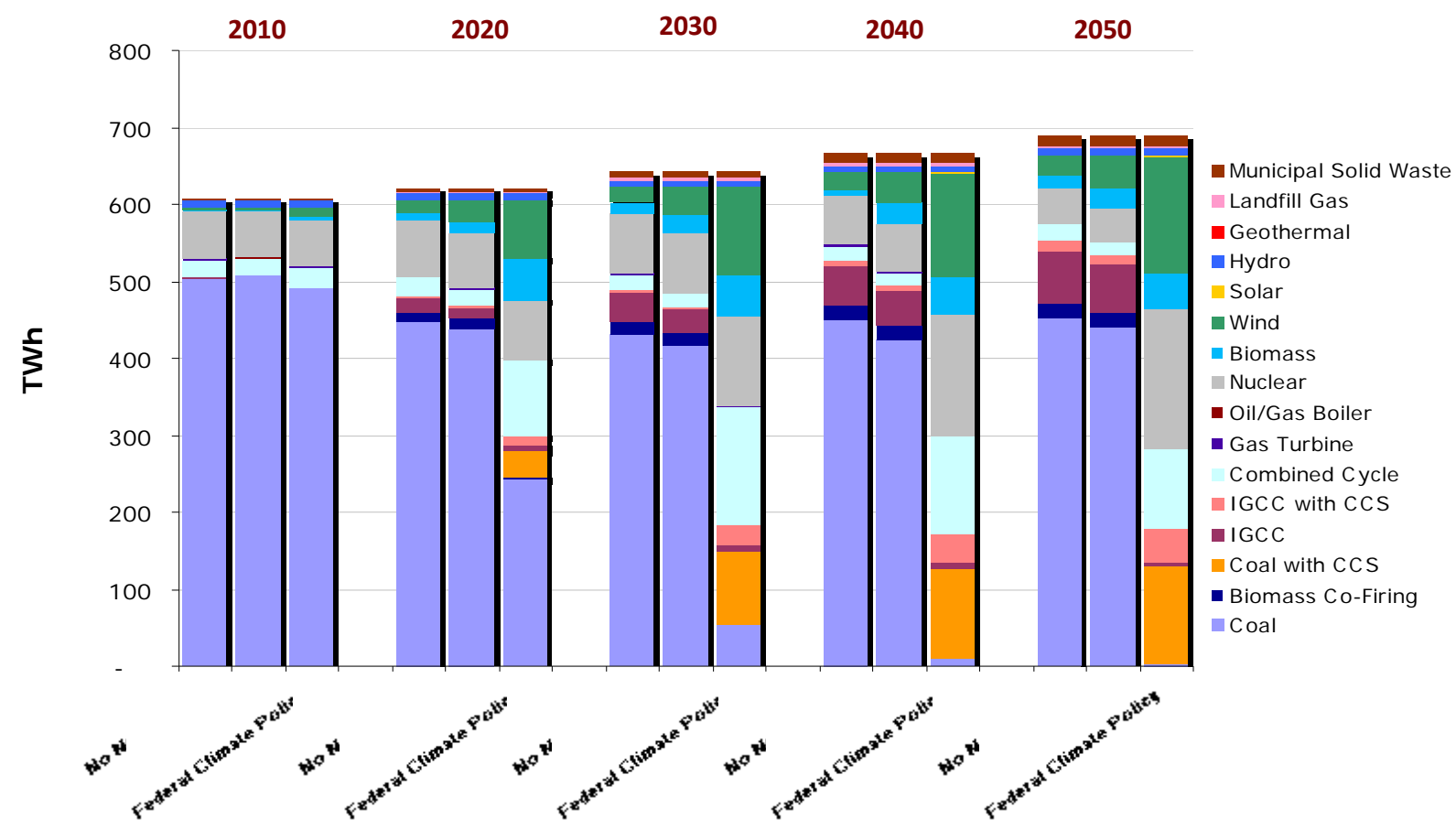

Figure 33 ECAR Generation with No Policy, Federal RPS, and Federal Climate Policy

\section{C.2 Other Studies}

There are several studies either completed or currently being carried out by other groups. Two of these are looking at the interconnection needs to meet large wind transfers in the eastern interconnections.

The Joint Coordinated System Plan (JCSP 2008) analysis is “a conceptual regional transmission and generation system plan for a large portion of the Eastern Interconnection in the United States, developed with the participation of most of the major transmission operators in the 
Eastern Interconnection. This initial effort looks at two scenarios that expand transmission and generation opportunities between 2008 and 2024 - a Reference Scenario and a 20\% Wind Energy Scenario in support of the U.S. Department of Energy's Eastern Wind Integration and Transmission Study."

The analysis was a collaborative project between the Midwest ISO, SPP, PJM, TVA, MAPP, and some other members of SERC. The New York ISO and ISO New England participated as well, but later rejected the results because they felt more of their power would come from Canada than across the Midwest. While power flows to the southeast were analyzed, details on the amounts to the different subregions and to Florida were not examined. Figure 34 below from their report highlights the conceptual additional transmission lines required to meet $20 \%$ of generation from wind by 2024.

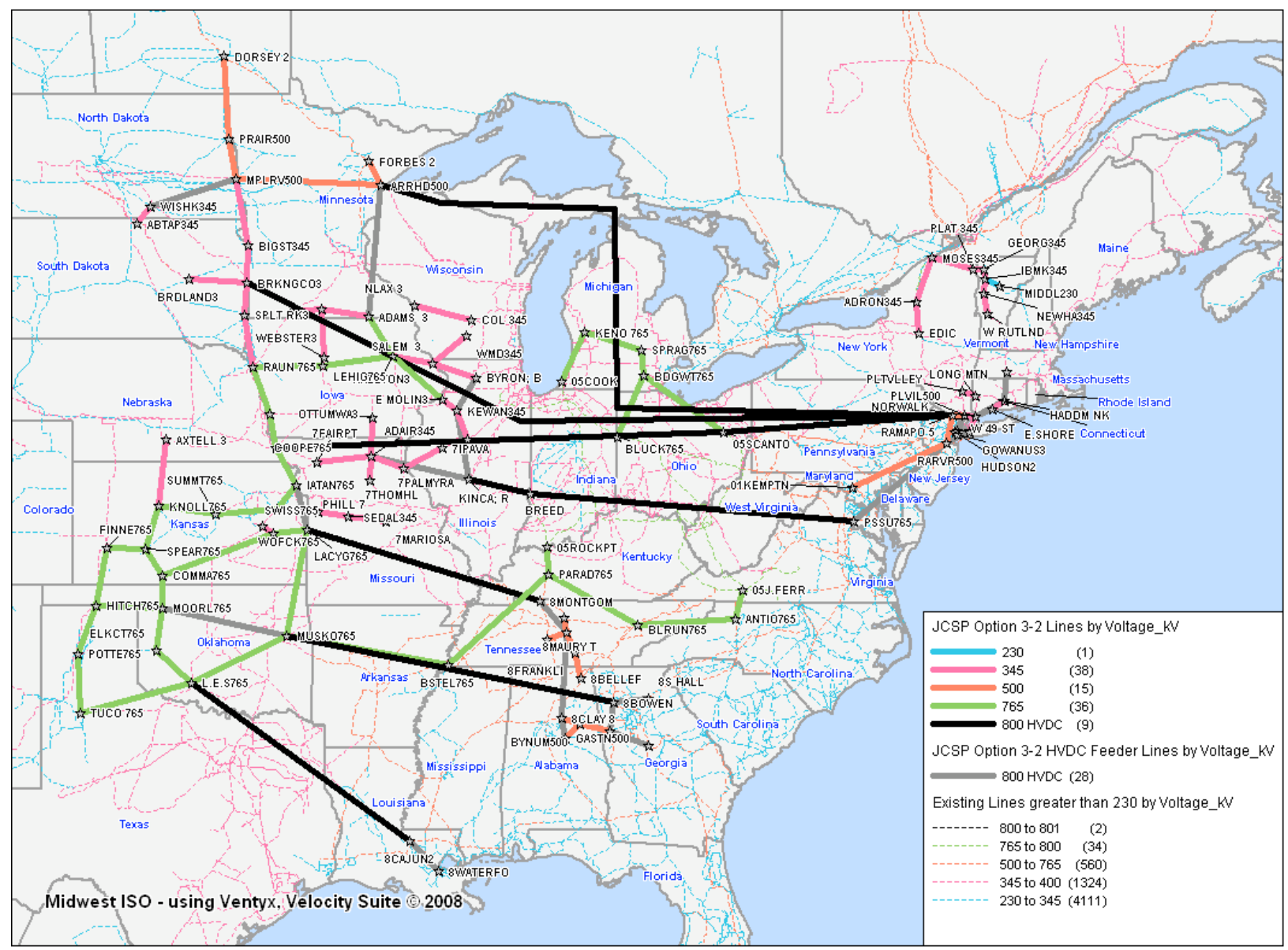

Figure 34. 20\% Wind Energy Scenario Conceptual Transmission Overlay (Source JCSP 2008)

The JCSP scenario shown above was done in support of the DOE Eastern Wind Integration and Transmission Study (EWITS). This study is analyzing five scenarios: Reference; 20\% - High Capacity Factor, On Shore Wind; 20\% - Hybrid with Offshore Wind; 20\% - Local, with Aggressive Offshore; and 30\% - Aggressive On- and Off-Shore. The study is looking at operational impacts and costs from large-scale wind development and the benefits/costs of local versus remote wind generation strategies. Aside from TVA, the study is not including the 
Southeast in its study, although they do consider the regional demands in the analysis (Figure 35). The study is ongoing, with the final report not due until August 2009, but several interesting analyses have already been presented at seminars and workshops. For example, Figure 35 shows the interchange energy flows under Scenario 2, hybrid local and offshore wind generation.

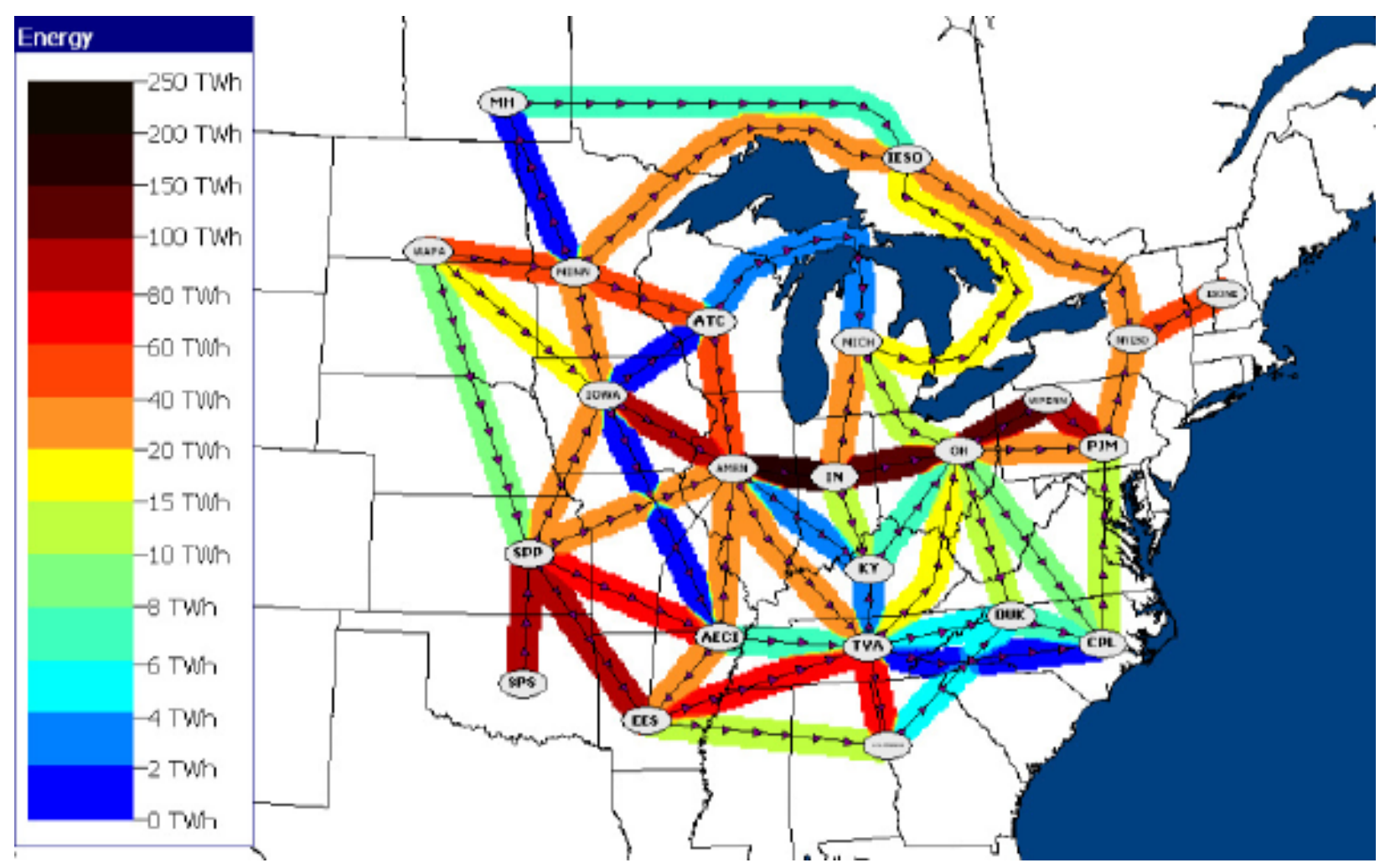

Figure 35. Scenario 2 Interface Contour: Annual Energy Difference Copper Sheet Minus Constrained Case (Source NREL 2009) 